\author{
UNIVERSIDADE DE SÃO PAULO \\ FACULDADE DE MEDICINA DE RIBEIRÃO PRETO \\ Departamento de Neurociências e Ciências do Comportamento \\ Programa de Pós-Graduação em Saúde Mental
}

Luciana Inácia de Alcântara

CONSUMO DE ÁLCOOL NA GESTAÇÃO E SUA RELAÇÃO COM O DESENVOLVIMENTO COGNITIVO DOS FILHOS NA IDADE ESCOLAR

RIBEIRÃO PRETO 
Luciana Inácia de Alcântara

\section{CONSUMO DE ÁLCOOL NA GESTAÇÃO E SUA RELAÇÃO COM O DESENVOLVIMENTO COGNITIVO DOS FILHOS NA IDADE ESCOLAR}

Tese apresentada à Faculdade de Medicina de Ribeirão Preto da Universidade de São Paulo para obtenção do título de Doutora em Saúde Mental

Área de Concentração: Saúde Mental

Orientador: Prof. Dr. Erikson Felipe Furtado

\section{RIBEIRÃO PRETO}




\section{AUTORIZO A REPRODUÇÃO E DIVULGAÇÃO TOTAL OU PARCIAL DESTE TRABALHO, POR QUALQUER MEIO CONVENCIONAL OU ELETRÔNICO, PARA FINS DE ESTUDO OU DE PESQUISA, DESDE QUE CITADA A FONTE.}

\section{FICHA CATALOGRÁFICA}

Alcântara, Luciana Inácia

Consumo de álcool na gestação e sua relação com o desenvolvimento cognitivo dos filhos na idade escolar, Ribeirão Preto, 2012

$137 \mathrm{p}$.

Tese de doutorado, apresentada junto ao Programa de Saúde Mental do Departamento de Neurociências e Ciências do Comportamento da Faculdade de Medicina de Ribeirão Preto da Universidade de São Paulo para obtenção de título de Doutora em Saúde Mental

Área de Concentração: Saúde Mental

Orientador: Prof. Dr. Erikson Felipe Furtado

1 - Álcool, 2 - Gestação,

3 - Desenvolvimento cognitivo infantil,

4- Escala de Maturidade Mental Columbia, 5- CBCL 


\section{FOLHA DE APROVAÇÃO}

\section{Luciana Inácia de Alcântara}

Tese apresentada à Faculdade de Medicina de Ribeirão Preto da Universidade de São Paulo para a obtenção do título de Doutora. Área de concentração: Saúde Mental Orientador: Prof. Dr. Erikson Felipe Furtado

Aprovado em:

\section{Banca examinadora:}

Prof. Dr.

Instituição:

Julgamento:

Assinatura:

Prof. Dr.

Instituição:

Julgamento:

Assinatura:

Prof. Dr.

Instituição:

Julgamento:

Assinatura:

Prof. Dr.

Instituição:

Julgamento:

Assinatura:

Prof. Dr.

Instituição:

Julgamento:

Assinatura: 
Para Laura, Luísa, Carlos, Celso (in memorian) e Olímpia 


\section{AGRADECIMENTOS}

Ao Prof. Dr. Erikson Felipe Furtado pelos ensinamentos, incentivo e apoio,

Ao Dr. Mateus Angelucci e Dr. Ricardo Dmetruk pelo auxilio na coleta de dados,

Ao PAI-PAD e FAEPA pelo apoio financeiro para realização do estudo

A todos os colaboradores do PAI-PAD e do Departamento de Neurociências e Ciências do Comportamento que direta ou indiretamente colaboraram para a realização deste trabalho

A Secretaria de Ensino do Estado de São Paulo pela colaboração na localização dos endereços das crianças deste estudo,

As crianças, mães e cuidadores.... 


\section{RESUMO}

Alcântara, L. I., Consumo de álcool na gestação e sua relação com o desenvolvimento cognitivo dos filhos na idade escolar. 137 folhas. Tese (doutorado) - Faculdade de Medicina de Ribeirão Preto, Universidade de São Paulo. Ribeirão Preto. 2012.

O consumo de álcool durante a gestação tem sido associado a alterações no desenvolvimento físico, neurológico e comportamental da criança, sendo que muitas das consequências sobre o desenvolvimento infantil apresentam ampla variação em extensão e gravidade. Os efeitos podem variar desde uma relativa normalidade até a morte perinatal e Síndrome Fetal do Álcool (SFA). No presente estudo foi avaliado o desenvolvimento cognitivo de crianças em idade escolar em relação ao padrão de consumo de álcool materno. Foram avaliadas oitenta e seis crianças de 8 a 9 anos de idade cujas mães $(N=449)$ haviam sido entrevistadas em 2001 durante o terceiro trimestre de gestação sobre o padrão de consumo de álcool e outras substâncias psicoativas, em um serviço obstétrico municipal da rede pública. Para avaliação cognitiva do grupo de crianças na idade escolar foi utilizada a Escala de Maturidade Mental Columbia (EMMC). O grupo constituído pelas mães ou cuidadores respondeu a um questionário sobre as condições sociodemográficas, saúde geral, e uso materno de álcool durante a gestação e recente. Foi realizada uma anamnese sobre o desenvolvimento neuropsicomotor e condições clínicas pregressas e atuais da criança. Foi utilizado o Child Behavior Checklist (CBCL 6-18 anos) para a identificação de problemas de saúde mental na infância. Resultados mostram que, em relação à avaliação cognitiva das crianças, o RPI (resultado padrão por idade) variou de 64 a 134, com valor médio de 99,95 ( \pm 16,01) e mediana de 103. Associação estatisticamente significativa foi observada entre os escores de RPI acima de 99,95 e maior idade materna e maior peso ao nascimento ( $p=0,01$ e 0,05 respectivamente). Diferença significativa também foi observada em relação ao número de filhos. Crianças com famílias com três ou mais filhos apresentaram RPI médio de 106,4 versus RPI de 99,10 para aquelas com famílias com menos de três filhos $(P=0.04)$. Separando a amostra por gênero, observamos escores médios menores na Escala de Maturidade Mental Columbia em meninos filhos de mães que declararam cor mulata ou negra $(p=0,02)$, que fizeram uso em dias de qualquer quantidade de álcool na gestação maior que a média $(p=0.01)$ e também naqueles em que as mães usaram três ou mais doses de álcool por ocasião durante a gestação acima da média ( $p<0.0001$ ). Não foram observadas diferenças significativas para as outras variáveis analisadas. Em relação aos problemas de comportamento quando avaliados pelo $\mathrm{CBCL}$, diferenças significativas foram observadas em relação ao uso de álcool durante a gestação no $2^{\circ}, 3^{\circ}$ trimestres e uso nos três trimestres com dados do GESTA-ÁLCOOL ( $p=0,05, p=0,01$ e $p=0,02$ respectivamente) e no $1^{\circ}$ trimestre da gestação $(p=0,05)$, uso de qualquer quantidade de álcool em dias acima da média $(p=0,01)$, uso de três ou mais doses por ocasião acima da média $(p=0,05)$ com dados do INFANTO-ÁLCOOL. Foram observadas também diferenças significativas em relação ao uso atual de tabaco $(p=0,006)$, religião $(p=0,03)$ e escores médios de RPI da Escala de Maturidade Mental Columbia ( $p=0,002)$ e escores de RPI um desvio-padrão abaixo da média $(p=0,03)$. Não foram observadas diferenças de média para nenhuma das outras 
variáveis analisadas. O uso leve/moderado de álcool na gestação esteve associado ao menor desempenho cognitivo e problemas comportamentais totais, especialmente em meninos. Estudos controlados com um número maior de casos e a introdução de marcadores biológicos de exposição ao álcool na gestação são necessários, a fim de possibilitar uma detecção precoce dos efeitos adversos, uma melhor compreensão da gravidade e da extensão dos danos no desenvolvimento cognitivo e identificação de funções cognitivas específicas que possam ser mais afetadas pela exposição pré-natal ao álcool, propiciando uma intervenção precoce nos possíveis déficits encontrados.

Palavras chave: Álcool, gestação, desenvolvimento cognitivo infantil, Escala de Maturidade Mental Columbia, CBCL 


\begin{abstract}
Alcântara, L.l. Alcohol consumption in pregnancy and children cognitive development at school age. 137 folhas. Tese (doutorado) - Faculdade de Medicina de Ribeirão Preto, Universidade de São Paulo. Ribeirão Preto. 2012.
\end{abstract}

Prenatal alcohol exposure has been associated to problems in physical, neurological and behavioral child development and many of the consequences on childhood development show a wide range in extension and severity. The effects can vary from relative normality to perinatal death and fetal alcohol syndrome (FAS). In this study we analyzed the cognitive development of children at school age regarding to the maternal alcohol consumption at pregnancy. We evaluated eighty six children from eight to nine years old whose mothers $(N=449)$ have been interviewed in 2001 during the third trimester of pregnancy about the alcohol and other psychoactives substances pattern consumption, in a public obstetric hospital. Children cognitive status was assessed using the Columbia Mental Maturity Scale (CMMS). The group composed by mothers or caretakers answered a questionnaire about socio-demographic data, general health, prenatal and recent alcohol use. A brief anamnesis on neuropsychomotor development and previous and recent clinical conditions was made. The Child Behavior Checklist (CBCL 6-18 years) was used to identify mental health disorders in childhood. Regarding to the children cognitive evaluation results showed that the ADS (age deviation scores) range from 64 to 134, with a mean value of $99.95( \pm 16.01)$ e median of 103 . Statistical significant association was found between RPI scores above 99.95 and older maternal age and birth weight ( $p=0.01, p=0.05$ respectively). Analyzing the sample in relation to gender, we observed lower scores in Columbia Mental Maturity Scale in boys whose mothers declared color mulatto or black $(p=0.02)$, used in days any quantity of alcohol during pregnancy higher than average $(p=0.01)$ and also in those boys whose mothers used three or more doses of alcohol per occasion during pregnancy above average $(p<0.0001)$. No significant differences were observed for other variables analyzed. Significant differences were observed in relation to total behavior problems, when evaluated by $C B C L$, and alcohol use during gestation in $2^{\text {nd }}, 3^{\text {rd }}$ trimesters and use in all three trimesters with prospective data $(p=0.05, p=0.01$ and $p=0.02$ respectively) and in $1^{\circ}$ trimester of pregnancy $(p=0.05)$, use of any quantity of alcohol in days above average $(p=0.01)$, use of three or more doses per occasion above average $(p=0.05)$ with retrospective data. Significant differences were also observed in relation to recent tobacco use $(p=0.006)$, religion $(p=0.03)$, mean scores of RPI in Columbia Mental Maturity Scale $(p=0.002)$ and scores of RPI one standard deviation below the mean $(p=0.03)$. No differences were observed for other variables analyzed. Our findings suggest that, up to now, low/moderate alcohol use in gestation was associated to lower cognitive performance and total behavior problems, especially in boys. More controlled studies using a larger number of subjects and the introduction of biological markers of alcohol exposure in pregnancy are necessary in order to detect the adverse effects, to understand the extension of damages in cognitive development and to identify specific cognitive functions that could be more affected by prenatal alcohol exposure, contributing for development of early interventions.

Key words: Alcohol, pregnancy, childhood cognitive development, Columbia Mental Maturity Scale, CBCL. 


\section{LISTA DE TABELAS}

Tabela 1 - Quantidade de mães que referiram uso de qualquer quantidade de álcool na gestação e uso de três ou mais doses por ocasião obtidas na entrevista retrospectiva.

Tabela 2 - Comparação de variáveis de acordo com os escores da Escala Columbia acima e abaixo do valor médio de RPI

Tabela 3 - Comparação de variáveis de acordo com os escores da Escala Columbia situados um DP acima ou abaixo do valor médio de RPI.

Tabela 4 - Escores de RPI obtidos da escala Columbia versus variáveis dicotômicas analisadas (teste t- Student).

Tabela 5 - Significância (valor de p), odds ratio e 95\% de intervalo de confiança (OR - 95\% IC) para escores de RPI de acordo com média (< ou $\geq 99,95)$ e -1 desvio padrão (< ou $\geq 83,9$ ) em associação com variáveis dicotômicas estudadas (teste exato de Fisher)

Tabela 6 - T-escores de problemas totais de comportamento obtidos pelo $\mathrm{CBCL}$ versus variáveis dicotômicas analisadas (teste t- Student)

Tabela 7 - Modelo final de regressão linear múltipla para T-escores do CBCL com as variáveis uso de álcool no $3^{\circ}$ trimestre (GESTA-ÁLCOOL), uso de tabaco na gestação, religião e idade materna

Tabela 8 - Significância (valor de p), odds ratio e 95\% de intervalo de confiança (OR - 95\% IC) para T-escores de problemas totais de comportamento do CBCL em associação com variáveis dicotômicas estudadas (teste exato de Fisher).

Tabela 9 - Descrição dos artigos selecionados que avaliam escore de QI médio de acordo com exposição de crianças ao álcool na gestação. 


\section{LISTA DE FIGURAS}

Figura 1 - Frequências dos escores de RPI obtidos nas 86 crianças avaliadas

Figura 2 - Escores de RPI da Escala de Maturidade Mental Columbia em meninos em relação à cor referida da pele $(A)$, uso pelas mães em dias de qualquer quantidade de álcool na gestação (B) e uso de três ou mais doses de álcool por ocasião durante a gestação (C). As linhas correspondem ao valor médio de RPI.

Figura 3 - Frequências dos T-escores de problemas totais de comportamento do CBCL obtidos nas 83 crianças avaliadas.

Figura 4 - Valores de T-escores de problemas totais em meninos em relação ao uso de tabaco na gestação $(A)$, uso de tabaco atual $(B)$, uso de álcool pela mãe no $3^{\circ}$ trimestre $(C)$, uso de álcool pela mãe no $2^{\circ}$ trimestre (D), uso de álcool pela mãe nos três trimestres de gestação $(E)$, uso pela mãe em dias de qualquer quantidade de álcool na gestação $(F)$ e uso de três ou mais doses de álcool por ocasião durante a gestação $(G)$ em crianças do sexo masculino. As linhas correspondem ao valor médio do T-escore

Figura 5 - Valores de T-escores de problemas totais em meninas em relação à religião (A), e escores da Escala de Maturidade Mental Columbia (B) em crianças do sexo feminino. As linhas correspondem ao valor médio do T-escore do CBCL...61 


\section{LISTA DE ABREVIATURAS}
AA - $\quad$ Álcool Absoluto
ARBD - $\quad$ Alcohol-Related Birth Defects
ARND - $\quad$ Alcohol-Related Neurodevelopmental Disorder
AUDIT - $\quad$ Alcohol Use Disorders Identification Test
BMA - $\quad$ British Medical Association
CAGE - $\quad$ Cut down, Annoyed, Guilty e Eye-opener
CBCL - $\quad$ Child Behavior Checklist
CEBRID - Centro Brasileiro de Informações sobre Drogas
CID-10 - Classificação Internacional de Doenças, versão 10
CR - $\quad$ coeficientes de regressão
DEAF - $\quad$ Distúrbios do espectro alcoólico fetal
DP - desvio-padrão
EFA - $\quad$ Efeitos Fetais do Álcool
EMMC - $\quad$ Escala de Maturidade Mental Columbia
FAEPA - $\quad$ Fundação de Apoio ao Ensino e Pesquisa do Hospital das Clínicas da Faculdade de Medicina de Ribeirão Preto.
FSIQ - $\quad$ Full Scale Intelligence Quotient
GCl - $\quad$ General Cognitive Index
IC - Intervalo de Confiança
IM - $\quad$ Índice de Maturidade (IM)
IOM - $\quad$ Institute Of Medicine
IPD - $\quad$ Indications of Problem Drinking
K-ABC - $\quad$ Kaufman Assessment Battery for Children
MC - $\quad$ Mental Composite
OR - $\quad$ Odds Ratio 
Oz - $\quad$ Onça Fluída (Medida de volume equivalente a 29,57 ml)

PET - $\quad$ Positron emission tomography

PFAS - $\quad$ Partial Fetal Alcohol Syndrome

QI - $\quad$ Quociente de Inteligência

QMPA - Q Questionário de Morbidade Psiquiátrica

$\mathrm{R}^{2}$ - $\quad$ Coeficiente de Determinação

RNA - $\quad$ Ácido Riboxinucleico

RNM - $\quad$ Ressonância nuclear magnética

RPI - $\quad$ Resultado Padrão de Idade

SFA - $\quad$ Síndrome Fetal do Álcool

SPECT - $\quad$ Emission computed tomography

SUS - $\quad$ Sistema Único de Saúde

T-ACE - $\quad$ Tolerance, Annoyed, Cut Down and Eye-Opener

VIQ - $\quad$ Verbal Intelligence Quotient

WISC - $\quad$ Wechsler Intelligence Scales

WPPSI - $\quad$ Wechsler Preschool and Primary Scales Of Intelligence

WRAT-R - Wide Range Achievement Test - Revised 


\section{SUMÁRIO}

1 - INTRODUÇÃO

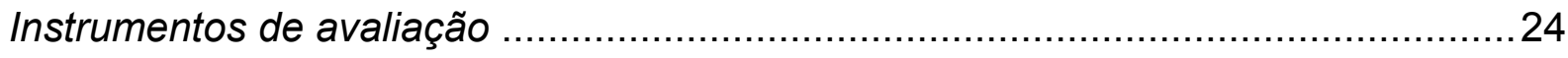

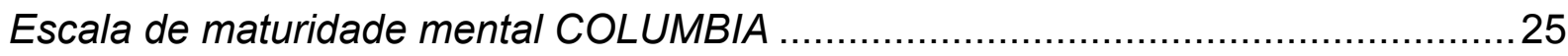

2 - OBJETIVOS.

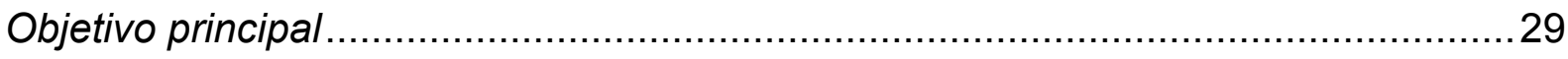

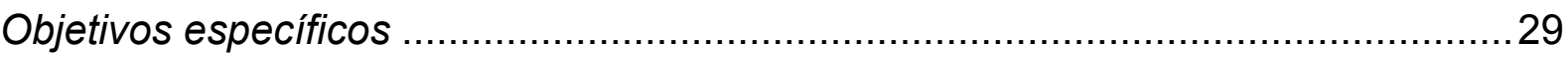

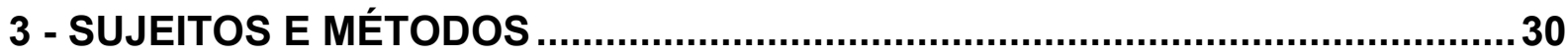

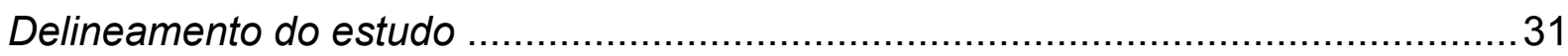

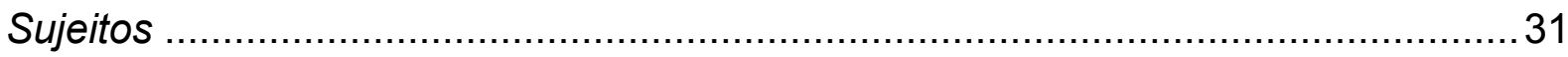

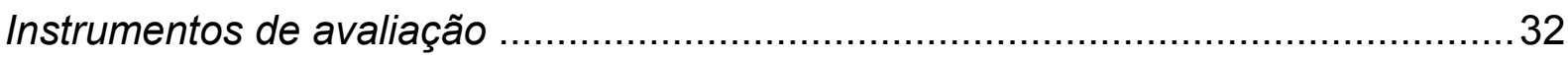

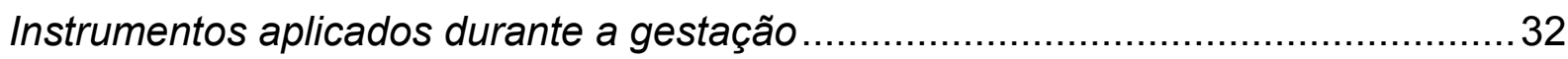

Instrumentos aplicados no estudo atual (idade escolar) ......................................... 33

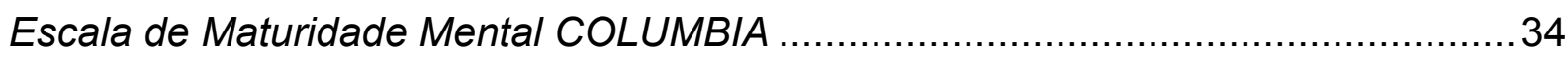

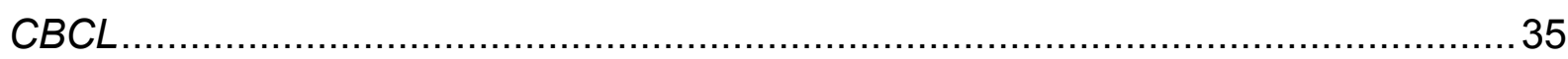

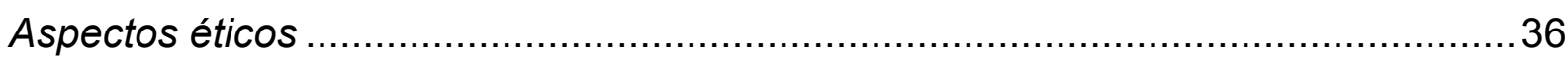

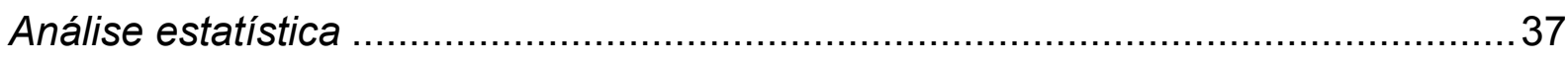

4 - RESULTADOS

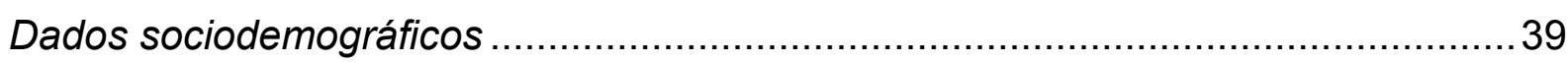

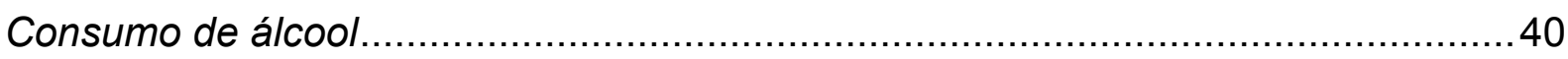

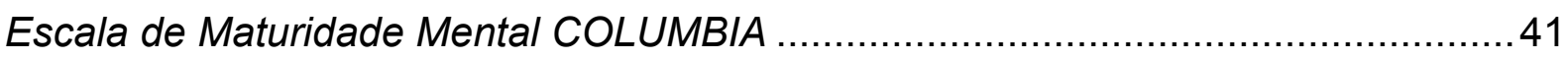

Escala de Maturidade Mental COLUMBIA versus variáveis analisadas....................42

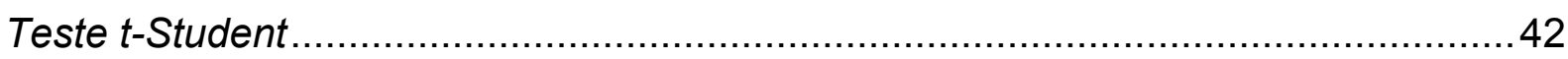

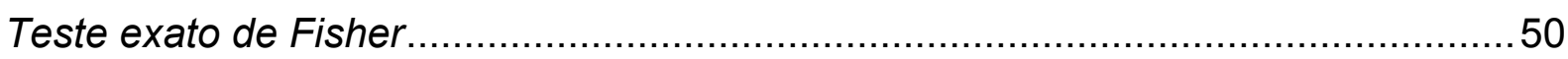

Inventário de Comportamentos da Infância e Adolescência (CBCL).........................51

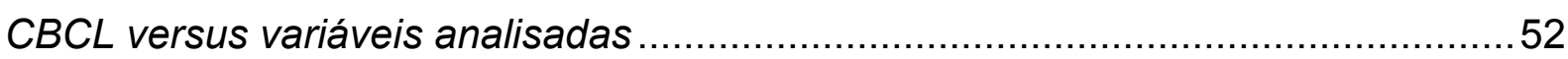

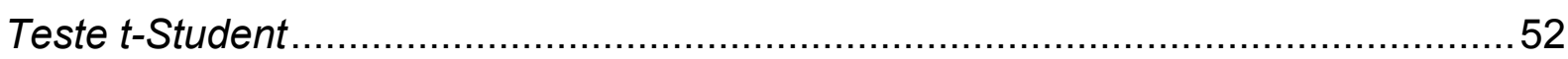

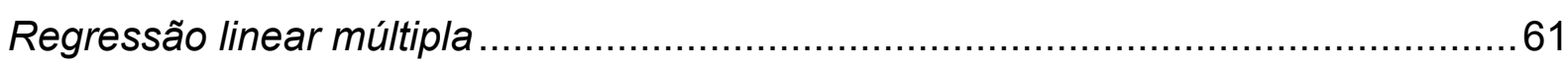

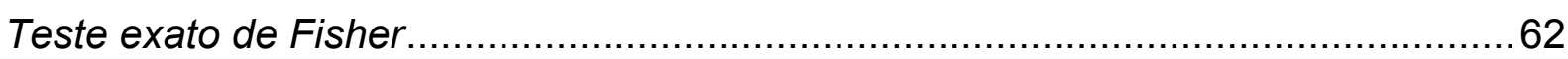


5 - DISCUSSÃO

.64

6 - CONCLUSÕES.

.75

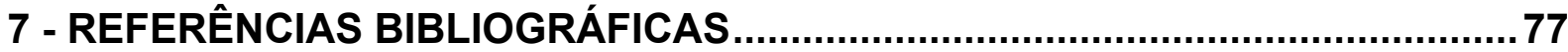

APÊNDICE

ANEXOS 
1 - INTRODUÇÃO 
O álcool é uma substância utilizada pela humanidade desde os seus primórdios, ocupando um lugar privilegiado em todas as culturas. Bebidas alcoólicas fermentadas eram preparadas e consumidas em várias partes do mundo antes da expansão colonial européia. A partir daí, houve uma mudança importante no modo de produção e consumo do álcool, principalmente após a revolução industrial. Novas formas de bebidas alcoólicas foram introduzidas, passando gradualmente de uma forma de preparação e consumo doméstico e comunitário, para um produto industrial com maior disponibilidade (ROOM et al., 2005). O consumo excessivo de álcool tornou-se um problema de saúde com importantes consequências sociais e econômicas.

Em aproximadamente 40 anos, estudos científicos têm proporcionado avanços substanciais na compreensão dos problemas relacionados ao consumo excessivo de álcool, assim como do tratamento e prevenção (ROOM et al., 2005; NICCOLS, 2007).

O consumo de álcool durante a gestação tem sido associado a alterações no desenvolvimento físico, neurológico e comportamental da criança, sendo que muitas das consequências sobre o desenvolvimento infantil apresentam ampla variação em extensão e gravidade (COLES et al., 1991; SOOD et al., 2001; STEINHAUSEN et al.,2003; FURTADO et al, 2002, 2006; HUIZINK; MULDER, 2006; NICCOLS, 2007). Nos Estados Unidos, mais de $50 \%$ das mulheres em idade fértil consomem álcool, sendo que $20 \%$ continuam a consumir durante a gestação (BAILEY et al., 2004). Aproximadamente $16 \%$ das crianças são expostas ao álcool no período pré-natal (SOOD et al., 2001). Na Grã-Bretanha aproximadamente $90 \%$ das mulheres consomem bebidas alcoólicas pelo menos ocasionalmente sendo que vem ocorrendo também um aumento significativo do consumo pesado de álcool entre 
mulheres jovens (BMA, 2007). No Brasil, estudos mostram que a prevalência de dependência de álcool no sexo feminino é de $5,7 \%$ e aproximadamente $22 \%$ das mulheres consomem álcool em níveis de risco para o feto durante a gestação (CEBRID 2005; FABBRI et al.,2007). A confirmação do uso de álcool na gestação nem sempre é fácil por uma série de fatores incluindo: a subestimação do consumo pela mulher devido constrangimento em informá-lo em função do estigma social associado ao uso; despreparo do profissional de saúde para investigar adequadamente ou valorizar as queixas compatíveis com o hábito de beber; dificuldade de especificar os níveis de consumo nos primeiros estágios da gravidez; pouca acurácia dos registros de uso de álcool materno; uso limitado de instrumentos de rastreamento do padrão de consumo de álcool materno e ausência de marcadores biológicos confiáveis para consumo de álcool materno (LARROQUE et al., 1995; COSTA et al., 1998; JACOBSON et al., 2002; BMA, 2007).

Os efeitos da exposição pré-natal ao álcool podem variar desde uma relativa normalidade até a morte perinatal e Síndrome Fetal do Álcool (MATTSON; RILEY, 1998). O uso de álcool está associado de maneira dose-dependente à restrição do crescimento fetal, deficiências cognitivas, aumento da morbidade e mortalidade, desenvolvimento da Síndrome Fetal do Álcool (SFA) e outros transtornos do comportamento infantil associados à exposição intra-útero ao álcool (formas incompletas da SFA). A Síndrome Fetal do Álcool foi inicialmente descrita em 1973 por Jones e Smith e refere-se a um conjunto de anormalidades físicas, comportamentais e cognitivas (MATTSON; RILEY, 1998). Achados clínicos incluem retardo de crescimento pré e pós-natal, disfunção do sistema nervoso central e dismorfias faciais (STEINHAUSEN et al., 1982; LARROQUE et al., 1995; SAMPSON et al., 1997; MATTSON; RILEY, 1998; ROEBUCK et al., 1999; BAILEY et al., 2004; 
JACOBSON et al., 2004). O termo Distúrbios do Espectro Alcoólico Fetal (DEAF) tem sido utilizado para descrever uma ampla variedade de efeitos adversos observados em indivíduos que foram expostos ao álcool durante a gestação. A Síndrome Fetal do Álcool representa o desfecho mais severo deste espectro que inclui também as categorias diagnósticas "partial fetal alcohol syndrome" (PFAS), "alcohol-related birth defects" (ARBD) e "alcohol-related neurodevelopmental disorder" (ARND), conforme sugeridas pelo Institute of Medicine (IOM) em 1996 (ERVALAHTI et. al.; 2007; NICCOLS, 2007). Estudos utilizando autópsia e técnicas de neuroimagem (RNM, PET e SPECT) têm propiciado avanços na investigação de alterações na estrutura cerebral de indivíduos com Distúrbios do Espectro Alcoólico Fetal e a relação com aspectos funcionais do cérebro. Anormalidades na forma e no tamanho do cérebro têm sido encontradas, especialmente em estruturas como gânglio basal, corpo caloso, cerebelo, hipocampo, lobo parietal e núcleo caudado dos indivíduos mais afetados. A utilização de modelos animais em estudos sobre DEAF tem contribuído na confirmação de resultados de estudos com modelos humanos, possibilitando a utilização de várias variáveis confundidoras e a identificação de anomalias cerebrais não previamente identificadas em estudos humanos. A maioria dos estudos com modelos animais tem utilizado níveis pesados de exposição ao álcool, sendo que o achado neurocomportamental mais comum é um nível aumentado de atividade e comportamento exploratório. A magnitude desses efeitos é dose-dependente (HUIZINK; MULDER, 2006; NICCOLS, 2007; RILEY et. al., 2011; JACOBSON et.al., 2011). É importante lembrar que os Distúrbios do Espectro Alcoólico Fetal (DEAF) podem ser completamente evitados através da eliminação do uso de álcool durante a gestação. Nos Estados Unidos, os custos associados aos cuidados de crianças com diagnóstico de Síndrome Fetal do 
Álcool têm aumentado. Em 1991 foi estimado em aproximadamente 75 milhões de dólares. Um estudo recente estimou um custo anual de 3,6 bilhões de dólares isto sem considerar os demais efeitos da exposição ao álcool durante a gestação, o que demonstra um impacto social e econômico importante (MATTSON; RILEY,1998; RILEY et. al. 2011). No Canadá, foi estimado um custo anual com indivíduos diagnosticados com Distúrbios do Espectro Alcoólico Fetal, do nascimento até 53 anos, em cerca de cinco bilhões de dólares (STADE et al., 2009). Determinar a incidência de DEAF é difícil devido à falta de dados estatísticos consistentes e confiáveis e dificuldade de realização de diagnósticos (BMA, 2007). Estima-se que nos Estados Unidos, aproximadamente um em cada 100 nascidos vivos apresentem formas completas ou incompletas de SFA (SAMPSON et al., 1997). Na Itália a incidência de DEAF foi entre 20,3 a 40,5 por 1000 nascidos vivos (BMA, 2007; RILEY, 2011). As mais altas taxas de SFA completa ou incompleta têm sido reportadas na África do Sul, variando de 68,0 a 89,2 por 1000 nascidos vivos em uma população miscigenada do ponto de vista racial e com alta prevalência de uso de álcool de risco. Na Austrália entre as populações indígenas, a incidência de DEAF foi estimada em 4,7 por 1000 nascidos vivos. As populações que apresentam maior risco são aquelas que apresentam maior grau de privação social e pobreza (RILEY et. al. 2011; BMA, 2007). No Brasil, há poucos dados estatísticos sobre a incidência de SFA, estima-se que um por 1000 recém-nascidos apresentem SFA (FREIRE et. al., 2005). O dano causado pelo álcool no desenvolvimento da criança depende do padrão de consumo materno, do estágio da gestação em que a exposição ao álcool ocorreu além de outros fatores de risco como: fatores genéticos, metabolismo materno e fetal, estado nutricional da mãe, uso de outras drogas, condição de saúde da mãe, idade materna e padrão socioeconômico. Estudos têm 
mostrado evidências consistentes da associação entre o consumo pesado de álcool durante a gestação e desenvolvimento da SFA, no entanto resultados de estudos sobre níveis de consumo de baixo a moderado ainda são controversos (NICCOLS, 2007; BMA, 2007; RILEY, 2011. Crianças que apresentam as formas completa ou incompleta da SFA podem manifestar problemas cognitivos, comportamentais e psicossociais que causam vários prejuízos ao longo da vida, embora o resultado das manifestações possa variar com a idade e circunstâncias (MATTSON; RILEY, 1998; KELLY et al., 2000; MANNING; HOYME, 2007).

Os efeitos adversos da exposição pré-natal ao álcool sobre o desenvolvimento da criança variam num continuum. Os indivíduos afetados podem apresentar rebaixamento cognitivo, dificuldades relacionadas à abstração, atenção, linguagem receptiva, função executiva, concentração, memorização e julgamento crítico. Alterações do comportamento como hiperatividade, impulsividade, problemas de conduta como mentir e roubar, comportamento sexual inadequado e comportamento opositor são comuns e diferem quantitativamente e qualitativamente de outras alterações encontradas em formas diferentes de retardo mental (STREISSGUTH et al. ; 1991,1994; ROEBUCK et al., 1999; BROWN et al., 1991; JANZEN et al.,1995; HUIZINK; MULDER, 2006; BMA, 2007, FAGERLUND et al., 2011). Em relação ao funcionamento cognitivo, estudos têm mostrado uma associação da exposição pré-natal ao álcool a um decréscimo dos escores de QI (quociente de inteligência). A maioria das crianças com diagnóstico de SFA apresenta escores médios de QI de 60 a 65 variando de 16 a 120. Os achados variam dependendo da amostra do estudo, dos instrumentos de avaliação utilizados, de fatores potencialmente confundidores como nível socioeconômico e cultural, QI materno, uso de outras substâncias psicoativas e outros. Estudos longitudinais 
indicam que os escores de QI dessas crianças permanecem estáveis até a idade adulta. Um aspecto controverso relacionado ao funcionamento cognitivo dessas crianças diz respeito ao grau em que os déficits encontrados são decorrência da exposição pré-natal ao álcool ou de um ambiente pouco estimulante e/ou negligente propiciado por mães usuárias de álcool (MATTSON, RILEY, 1998; JACOBSON et al., 2004; NICCOLS, 2007). A maioria dos estudos tem investigado predominantemente os efeitos do uso excessivo de álcool durante a gestação, em relação à Síndrome Fetal do Álcool. Apenas recentemente estudos têm sugerido a associação entre uso baixo e moderado de álcool na gestação e prejuízos no desenvolvimento cognitivo e comportamental dos filhos (SOOD et al., 2001; LARROQUE et al., 1995; HUIZINK; MULDER, 2006). Jacobson et. al. (2004) encontraram associação significativa entre exposição pré-natal ao álcool de moderada a excessiva e escores de QI de crianças de 7,5 anos cujas mães tinham maior idade. Willford et. al. (2006) encontraram associação significativa entre uso moderado de álcool durante a gestação e escores de QI entre crianças afroamericanas de 10 anos de idade, porém a mesma associação não foi encontrada entre as crianças que eram caucasianas. No entanto, alguns estudos não têm encontrado associação entre consumo de álcool na gestação e desenvolvimento cognitivo dos filhos. Nulman et al. (2004) compararam 51 crianças expostas ao consumo "binge" de álcool no primeiro trimestre de gestação a 51 crianças não expostas a nenhuma substância teratogênica, não foi encontrada associação com desenvolvimento cognitivo e linguagem. Janzen et al. (1995) compararam o desempenho neuropsicológico de 10 crianças com SFA e 10 sem SFA e encontraram déficits significativos nas medidas de inteligência e linguagem do grupo com SFA. Coles et al. (1991) investigaram os efeitos físicos e cognitivos da 
exposição pré-natal ao álcool em uma sub-amostra de 68 crianças, sendo 25 expostas durante toda a gestação, 22 cujas mães interromperam o uso no segundo trimestre e 21 não expostas. O grupo exposto durante toda a gestação apresentou déficits significativos no funcionamento intelectual e os dois grupos expostos apresentaram déficits em habilidades acadêmicas (matemática e leitura). Greene et al. (1991) investigaram os efeitos teratogênicos do uso de álcool durante a gestação no desenvolvimento cognitivo de uma coorte de 359 crianças avaliadas aos seis meses, um dois, três e quatro anos e 10 meses. Não foi encontrada evidência de efeitos adversos do uso de álcool na ausência de SFA. Larroque, Kaminski (1998) investigaram os efeitos da exposição pré-natal ao uso moderado de álcool no desenvolvimento de 160 crianças aos quatro anos e meio. O consumo de 1,5 oz $\mathrm{AA} /$ dia ou mais esteve relacionado a um decréscimo de sete pontos no índice cognitivo geral das escalas McCarthy, ajustado em relação aos fatores confundidores. Freid et al. $(1990 ; 1992)$ investigaram a associação entre a exposição pré-natal ao álcool, maconha e cigarro e desenvolvimento neuropsicomotor de uma coorte em seguimento desde o nascimento. Não foi encontrada relação significativa entre consumo relativamente baixo de álcool durante a gestação e índice cognitivo geral das escalas McCarthy das crianças avaliadas aos três, quatro, cinco e seis anos, aos três anos foi encontrada associação com linguagem. Russell et al. (1991) investigaram os efeitos da exposição pré-natal ao álcool no crescimento, dismorfologia e desenvolvimento cognitivo de crianças de seis anos de idade. Crianças cujas mães tinham mais de uma indicação de uso problemático de álcool apresentaram QI verbal em média 7,1 pontos menor e escores no teste Token 4,3 pontos menor do que aquelas cujas mães tinham menos indicações. Streissguth et al. (1999) investigaram a associação entre exposição pré-natal ao álcool e cigarro e 
QI de uma coorte de 421 crianças aos quatro anos de idade. O consumo de mais de 1,5 oz AA/dia durante a gestação esteve relacionado a um decréscimo médio de QI de aproximadamente cinco pontos, controlando variáveis confundidoras. Considerando que muitas vezes seja difícil distinguir os déficits cognitivos e neurocomportamentais de indivíduos que foram expostos ao álcool daqueles com condições de diferentes etiologias como Transtorno de Déficit de Atenção e Hiperatividade, considerando ainda que em geral os testes neuropsicológicos padronizados são complexos e multifacetados, podendo propiciar pouca informação sobre aspectos específicos do funcionamento do sistema nervoso central que podem estar afetados nos distúrbios do espectro alcoólico fetal, alguns estudos têm proporcionado avanços no diagnóstico diferencial utilizando técnicas de neuroimagem para identificação de anormalidades estruturais em determinadas regiões cerebrais e biomarcadores de exposição a álcool. O termo biomarcador pode se referir a um marcador biológico de exposição ao álcool ou a um "ponto final" biológico que indica uma patologia, como micro RNA. Marcadores biocomportamentais consistem de processos neurais que estão alterados pela exposição pré-natal ao álcool, os quais seriam mediadores dos déficits neurocomportamentais observados nos Distúrbios do Espectro Alcoólico Fetal. Outro tipo de biomarcador de exposição ao álcool que tem sido utilizado é o éster etílico de ácidos graxos. Quando o álcool é metabolizado ele se acumula no mecônio e este metabólito pode ser usado como um marcador de exposição ao álcool no $2^{\circ}$ e $3^{\circ}$ trimestres de gestação (JACOBSON, et al.; 2011; RILEY, 2011). 


\section{Instrumentos de avaliação}

A avaliação de saúde mental de crianças e adolescentes utiliza-se cada vez mais de instrumentos padronizados. Existe uma grande quantidade e variedade de instrumentos com diferentes finalidades, utilizados para identificar problemas de saúde mental, efetuar diagnóstico psiquiátrico, mensurar o desenvolvimento infantil, a inteligência, adaptação social, personalidade e dinâmica emocional, entre outras aplicações. Assim como para adultos, uma questão relevante a ser considerada na avaliação da criança é a escolha do modo mais adequado, se observação direta do comportamento ou através de questionários ou inventários, que na maioria das vezes depende do aspecto a ser avaliado.

Considerando que a criança é um ser em desenvolvimento, os instrumentos de avaliação utilizados devem apresentar versões adequadas de acordo com a faixa etária. A fim de produzir uma informação mais acurada, tem sido sugerida a combinação das informações do cuidador, do professor e da criança. Dessa forma, os instrumentos de avaliação utilizados na infância costumam apresentar versões para diferentes informantes (DUARTE; BORDIN, 2000). O desenvolvimento cognitivo é um dos aspectos importantes a serem considerados na avaliação de saúde mental infantil, pois seu prejuízo parece estar relacionado à psicopatologia na infância. $\mathrm{Na}$ avaliação cognitiva é necessário considerar os domínios da cognição (atenção, percepção, memória e funções executivas) (SPARROW; DAVIS, 2000; DUARTE; BORDIN, 2000). Vários instrumentos de avaliação cognitiva têm sido utilizados em estudos que investigam a relação entre consumo de álcool na gestação e desenvolvimento dos filhos. De maneira geral, os resultados mostram prejuízos no desenvolvimento cognitivo dessas crianças (COLES et al., 1991; STEINHAUSEN et al., 1993; 1994; SPOHR et al.,1993; STEINHAUSEN; SPOHR 1998; MATTSON; RILEY, 1998; JACOBSON et al., 
2002; 2004; BAILEY et al., 2004; HUIZINK; MULDER, 2006). Dentre os instrumentos tradicionalmente utilizados na avaliação cognitiva da criança através das habilidades verbais e não-verbais, destaca-se a "Bayley Scale of Infant Development" que determina o nível de desenvolvimento de crianças entre um mês e três anos e meio de idade. No caso de crianças mais velhas, a avaliação é realizada através dos testes de inteligência sendo que, os mais utilizados são o Stanford-Binet e as "Wechsler Intelligence Scales" (WISC) cujos testes diferem de acordo com a idade da criança. O WPPSI-R é utilizado para crianças entre três anos e sete anos e três meses e o WISCIII para crianças entre seis anos e dezesseis anos e 11 meses (MATTSON; RILEY, 1998; DUARTE; BORDIN, 2000).

No Brasil, existem poucos instrumentos de avaliação da inteligência com dados normativos brasileiros e propriedades psicométricas aqui estabelecidas. Um desses instrumentos é a Escala de Maturidade Mental Columbia (FERNANDES; PULLIN, 1981; ALVES; DUARTE, 1993; DUARTE; BORDIN, 2000).

\section{Escala de maturidade mental COLUMBIA}

O desenvolvimento da Escala de Maturidade Mental Columbia (ALVES; DUARTE, 1993), resultou da necessidade de fornecer um instrumento mais satisfatório para estimar a capacidade mental de crianças com paralisia cerebral ou outras disfunções que envolvam prejuízo de funções motoras ou verbais. Antes de 1947, quando os autores iniciaram o trabalho que levou ao desenvolvimento da Escala de Maturidade Mental Columbia, foram feitas tentativas para adaptar ou modificar os testes de capacidade mental disponíveis, a fim de torná-los adequados para aqueles grupos de crianças, porém com sucesso parcial. Durante o desenvolvimento da escala ficou clara a necessidade de selecionar um item que 
pudesse ser realizado satisfatoriamente tanto por crianças com deficiências como pelas demais crianças. Era, portanto, necessário que este item exigisse um mínimo de resposta verbal ou motora e que fosse uma tarefa que pudesse ser facilmente comunicada para a criança. Por satisfazer tais requisitos, o exercício de classificação pictórica foi selecionado. Na preparação da escala, foram tomados cuidados para garantir que os objetos representados fossem familiares a virtualmente todas as crianças nos Estados Unidos. O desempenho da criança é o resultado da interação de vários fatores que afetam sua capacidade de lidar com o material apresentado no teste, sendo importante o uso e interpretação adequada dos dados normativos que acompanham o teste assim como, a consideração de fatores sociais, econômicos e outros fatores ambientais. Três edições da escala foram publicadas nos anos de 1954, 1959 e 1972, quando foram introduzidas modificações importantes. Dos noventa e dois itens da edição de 1972, 50 são novos e dos 42 provenientes da edição de 1959, dois permanecem sem modificações e os 40 restantes foram modificados pela necessidade de eliminar opções pobres de respostas ou para atualizar certos desenhos. A edição de 1959 foi publicada no Brasil em 1967, porém sem ter sido padronizada para as nossas crianças. Em 2001, a edição de 1972 foi publicada no Brasil após estudo de padronização realizado no município de São Paulo. Para a padronização brasileira foi realizado estudo de precisão teste-reteste. Os coeficientes de correlação obtidos variaram de 0,73 a 0,90 . Os estudos originais americanos mostram coeficientes entre 0,84 a 0,86 . A fim de verificar a validade da EMMC, foram comparados os resultados da EMMC e do RAVEN. A correlação entre os dois testes foi 0,60 para o grupo total. Estudo original americano encontrou correlação de 0,67 com o teste Stanford-Binet e entre 0,62 a 0,69 com o teste "Otis Lennon Mental Ability" (ALVES; DUARTE, 2001). 
Esta escala tem sido amplamente utilizada em uma série de estudos com diferentes finalidades e delineamentos, como em crianças com lesões cerebrais e distúrbios neurológicos, surdez, baixo nível socioeconômico, retardo mental, distúrbios da fala, crianças com baixo peso ao nascimento, depressão materna e alcoolismo parental (ALVES; DUARTE, 2001; STEINHAUSEN; SPOHR,1998; FOBE et al.,1999; FERNANDES; PULLIN, 1981; MARQUES et al., 2002; GUTBROD et al., 2000; KURSTJENS; WOLKE, 2001; FURTADO et al., 2002; 2006). 
2 - OBJETIVOS 


\section{Objetivo principal}

Estudar o efeito da exposição pré-natal ao álcool sobre o desenvolvimento cognitivo em crianças em idade escolar.

\section{Objetivos específicos}

Avaliar comparativamente o desenvolvimento cognitivo de crianças em idade escolar em relação ao padrão de consumo materno de álcool durante a gestação.

Avaliar o desenvolvimento cognitivo de crianças em idade escolar em relação às condições sociodemográficas.

Avaliar a relação entre desenvolvimento cognitivo e problemas de comportamento em crianças em idade escolar considerando a exposição pré-natal ao álcool. 
3 - SUJEITOS E MÉTODOS 


\section{Delineamento do estudo}

O presente estudo é longitudinal e retrospectivo, parte de um projeto iniciado em 2001 sobre exposição fetal ao álcool durante a gestação. Trata-se de uma amostra de conveniência para o estudo do consumo de álcool na gestação e sua relação com desenvolvimento, saúde geral e psicopatologia na idade escolar. Foram recolhidas informações sobre fatores individuais, psicossociais e biológicos mediante aplicação de instrumentos sistematizados em dois grupos de sujeitos (mães ou cuidadores e crianças).

\section{Sujeitos}

A amostra do estudo foi constituída de crianças de oito a nove anos de idade cujas mães $(N=449)$ foram entrevistadas em 2001 (projeto Gesta-Álcool), em um serviço obstétrico da rede municipal da cidade de Ribeirão Preto, conveniada ao Sistema Único de Saúde (SUS) durante o $3^{\circ}$ trimestre de gestação $\left(31^{a}\right.$ e $32^{a}$ semanas). Foram coletados dados sociodemográficos, história gestacional, saúde materna e padrão de consumo de álcool e outras substâncias psicoativas. O critério de inclusão foi a concordância mediante assinatura do Termo de Consentimento Livre e Esclarecido pela mãe ou cuidador. O critério de exclusão foi a não concordância de participação no estudo. A coleta de dados foi feita no período de 18 de agosto de 2009 a 7 de outubro de 2010. Para a coleta de dados e demais aspectos do estudo, foram utilizados os recursos do Núcleo de Estudo e Pesquisa em Psiquiatria Clínica e Psicopatologia e do Serviço Ambulatorial de Clínica Psiquiátrica do Hospital das Clínicas da Faculdade de Medicina de Ribeirão Preto-USP. As mães foram inicialmente convidadas a participar do estudo por correspondência e posteriormente por telefone para agendamento das entrevistas. Devido dificuldade de localização de parte da 
amostra, foi feita a atualização dos endereços das mães através da Secretaria Estadual de Ensino. As despesas com transporte e alimentação das mães ou cuidadores e crianças foram integralmente cobertas através de auxílio a pesquisa fornecido pela FAEPA (Fundação de Apoio ao Ensino e Pesquisa do Hospital das Clínicas da Faculdade de Medicina de Ribeirão Preto).

Das quatrocentas e quarenta e nove mães participantes do estudo GESTAÁLCOOL, 36 haviam mudado de cidade, e 151 não foram localizadas. Um grupo de 183 mães foi localizado das quais 64 recusaram e 33 não compareceram à entrevista. Outras 79 mães com endereço ativo, não puderam ser contatadas mesmo após várias tentativas. Foram entrevistadas as mães e avaliados os filhos para um grupo final de 86 pares mãe-filho.

\section{Instrumentos de avaliação}

\section{Instrumentos aplicados durante a gestação}

No projeto Gesta-Álcool em 2001, quando foram colhidas informações diretamente com as mães durante o seu terceiro trimestre de gestação,foi utilizando o questionário TACE como critério para consumo de álcool de risco. Também foram utilizados um questionário estruturado para coleta de dados sociodemográficos, história gestacional e saúde materna, o Questionário de Morbidade Psiquiátrica (QMPA) e questionário estruturado para avaliação de uso nocivo ou dependência ao álcool de acordo com a Classificação Internacional de Doenças (CID-10) (PINHEIRO et al., 2005).

O T-ACE (Tolerance, Annoyed, Cut down e Eye-opener) é um questionário breve semelhante ao CAGE (Cut down, Annoyed, Guilty e Eye-opener), trata-se de um teste com quatro questões, aplicável em um a dois minutos de conversação que foi padronizado para a rotina e prática dos serviços de ginecologia e obstetrícia. As quatro 
questões principais integrantes do questionário procuram: levantar informações sobre a tolerância (Tolerance - T); investigar a existência de aborrecimento com relação às críticas de familiares e terceiros sobre o modo de beber da gestante (Annoyed - A); avaliar a percepção da necessidade de redução do consumo (Cut Down - C); e conseguir informações sobre a persistência do consumo e dependência, por meio de forte desejo e compulsão para beber durante a manhã (Eye-opener - E). Cada uma das quatro questões possui uma pontuação que varia de zero a dois pontos, para a primeira questão, e de zero a um ponto da segunda à quarta questão. Quanto maior a pontuação, maior o risco do excesso de álcool causar problemas para o feto. Foi utilizado como ponto de corte para positividade do teste um escore maior ou igual a dois para consumo de risco (FABBRI et al., 2007).

\section{Instrumentos aplicados no estudo atual (idade escolar)}

Os instrumentos de avaliação foram aplicados em dois grupos de sujeitos. $\mathrm{O}$ primeiro grupo foi constituído pelas mães ou cuidadores que responderam a um questionário sobre as condições sociodemográficas, saúde geral, uso materno de álcool durante a gestação e recente. Foi realizada uma breve anamnese sobre o desenvolvimento neuropsicomotor e condições clínicas pregressas e atuais da criança. Foi utilizado o Child Behavior Checklist (CBCL 6-18 anos) para a identificação de problemas de saúde mental na infância.

O segundo grupo foi constituído pelas crianças. Para avaliação cognitiva do grupo de crianças na idade escolar foi utilizada a Escala de Maturidade Mental Columbia. Os examinadores responsáveis pela aplicação da escala nas crianças, não tiveram conhecimento dos dados referentes ao uso de álcool durante a gestação assim como, dos demais dados obtidos dos instrumentos de avaliação do projeto. 


\section{Escala de Maturidade Mental COLUMBIA}

A Escala de Maturidade Mental Columbia é um teste individual, não-verbal, que fornece uma estimativa da capacidade de raciocínio geral de crianças com idade entre três anos e seis meses e nove anos e 11 meses. Ela é composta de noventa e dois itens de classificação pictóricos e figurativos, que estão organizados em uma série de oito níveis sobrepostos. A criança realiza um segmento do teste correspondente ao nível mais adequado para a sua idade cronológica. O número de itens apresentados depende do nível que está sendo administrado, variando de cinquenta e cinco a sessenta e seis. Cada item consiste de uma série de três a cinco desenhos impressos num cartão de seis por nove polegadas. Os objetos representados estão, em geral, dentro do campo de experiência da maioria das crianças. Para cada item é solicitado à criança que olhe todas as figuras do cartão e selecione aquela que é diferente, ou que não se relaciona com as demais, apontando então sua escolha. A discriminação varia desde a percepção de diferenças na cor, tamanho ou forma, ao reconhecimento de relações sutis em pares de figuras, a fim de excluir uma dentro da série de desenhos. Com exceção do grupo de itens perceptivos dos três primeiros níveis, não há itens sucessivos baseados no mesmo conceito ou regra, ou seja, cada um apresenta um enigma novo para a criança. Os itens são organizados em ordem de dificuldade aproximada. A duração de aplicação da escala varia de 15 a 20 minutos, incluindo ensinar a tarefa à criança usando três itens de exemplo do nível apropriado à sua idade cronológica. O total de pontos ou número de itens respondidos corretamente em um determinado nível da Escala corresponde aos escores brutos, que são traduzidos em um ou mais escores derivados, os quais são baseados no desempenho das crianças de uma idade cronológica específica testadas no programa de padronização. A descrição de 
desempenhos na Escala é feita através do Resultado Padrão de Idade (RPI), que é um escore padrão com variação de 50 a 150, com média de 100 e desvio padrão de 16 unidades para cada grupo de idade cronológica que produziu os dados normativos. O RPI pode ser convertido em percentil e estanino. O percentil indica o número de crianças num grupo típico de 100 com resultado igual ou inferior a um dado RPI. O estanino é um escore padrão de um dígito, variando de um mínimo de 1 até um máximo de 9, com valor médio de 5 para cada grupo etário da Escala. Dado que os resultados do teste não podem ser tomados como indicadores absolutamente precisos, é importante considerar o conceito de erro padrão de medida na interpretação do RPI dependendo do nível administrado. De acordo com as normas brasileiras, devem ser observados os seguintes erros padrão de medida: nível A- 6 pontos, nível $\mathrm{B}-5$ pontos e níveis $\mathrm{C}$ à $\mathrm{H}-6$ pontos. Outro indicador que pode ser utilizado na interpretação dos resultados é o Índice de Maturidade (IM), que informa o desempenho numa escala de 13 pontos sendo que cada um deles corresponde ao desempenho médio de um dos 13 grupos etários de amplitude de seis meses que foram testados no programa de padronização (ALVES; DUARTE, 2001). A escolha da Escala de Maturidade Mental Columbia para ser utilizada no projeto, justificou-se pela praticidade de aplicação ao considerarmos o tamanho da amostra, por tratar-se de um teste não verbal cuja tarefa pode ser facilmente comunicada para a criança.

\section{CBCL}

O CBCL - "Child Behavior Checklist” (ACHENBACH, 1991) é o instrumento mais utilizado mundialmente para identificar problemas de saúde mental em crianças e adolescentes a partir de informações dos pais que inclui 118 itens e já foi traduzido em 55 idiomas. Há versões para crianças de 18 meses a cinco anos (CBCL/2-3) e para crianças de seis a 18 anos (CBCL/6-18). Ele avalia duas grandes áreas sindrômicas 
compostas de sintomas psiquiátricos, a saber: grupo dos sintomas externalizáveis (agressividade, hiperatividade, delinquência) e grupo dos sintomas internalizáveis (queixas ansiosas e depressivas, queixas somáticas e esquiva social). Há ainda um grupo que avalia competência social, alteração do pensamento e desatenção. O CBCL apresenta boa consistência interna, o que permite uma avaliação global e favorece o diagnóstico clínico acurado. O princípio de construção do CBCL foi totalmente empírico, baseado no tratamento estatístico (análise fatorial) de uma lista de queixas na área de saúde mental, freqüentemente presente em prontuários médicos. A versão brasileira do CBCL (6-18 anos) é denominada "Inventário de Comportamentos da Infância e Adolescência" tendo sido validado no Brasil por BORDIN et al, 1995.

\section{Aspectos éticos}

Os informantes (mães ou cuidadores) foram informados e consultados sobre sua concordância em participar do estudo. Foram selecionados aqueles que concordaram em participar, expresso através do Termo de Consentimento Livre e Esclarecido, redigido conforme os princípios da Resolução n 196/96 sobre pesquisa envolvendo seres humanos - Conselho Nacional de Saúde/ Ministério da Saúde. O pesquisador-responsável e seus colaboradores declararam-se comprometidos a cumprir e zelar pelos seguintes direitos dos sujeitos da amostra do estudo: privacidade e sigilo dos seus dados pessoais, informação continuada sobre o estudo, encaminhamento para auxílio de saúde quando for necessário, ressarcimento das despesas que os sujeitos venham a ter para atendimentos do estudo, indenização por dano relacionado ao estudo e a publicação dos resultados, além dos direitos e garantias devidamente expressas na Resolução 196/96. O projeto foi aprovado pelo Comitê de Ética em Pesquisa, processo nº 8609-2009. 


\section{Análise estatística}

Foram analisados a associação entre os valores de RPI e dados obtidos durante a gestação (Projeto Gesta-Álcool), idade gestacional, idade da mãe no momento do parto, religião (praticante versus na praticante), escolaridade, número de filhos, situação de emprego, cor referida da pele, estado civil, renda familiar, tipo de parto, peso ao nascimento, índice de Apgar do recém-nascido no primeiro e no quinto minuto, uso de tabaco durante a gestação, pontuação no teste T-ACE (consumo de risco), consumo de qualquer quantidade de álcool no $1^{\circ}, 2^{\circ}$ e $3^{\circ}$ trimestres da gestação, uso nos três trimestres de gestação, uso de álcool anterior a gestação, ocasião ou problema relacionado ao uso de álcool antes e durante a gestação. Foram analisados também os dados obtidos durante entrevista atual com as mães (INFANTO-ÁLCOOL): uso de tabaco, consumo de álcool durante a gestação (dado retrospectivo), e atual (analisado pelo teste AUDIT).

Para exame comparativo entre grupos utilizando medidas de distribuição central foi utilizado o teste t-Student bi-caudal. Para a verificação de diferentes frequências e proporções entre os grupos foi utilizado o teste exato de Fisher. Modelo de regressão linear múltipla foi utilizado para predizer o resultado da variável dependente, a partir de um conjunto de variáveis independentes. As análises foram realizadas utilizando-se o software SPSS versão 15.0, sendo considerados como significantes valores de probabilidade $p \leq 0,05$. 
4 - RESULTADOS 


\section{Dados sociodemográficos}

A idade das mães variou de 15 a 40 anos, com média de 24,9 e mediana de 24 anos. A idade gestacional $(n=68)$ variou de 36 a 42 semanas, com média de 39,92 e mediana de 40 semanas. Em relação ao gênero, $44(51,2 \%)$ eram meninos e $42(48,8 \%)$ meninas. O peso das crianças $(n=73)$ ao nascimento variou de 2.390 a $4.275 \mathrm{~g}$ com média de $3.246 \mathrm{~g}$ e mediana de $3.357 \mathrm{~g}$. Em relação ao tipo de parto ( $n=72) 42$ foram naturais $(58,3 \%), 3$ fórceps $(4,2 \%)$ e $27(37,5 \%)$ cesáreas. O escore de Apgar médio no $1^{\circ}$ minuto foi de 8,1 e no $5^{\circ}$ minuto de 9,6 . Em relação à escolaridade ( $n=86)$, 15 mães $(17,4 \%)$ tinham ensino básico, $41(47,7 \%)$ ensino fundamental, $29(33,7 \%)$ ensino médio/técnico e um $(1,2 \%)$ ensino superior. Em relação à cor referida da pele $47(54,6 \%)$ se declararam brancas, 20 (23,2\%) negras e $18(20,9 \%)$ mulatas/pardas e um outros $(1,2 \%)$.

Em relação ao estado civil, $12(13,9 \%)$ se declararam solteiras ou separadas, $34(40 \%)$ casadas, $39(45,9 \%)$ amasiadas, uma $(1,2 \%)$ viúva. Quanto à renda familiar 29 (33,7\%) tinham renda maior que cinco salários mínimos e 57 (66,3\%) de menos de cinco salários mínimos. Vinte mães $(23,3 \%)$ declararam situação de emprego ativo, $50(58,1 \%)$ inativo e 16 (18,6\%) estavam licenciadas para tratamento. Quarenta e cinco $(52,3 \%)$ mães eram praticantes de algum tipo de religião e 41 (47,7\%) não praticantes.

Em relação à escolaridade das crianças no momento da avaliação cognitiva e comportamental, cinco $(6 \%)$ crianças cursavam o $2^{\circ}$ ano do ensino fundamental, 61 $(72,6 \%)$ o $3^{\circ}$ ano, $17(20,2 \%)$ o $4^{\circ}$ ano e um (1,2\%) o $5^{\circ}$ ano. Em duas crianças este dado não estava disponível. 


\section{Consumo de álcool}

Dos dados coletados durante a gestação foram avaliados o consumo de álcool através da pontuação total e positividade (ponto-de-corte $\geq$ dois) no teste T$\mathrm{ACE}$, uso de qualquer quantidade de álcool durante toda a gestação, no $1^{\circ}, 2^{\circ}$ e $3^{\circ}$ trimestres, uso de álcool anterior a gestação, ocasião ou problema relacionado ao uso de álcool antes e durante a gestação.

Uso de qualquer quantidade de álcool durante qualquer período da gestação foi referido por 44 de 86 gestantes $(51,2 \%)$, destas $26(30,2 \%)$ utilizaram no $3^{\circ}$ trimestre, $33(38,3 \%)$ no $2^{\circ}$ trimestre e $37(43 \%)$ no $1^{\circ}$ trimestre. Dezessete gestantes (20\%) referiram uso de álcool durante toda a gestação. Dez gestantes referiram algum tipo de problema decorrente do uso de álcool (sintomas físicos de intoxicação). O teste T-ACE positivo, indicando consumo de risco durante a gestação, foi observado em 19 de $86(22,1 \%)$ das gestantes entrevistadas.

Os dados sobre o consumo de álcool obtidos retrospectivamente, mostraram diferença em relação aos obtidos durante a gestação. Nesta entrevista 15 mães $(17,4 \% ; 86)$ referiram ter utilizado qualquer quantidade de álcool durante $03^{\circ}$ trimestre da gestação, $14(16,3 \%)$ durante o $2^{\circ}$ trimestre e $25(29 \%)$ durante $\circ 1^{\circ}$ trimestre. Trinta mães (34,9\%) referiram uso de álcool em qualquer quantidade durante a gestação. O uso de três ou mais doses por ocasião foi referida por 13 mães $(15,1 \%)$ durante toda a gestação, com variação de uma a 270 ocasiões. Apenas dois pacientes apresentaram mais de 75 ocasiões por gestação. A quantidade de mães que referiram uso de álcool em qualquer quantidade e uso de três ou mais doses por ocasião são mostrados na tabela 1. Considerando todas as mães analisadas a média de dias de uso de álcool durante a gestação foi de 12,3 dias e uso de três ou mais doses por ocasião de 9,19. 
Tabela 1 - Quantidade de mães que referiram uso de qualquer quantidade de álcool na gestação e uso de três ou mais doses por ocasião obtidas na entrevista retrospectiva.

\begin{tabular}{ccc}
\hline & Quantidade de mães & Quantidade de mães/ $\geq 3$ doses/ocasião \\
\hline $1^{\circ}$ trimestre & $25 / 86(29 \%)$ & $12 / 86(13,9 \%)$ \\
\hline $2^{\circ}$ trimestre & $14 / 86(16,3 \%)$ & $9 / 86(10,4 \%)$ \\
\hline $3^{\circ}$ trimestre & $15 / 86(17,4 \%)$ & $9 / 86(10,4 \%)$ \\
\hline Gestação & $30 / 86(34,9 \%)$ & $13 / 86(15,1 \%)$ \\
\hline
\end{tabular}

\section{Escala de Maturidade Mental COLUMBIA}

A escala foi aplicada em 86 crianças, sendo $44(51,2 \%)$ do sexo masculino e $42(48,8 \%)$ do sexo feminino. Idade das crianças em meses variou de 95-120 (média 103,4, DP-4,67; mediana 103 meses). O RPI (resultado padrão por idade) variou de 64 a 134, com valor médio de 99,95, DP $\pm 16,01$ e mediana de 103. As frequências de distribuição dos escores de RPI são mostradas na figura 1.

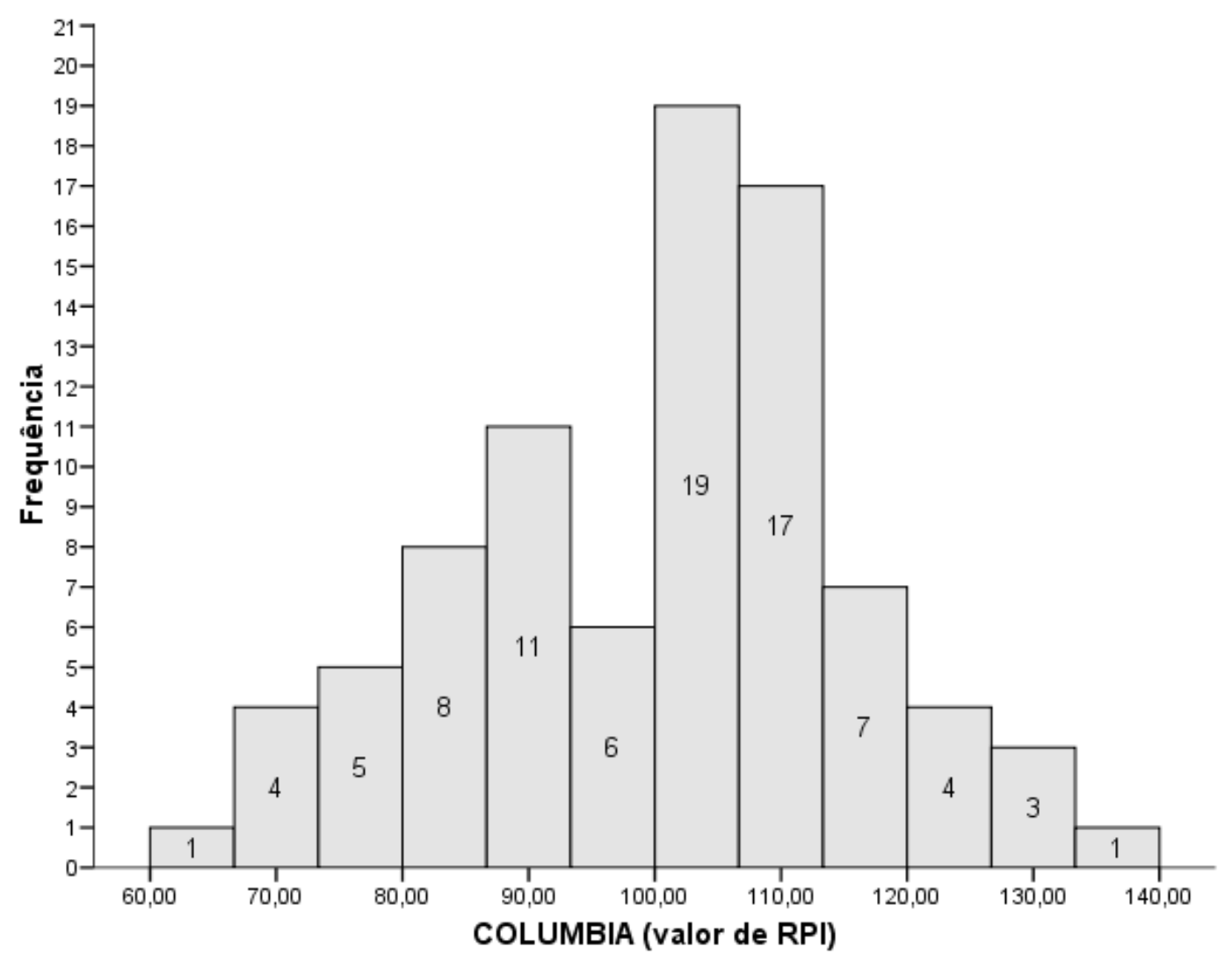

Figura 1 - Frequências dos escores de RPI obtidos nas 86 crianças avaliadas. 


\section{Escala de Maturidade Mental COLUMBIA versus variáveis analisadas}

\section{Teste t-Student}

Foram analisadas a associação entre os escores de RPI abaixo ou acima da média $(99,95)$, apresentados na Tabela 2 , ou abaixo ou acima de um DP $(83,9)$, apresentados na Tabela 3, e as variáveis obtidas retrospectivamente: quantidade (dias) de álcool consumida no $1^{\circ}, 2^{\circ}$ e $3^{\circ}$ trimestres, quantidade de três ou mais doses consumidas no $1^{\circ}, 2^{\circ}$ e $3^{\circ}$ trimestres, quantidade total (dias) de álcool na gestação e quantidade de uso de três doses ou mais na gestação, pontuação total de AUDIT (consumo atual); além de dados gestacionais e sociodemográficos obtidos durante a entrevista do GESTA-ÁLCOOL, utilizando-se o teste t-Student.

Associação estatisticamente significativa foi observada apenas entre os escores de RPI acima de 99,95 e maior idade materna $(p=0,01)$ e peso da criança ao nascimento $(p=0,05)$. A idade média das mães do grupo com $\operatorname{RPI} \geq 99,95$ no momento do parto foi de $25,98 \pm 5,4$ anos versus $23,3 \pm 4,5$ para o grupo de mães de crianças com RPI $<99,95$. O peso médio das crianças do grupo com $\operatorname{RPI} \geq 99,95$ foi de $3.420 \pm 444$ gramas versus $3220 \pm 410$ gramas para o grupo de crianças com $\mathrm{RPI}<99,95$. Não foi observada associação com as outras variáveis analisadas, conforme mostrado nas tabelas 2 e 3. 
Tabela 2 - Comparação de variáveis de acordo com os escores da escala Columbia acima e abaixo do valor médio de RPI.

\begin{tabular}{|c|c|c|c|c|c|}
\hline Variável & & $\mathbf{N}$ & Média & Desvio padrão & p \\
\hline \multicolumn{6}{|l|}{ Consumo de álcool } \\
\hline \multirow[t]{3}{*}{$1^{\circ}$ trimestre - quantidade (dias) } & >RPI médio & 50 & 3,08 & 9,25 & 0,25 \\
\hline & $\leq \mathrm{RPI}$ médio & 35 & 6,60 & 16,29 & \\
\hline & TOTAL & 85 & 4,52 & 12,66 & \\
\hline \multirow[t]{3}{*}{$1^{\circ}$ trimestre $-\geq 3$ doses/ocasião } & >RPI médio & 50 & 1,94 & 8,86 & 0,45 \\
\hline & $\leq \mathrm{RPI}$ médio & 35 & 4,17 & 15,90 & \\
\hline & TOTAL & 85 & 2,85 & 12,22 & \\
\hline \multirow[t]{3}{*}{$2^{\circ}$ trimestre - quantidade (dias) } & >RPI médio & 50 & 2,60 & 11,64 & 0,33 \\
\hline & $\leq \mathrm{RPI}$ médio & 35 & 5,74 & 16,49 & \\
\hline & TOTAL & 85 & 3,89 & 13,84 & \\
\hline \multirow[t]{3}{*}{$2^{\circ}$ trimestre $-\geq 3$ doses/ocasião } & >RPI médio & 50 & 3,56 & 15,86 & 0,89 \\
\hline & $\leq \mathrm{RPI}$ médio & 35 & 4,02 & 15,92 & \\
\hline & TOTAL & 85 & 3,75 & 15,79 & \\
\hline \multirow[t]{3}{*}{$3^{\circ}$ trimestre - quantidade (dias) } & >RPI médio & 50 & 3,02 & 13,01 & 0,58 \\
\hline & $\leq \mathrm{RPI}$ médio & 35 & 4,80 & 15,97 & \\
\hline & TOTAL & 85 & 3,75 & 14,24 & \\
\hline \multirow[t]{3}{*}{$3^{\circ}$ trimestre $-\geq 3$ doses/ocasião } & >RPI médio & 50 & 2,14 & 12,79 & 0,67 \\
\hline & $\leq \mathrm{RPI}$ médio & 35 & 3,48 & 15,34 & \\
\hline & TOTAL & 85 & 2,69 & 13,83 & \\
\hline \multirow[t]{3}{*}{ Total na gestação (dias) } & >RPI médio & 50 & 8,70 & 33,38 & 0,37 \\
\hline & $\leq \mathrm{RPI}$ médio & 35 & 17,14 & 48,24 & \\
\hline & TOTAL & 85 & 12,17 & 40,12 & \\
\hline Total na gestação & >RPI médio & 50 & 7,64 & 34,41 & 0,65 \\
\hline \multirow[t]{2}{*}{ ( $\geq 3$ doses/ocasião) } & $\leq \mathrm{RPI}$ médio & 35 & 11,68 & 46,98 & \\
\hline & TOTAL & 85 & 9,30 & 39,85 & \\
\hline \multirow[t]{3}{*}{ Escore total do AUDIT } & >RPI médio & 50 & 1,86 & 3,52 & 0,82 \\
\hline & $\leq \mathrm{RPI}$ médio & 35 & 2,02 & 3,06 & \\
\hline & TOTAL & 85 & 1,92 & 3,32 & \\
\hline \multirow[t]{3}{*}{ Idade maternal ${ }^{(*)}$} & >RPI médio & 51 & 25,98 & 5,46 & $0,01^{*}$ \\
\hline & $\leq \mathrm{RPI}$ médio & 35 & 23,31 & 4,49 & \\
\hline & TOTAL & 86 & 24,89 & 5,22 & \\
\hline \multirow[t]{3}{*}{ Idade gestacional } & >RPI médio & 51 & 40,05 & 1,51 & 0,42 \\
\hline & $\leq \mathrm{RPI}$ médio & 35 & 39.15 & 1,50 & \\
\hline & TOTAL & 86 & 39,92 & 1,75 & \\
\hline \multirow[t]{3}{*}{ Peso ( ${ }^{(x)}$} & >RPI médio & 51 & $3420 \mathrm{~g}$ & 444 & $0,05^{\star}$ \\
\hline & $\leq \mathrm{RPI}$ médio & 35 & $3220 \mathrm{~g}$ & 410 & \\
\hline & TOTAL & 86 & $3346 \mathrm{~g}$ & 440 & \\
\hline \multirow[t]{3}{*}{ Apgar $1^{\circ}$ minuto } & >RPI médio & 51 & 8,2 & 2,2 & 0,68 \\
\hline & $\leq \mathrm{RPI}$ médio & 35 & 7,9 & 2,6 & \\
\hline & TOTAL & 86 & 8,1 & 2,4 & \\
\hline \multirow[t]{3}{*}{ Apgar $5^{\circ}$ minuto } & >RPI médio & 51 & 9,6 & 0,6 & 0,83 \\
\hline & $\leq \mathrm{RPI}$ médio & 35 & 9,1 & 1,1 & \\
\hline & TOTAL & 86 & 9,6 & 0,9 & \\
\hline \multirow[t]{3}{*}{ Número de filhos } & >RPI médio & 51 & 1,13 & 1,16 & 0,73 \\
\hline & $\leq \mathrm{RPI}$ médio & 35 & 1,05 & 1,02 & \\
\hline & TOTAL & 86 & 1,10 & 1,10 & \\
\hline
\end{tabular}

$$
\left(^{*}\right)-p \leq 0,05
$$


Tabela 3 - Comparação de variáveis de acordo com os escores da escala Columbia um DP acima ou abaixo do valor médio de RPI.

\begin{tabular}{|c|c|c|c|c|c|}
\hline Variável & & $\mathbf{N}$ & Média & Desvio padrão & $p$ \\
\hline \multicolumn{6}{|l|}{ Consumo de álcool } \\
\hline \multirow[t]{3}{*}{$1^{\circ}$ trimestre - quantidade (dias) } & $>\mathrm{RPI}-1 \mathrm{DP}$ & 68 & 4,32 & 13,58 & 0,69 \\
\hline & $\leq \mathrm{RPI}-1 \mathrm{DP}$ & 17 & 5,35 & 8,28 & \\
\hline & TOTAL & 85 & 4,52 & 12,66 & \\
\hline \multirow[t]{3}{*}{$1^{\circ}$ trimestre $-\geq 3$ doses/ocasião } & $>\mathrm{RPI}$-1DP & 68 & 3,02 & 13,20 & 0,72 \\
\hline & $\leq \mathrm{RPI}-1 \mathrm{DP}$ & 17 & 2,17 & 7,31 & \\
\hline & TOTAL & 85 & 2,85 & 12,22 & \\
\hline \multirow[t]{3}{*}{$2^{\circ}$ trimestre - quantidade (dias) } & $>\mathrm{RPI}-1 \mathrm{DP}$ & 68 & 4,05 & 15,00 & 0,75 \\
\hline & $\leq \mathrm{RPI}-1 \mathrm{DP}$ & 17 & 3,23 & 7,94 & \\
\hline & TOTAL & 85 & 3,89 & 13,84 & \\
\hline \multirow[t]{3}{*}{$2^{\circ}$ trimestre $-\geq 3$ doses/ocasião } & $>\mathrm{RPI}-1 \mathrm{DP}$ & 68 & 4,25 & 17,28 & 0,36 \\
\hline & $\leq \mathrm{RPI}-1 \mathrm{DP}$ & 17 & 1,76 & 7,27 & \\
\hline & TOTAL & 85 & 3,75 & 15,79 & \\
\hline \multirow[t]{3}{*}{$3^{\circ}$ trimestre - quantidade (dias) } & $>\mathrm{RPI}-1 \mathrm{DP}$ & 68 & 4,27 & 15,75 & 0,23 \\
\hline & $\leq \mathrm{RPI}-1 \mathrm{DP}$ & 17 & 1,64 & 4,49 & \\
\hline & TOTAL & 85 & 3,75 & 14,24 & \\
\hline \multirow[t]{3}{*}{$3^{\circ}$ trimestre $-\geq 3$ doses/ocasião } & $>\mathrm{RPI}-1 \mathrm{DP}$ & 68 & 3,14 & 15,35 & 0,27 \\
\hline & $\leq \mathrm{RPI}-1 \mathrm{DP}$ & 17 & ,88 & 3,63 & \\
\hline & TOTAL & 85 & 2,69 & 13,83 & \\
\hline \multirow[t]{3}{*}{ Total na gestação- quantidade (dias) } & $>\mathrm{RPI}-1 \mathrm{DP}$ & 68 & 12,66 & 43,87 & 0,73 \\
\hline & $\leq \mathrm{RPI}-1 \mathrm{DP}$ & 17 & 10,23 & 19,61 & \\
\hline & TOTAL & 85 & 12,17 & 40,12 & \\
\hline \multirow[t]{3}{*}{ Total na gestação - $\geq 3$ doses/ocasião } & $>\mathrm{RPI}-1 \mathrm{DP}$ & 68 & 10,42 & 43,66 & 0,60 \\
\hline & $\leq \mathrm{RPI}-1 \mathrm{DP}$ & 17 & 4,82 & 18,14 & \\
\hline & TOTAL & 85 & 9,30 & 39,85 & \\
\hline \multirow[t]{3}{*}{ Escore total do AUDIT } & $>\mathrm{RPI}$-1DP & 68 & 1,86 & 3,44 & 0,71 \\
\hline & $\leq \mathrm{RPI}-1 \mathrm{DP}$ & 17 & 2,17 & 2,87 & \\
\hline & TOTAL & 85 & 1,92 & 3,32 & \\
\hline \multirow[t]{3}{*}{ Idade maternal } & $>\mathrm{RPI}$-1DP & 69 & 25,13 & 5,33 & 0,38 \\
\hline & $\leq \mathrm{RPI}-1 \mathrm{DP}$ & 17 & 23,94 & 4,78 & \\
\hline & TOTAL & 86 & 24,89 & 5,22 & \\
\hline \multirow[t]{3}{*}{ Idade gestacional } & $>\mathrm{RPI}$-1DP & 69 & 39,87 & 1,57 & 0,49 \\
\hline & $\leq \mathrm{RPI}-1 \mathrm{DP}$ & 17 & 40,14 & 1,23 & \\
\hline & TOTAL & 86 & 39,92 & 1,50 & \\
\hline \multirow[t]{3}{*}{ Peso } & $>\mathrm{RPI}-1 \mathrm{DP}$ & 69 & $3358 \mathrm{~g}$ & 446 & 0,63 \\
\hline & $\leq \mathrm{RPI}-1 \mathrm{DP}$ & 17 & $3294 \mathrm{~g}$ & 427 & \\
\hline & TOTAL & 86 & 3346 & 440 & \\
\hline \multirow[t]{3}{*}{ Apgar $1^{\circ}$ minuto } & $>\mathrm{RPI}$-1DP & 69 & 8,3 & 2,2 & 0,33 \\
\hline & $\leq \mathrm{RPI}-1 \mathrm{DP}$ & 17 & 7,4 & 3,0 & \\
\hline & TOTAL & 86 & 8,1 & 2,4 & \\
\hline \multirow[t]{3}{*}{ Apgar $5^{\circ}$ minuto } & $>\mathrm{RPI}$-1DP & 69 & 9,7 & 0,9 & 0,37 \\
\hline & $\leq \mathrm{RPI}-1 \mathrm{DP}$ & 17 & 9,3 & 1,6 & \\
\hline & TOTAL & 86 & 9,6 & 0,9 & \\
\hline \multirow[t]{3}{*}{ Número de filhos } & $>\mathrm{RPI}-1 \mathrm{DP}$ & 69 & 1,14 & 1,17 & 0,38 \\
\hline & $\leq \mathrm{RPI}-1 \mathrm{DP}$ & 17 & 0,94 & 0,74 & \\
\hline & TOTAL & 86 & 1,10 & 1,10 & \\
\hline
\end{tabular}


Foram analisados também pelo teste t-Student a associação entre os escores de RPI obtidos na escala COLUMBIA como variável contínua e as variáveis dicotômicas T-ACE (positivo versus negativo), uso de qualquer quantidade de álcool consumida no $1^{\circ}, 2^{\circ}$ e $3^{\circ}$ trimestres ou durante os três trimestres da gestação, problema ou evento relacionado ao uso de álcool antes e durante a gestação em qualquer frequência, uso de tabaco durante a gestação (dado GESTA-ÁLCOOL), uso de qualquer quantidade de álcool consumida no $1^{\circ}, 2^{\circ}$ e $3^{\circ}$ trimestres ou durante qualquer fase da gestação, média de dias de uso de qualquer quantidade de álcool na gestação, média de uso de três ou mais doses de álcool por ocasião durante a gestação e uso de tabaco atual (dado retrospectivo - INFANTO-ÁLCOOL). Foram analisados também os dados sociodemográficos e gestacionais: estado civil (casada/amasiada versus solteira/separada/viúva), escolaridade (ensino fundamental versus médio/superior), situação de emprego (ativo versus inativo), renda familiar (menor ou maior ou igual a cinco salários mínimos), número de filhos menor ou maior ou igual a três filhos), tipo de parto (normal versus fórceps/cesárea), religião (praticante versus não praticante), índice de Apgar no $1^{\circ}$ e $5^{\circ}$ minutos menor ou maior ou igual a sete), cor referida da pele (branca versus mulata/negra) e idade materna (entre 18 e 36 anos versus menor que 18 ou maior que 36 anos) (dado GESTA-ÁLCOOL). Diferença significativa foi observada apenas em relação ao número de filhos. Crianças com famílias com três ou mais filhos apresentaram RPI médio de 106,4 versus RPI de 99,10 para aquelas com famílias com menos de três filhos $(p=0,04)$. Não foram observadas diferenças de média para nenhuma das outras variáveis analisadas. Estes dados são mostrados na tabela 4. 
Tabela 4 - Escores de RPI obtidos da escala Columbia versus variáveis dicotômicas analisadas (teste t- Student)

\begin{tabular}{|c|c|c|c|c|c|}
\hline Variável dicotômica & & $\mathbf{N}$ & RPI (média) & Desvio padrão & $p$ \\
\hline \multirow[t]{3}{*}{ T-ACE } & Negativo & 67 & 100,71 & 15,71 & 0,41 \\
\hline & Positivo & 19 & 97,26 & 17,15 & \\
\hline & Total & 86 & 99,95 & 16,00 & \\
\hline \multirow{3}{*}{$\begin{array}{l}\text { Uso álcool } 3^{\circ} \text { trim}^{*} \\
\text { (gesta-álcool) }\end{array}$} & Negativo & 58 & 100,32 & 16,51 & 0,70 \\
\hline & Positivo & 26 & 98,84 & 15,62 & \\
\hline & Total & 84 & 99,86 & 16,16 & \\
\hline \multirow{3}{*}{$\begin{array}{l}\text { Uso álcool } 2^{\circ} \text { trim}^{*} \\
\text { (gesta-álcool) }\end{array}$} & Negativo & 51 & 100,27 & 15,88 & 0,98 \\
\hline & Positivo & 33 & 100,36 & 15,99 & \\
\hline & Total & 84 & 100,30 & 15,83 & \\
\hline \multirow{3}{*}{$\begin{array}{l}\text { Uso álcool } 1^{\circ} \text { trim}^{*} \\
\text { (gesta-álcool) }\end{array}$} & Negativo & 45 & 99,97 & 15,16 & 0,60 \\
\hline & Positivo & 36 & 101,83 & 16,43 & \\
\hline & Total & 81 & 100,80 & 15,66 & \\
\hline \multirow{3}{*}{$\begin{array}{l}\text { Uso álcool nos } 3 \text { trimestres* } \\
\text { (gesta-álcool) }\end{array}$} & Negativo & 69 & 100,00 & 16,02 & 0,95 \\
\hline & Positivo & 17 & 99,70 & 16,42 & \\
\hline & Total & 86 & 99,95 & 16,00 & \\
\hline \multirow{3}{*}{$\begin{array}{l}\text { Uso álcool antes da gestação* } \\
\text { (gesta-álcool) }\end{array}$} & Negativo & 49 & 100,95 & 15,40 & 0,74 \\
\hline & Positivo & 33 & 99,75 & 16,70 & \\
\hline & Total & 82 & 100,47 & 15,85 & \\
\hline \multirow{3}{*}{$\begin{array}{l}\text { Problema/evento relacionado álcool } \\
\text { antes da gestação (gesta-álcool) }\end{array}$} & Negativo & 52 & 100,67 & 16,18 & 0,60 \\
\hline & Positivo & 34 & 98,85 & 15,91 & \\
\hline & Total & 86 & 99,95 & 16,00 & \\
\hline \multirow{3}{*}{$\begin{array}{l}\text { Problema/evento relacionado álcool } \\
\text { durante da gestação (gesta-álcool) }\end{array}$} & Negativo & 76 & 100,84 & 15,75 & 0,20 \\
\hline & Positivo & 10 & 93,20 & 17,15 & \\
\hline & Total & 86 & 99,95 & 16,00 & \\
\hline \multirow{3}{*}{$\begin{array}{l}\text { Uso álcool } 3^{\circ} \text { trim}^{*} \\
\text { (infanto-álcool) }\end{array}$} & Negativo & 70 & 98,87 & 16,26 & 0,23 \\
\hline & Positivo & 15 & 104,13 & 14,66 & \\
\hline & Total & 85 & 99,80 & 16,03 & \\
\hline \multirow{3}{*}{$\begin{array}{l}\text { Uso álcool } 2^{\circ} \text { trim }^{*} \\
\text { (infanto-álcool) }\end{array}$} & Negativo & 72 & 99,44 & 15,73 & 0,67 \\
\hline & Positivo & 13 & 101,76 & 18,16 & \\
\hline & Total & 85 & 99,80 & 16,03 & \\
\hline \multirow{3}{*}{$\begin{array}{l}\text { Uso álcool } 1^{\circ} \text { trim}^{*} \\
\text { (infanto-álcool) }\end{array}$} & Negativo & 60 & 99,56 & 16,50 & 0,86 \\
\hline & Positivo & 25 & 100,28 & 15,32 & \\
\hline & Total & 85 & 99,80 & 16,03 & \\
\hline \multirow{3}{*}{$\begin{array}{l}\text { Uso álcool gestação* } \\
\text { (infanto-álcool) }\end{array}$} & Negativo & 57 & 99,56 & 16,50 & 0,84 \\
\hline & Positivo & 28 & 100,28 & 15,32 & \\
\hline & Total & 85 & 99,80 & 16,03 & \\
\hline \multirow{3}{*}{$\begin{array}{l}\text { Uso álcool gestação (dias) } \\
\text { (infanto-álcool) }\end{array}$} & $>$ média $(12,3)$ & 72 & 100,65 & 16,26 & 0,29 \\
\hline & <média $(12,3)$ & 13 & 95,53 & 14,90 & \\
\hline & Total & 85 & 99,80 & 16,03 & \\
\hline \multirow{3}{*}{$\begin{array}{l}\text { Uso de } \geq 3 \text { doses/ocasião álcool } \\
\text { gestação (infanto-álcool) }\end{array}$} & >média $(9,19)$ & 76 & 100,22 & 16,49 & 0,56 \\
\hline & <média $(9,19)$ & 9 & 96,88 & 12,42 & \\
\hline & Total & 85 & 99,80 & 16,03 & \\
\hline
\end{tabular}


Tabela 4 - Escores de RPI obtidos da escala Columbia versus variáveis dicotômicas analisadas (teste t- Student) (continuação)

\begin{tabular}{|c|c|c|c|c|c|}
\hline Variável dicotômica & & $\mathbf{N}$ & RPI (média) & Desvio padrão & $p$ \\
\hline \multirow[t]{3}{*}{ Uso tabaco* } & Negativo & 71 & 99,26 & 16,02 & 0,69 \\
\hline & Positivo & 13 & 100,61 & 16,14 & \\
\hline & Total & 84 & 99,95 & 16,00 & \\
\hline \multirow[t]{3}{*}{ Uso tabaco na gestação* } & Negativo & 72 & 100,95 & 15,40 & 0,74 \\
\hline & Positivo & 13 & 99,75 & 16,70 & \\
\hline & Total & 85 & 100,47 & 15,85 & \\
\hline \multirow[t]{3}{*}{ Estado civil } & Casada/amasiada & 74 & 100,40 & 15,90 & 0,51 \\
\hline & Solteiro/separada/viúva & 12 & 97,16 & 17,03 & \\
\hline & Total & 86 & 99,95 & 16,00 & \\
\hline \multirow[t]{3}{*}{ Escolaridade } & Fundamental & 30 & 101,40 & 16,88 & 0,55 \\
\hline & Médio/superior & 56 & 99,17 & 15,61 & \\
\hline & Total & 86 & 99,95 & 16,00 & \\
\hline \multirow[t]{3}{*}{ Situação emprego } & Ativo & 20 & 104,55 & 14,29 & 0,12 \\
\hline & Inativo & 66 & 98,56 & 16.33 & \\
\hline & Total & 86 & 99,95 & 16,00 & \\
\hline \multirow[t]{3}{*}{ Renda familiar } & $<5$ salários mínimos & 57 & 98,98 & 15,83 & 0,44 \\
\hline & $\geq 5$ salários mínimos & 29 & 101,86 & 16,44 & \\
\hline & Total & 86 & 99,95 & 16,00 & \\
\hline Número de filhos & $<3$ & 76 & 99,10 & 16,57 & 0,04 \\
\hline \multirow[t]{2}{*}{ (gesta-álcool) } & $\geq 3$ & 10 & 106,40 & 8,79 & \\
\hline & Total & 86 & 99,95 & 16,00 & \\
\hline \multirow[t]{3}{*}{ Tipo de parto } & Normal & 42 & 99,45 & 16,39 & 0,73 \\
\hline & Cesárea/fórceps & 30 & 100,88 & 16,70 & \\
\hline & Total & 72 & 100,47 & 15,85 & \\
\hline \multirow[t]{3}{*}{ Religião } & Praticante & 45 & 98,00 & 15,91 & 0,24 \\
\hline & Não Praticante & 41 & 102,09 & 16,02 & \\
\hline & Total & 86 & 99,95 & 16,00 & \\
\hline \multirow[t]{3}{*}{ Apgar $1^{\circ}$ minuto } & $\geq 7$ & 58 & 100,17 & 15,40 & 0,83 \\
\hline & $<7$ & 15 & 99,00 & 19,89 & \\
\hline & Total & 73 & 99,80 & 16,03 & \\
\hline \multirow[t]{3}{*}{ Apgar $5^{\circ}$ minuto } & $\geq 7$ & 72 & 100,26 & & NA \\
\hline & $<7$ & 1 & 76,00 & & \\
\hline & Total & 73 & 99,80 & 16,03 & \\
\hline Cor da pele & Branca & 47 & 101,93 & 15,23 & 0,24 \\
\hline \multirow[t]{2}{*}{ (referida) } & Mulata/negra & 39 & 97,56 & 16,77 & \\
\hline & Total & 86 & 99,95 & 16,00 & \\
\hline \multirow[t]{3}{*}{ Idade materna } & Entre 18 e 36 anos & 75 & 100.29 & 16,13 & 0,61 \\
\hline & $<18$ ou $>36$ anos & 11 & 97,64 & 15,97 & \\
\hline & Total & 86 & 99,95 & 16,00 & \\
\hline
\end{tabular}

*- qualquer quantidade e freqüência de uso. 
Separando a amostra por gênero, observamos escores médios menores na Escala de Maturidade Mental Columbia em meninos filhos de mães que declararam cor mulata ou negra $(92,47 \pm 17,22)$ versus cor branca $(103,43 \pm 13,37)(p=0,02)$, que fizeram uso em dias de qualquer quantidade de álcool na gestação maior $(89,33$ $\pm 6,34)$ versus menor que a média $(99,60 \pm 16,79)(p=0,01)$ e também naqueles em que as mães usaram três ou mais doses de álcool por ocasião durante a gestação acima $(87,00 \pm 3,08)$ versus abaixo da média $(99,64 \pm 16,57)(p<0,0001)$ (figura 2$)$. Não foram observadas diferenças significativas para as outras variáveis analisadas.

Em relação às meninas nenhuma associação significativa foi encontrada entre valores de RPI e as variáveis analisadas. 

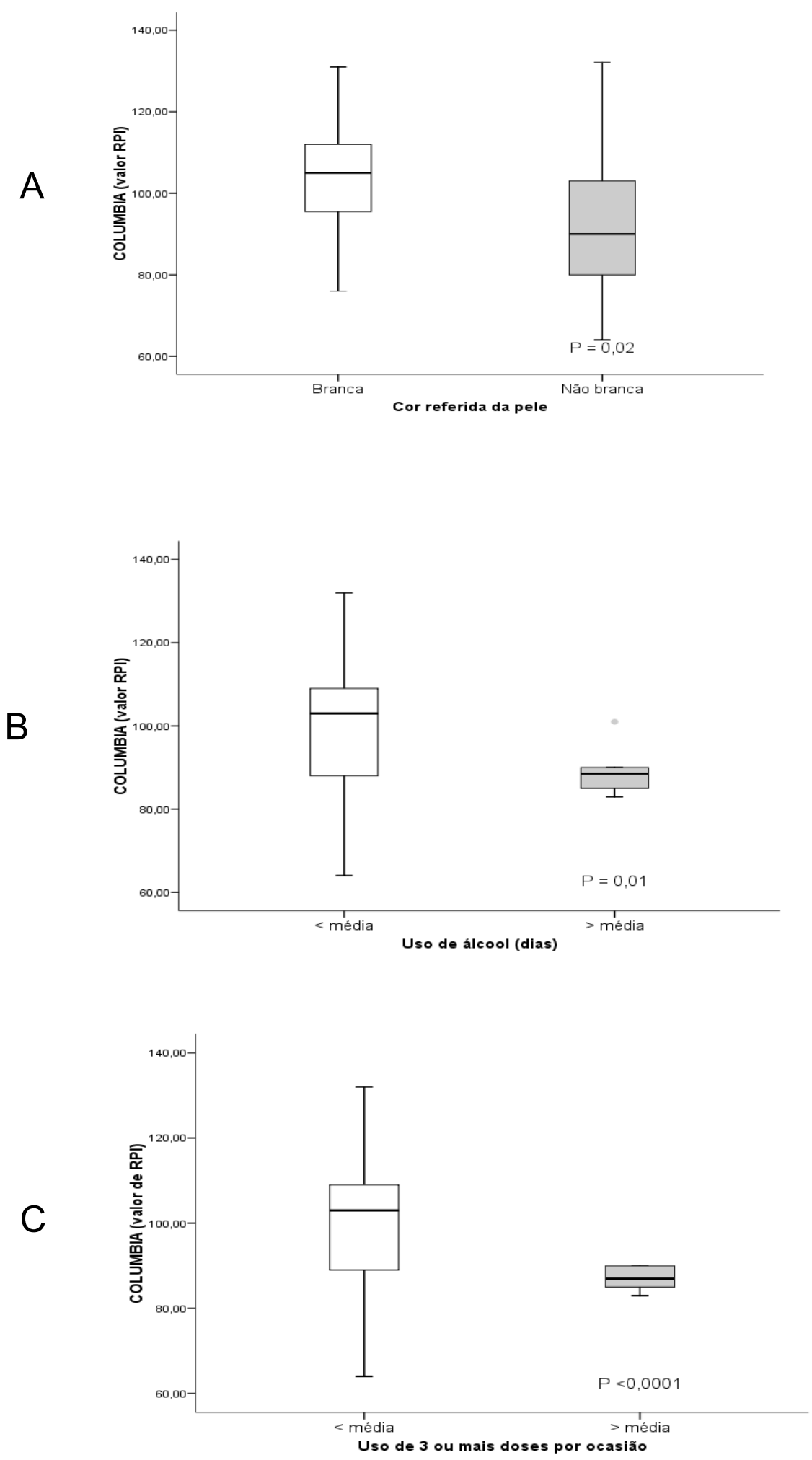

Figura 2 - Escores de RPI da Escala de Maturidade Mental Columbia em meninos em relação à cor referida da pele $(A)$, uso pelas mães em dias de qualquer quantidade de álcool na gestação (B) e uso de três ou mais doses de álcool por ocasião durante a gestação (C). As linhas correspondem ao valor médio de RPI. 


\section{Teste exato de Fisher}

Foram analisados ainda os escores de RPI da escala Columbia como variáveis dicotômicas, utilizando os escores médios e de -1 desvio padrão como pontos de corte em associação às variáveis dicotômicas T-ACE (positivo versus negativo), uso de qualquer quantidade de álcool consumida no $1^{\circ}, 2^{\circ}$ e $3^{\circ}$ trimestres ou durante os três trimestres, problema/evento relacionado ao uso de álcool antes e durante a gestação em qualquer freqüência, uso de tabaco na gestação (dado GESTAÁLCOOL), uso de tabaco atual, uso de qualquer quantidade de álcool consumida no $1^{\circ}, 2^{\circ}$ e $3^{\circ}$ trimestres, uso de qualquer quantidade de álcool em dias acima da média ou uso de três ou mais doses por ocasião acima da média (dado retrospectivo INFANTO-ÁLCOOL). Não foi observada associação estatisticamente significativa para nenhuma das variáveis analisadas. Estes dados são mostrados na tabela 5.

Tabela 5 - Significância (valor de p), odds ratio e 95\% de intervalo de confiança (OR - 95\% IC) para escores de RPI de acordo com média (< ou $\geq 99,95)$ e -1 desvio padrão (< ou $\geq$ 83,9) em associação com variáveis dicotômicas estudadas (teste exato de Fisher).

\begin{tabular}{|c|c|c|c|c|}
\hline \multirow[t]{2}{*}{ Variável dicotômica } & \multicolumn{2}{|c|}{ RPI Média } & \multicolumn{2}{|c|}{ RPI - 1DP } \\
\hline & OR $(95 \%$ IC) & $\mathrm{p}$ & OR $(95 \%$ IC) & $\mathrm{p}$ \\
\hline T-ACE & $1,42(0,50-3,95)$ & 0,59 & $1,63(0,49-5,41)$ & 0,51 \\
\hline Uso álcool $3^{\circ}$ trimestre ${ }^{1}$ & $1,12(0,43-2,85)$ & 0.81 & $1,28(0,47-3,94)$ & 0,77 \\
\hline Uso álcool $2^{\circ}$ trimestre $^{1}$ & $0,93(0,38-2,27)$ & 1,00 & $1,25(0,42-3,78)$ & 0,78 \\
\hline Uso álcool $1^{0}$ trimestre $^{1}$ & $0,77(0,31-1,90)$ & 0,65 & $1,31(0,4-4,15)$ & 0,77 \\
\hline Uso nos 3 trimestres ${ }^{1}$ & $1,38(0,47-4,02)$ & 0,59 & $1,32(0,31-4,73)$ & 0,73 \\
\hline $\begin{array}{l}\text { Problema/evento relacionado ao } \\
\text { uso de álcool antes da gestação }{ }^{1}\end{array}$ & $1,03(0,43-2,49)$ & 1,00 & $1,47(0,50-4,28)$ & 0,58 \\
\hline $\begin{array}{l}\text { Problema/evento relacionado ao } \\
\text { uso de álcool durante a gestação }{ }^{1}\end{array}$ & $2,43(0,63-9,35)$ & 0,30 & $3,23(0,79-13,1)$ & 0,10 \\
\hline Uso de tabaco na gestação ${ }^{1}$ & $2,22(0,69-7,09)$ & 0,23 & $1,81(0,49-6,70)$ & 0,46 \\
\hline Uso de tabaco atual $^{2}$ & $2,66(0,79-8,98)$ & 0,13 & $2,01(0,53-7,56)$ & 0,28 \\
\hline Uso álcool $3^{\circ}$ trimestre ${ }^{2}$ & $0,48(0,13-1,58)$ & 0,26 & $0,24(0,03-1,98)$ & 0,28 \\
\hline Uso álcool $2^{\circ}$ trimestre $^{2}$ & $0,59(0,16-2,08)$ & 0,54 & $0,69(0,14-3,46)$ & 1,00 \\
\hline Uso álcool $1^{0}$ trimestre $^{2}$ & $0,93(0,36-2,41)$ & 1,00 & $0,69(0,20-2,36)$ & 0,76 \\
\hline Uso álcool gestação (dias) ${ }^{2}$ & $1,83(0,58-6,02)$ & 0,36 & $1,24(0,30-5,12)$ & 0,71 \\
\hline Uso de $\geq 3$ doses/ocasião álcool ${ }^{2}$ & $1,91(0,47-7,71)$ & 0,47 & $0,46(0,05-4,02)$ & 0,68 \\
\hline Uso gestação $^{2}$ & $0,89(0,35-2,41)$ & 1,00 & $0,56(0,16-1,92)$ & 0,40 \\
\hline
\end{tabular}




\section{Inventário de Comportamentos da Infância e Adolescência (CBCL)}

Do total de oitenta e seis crianças avaliadas, o inventário foi obtido em oitenta e três crianças, sendo quarenta e uma (49\%) do sexo masculino e quarenta e duas (51\%) do sexo feminino. Idade das crianças em meses variou de 95 a 120 meses

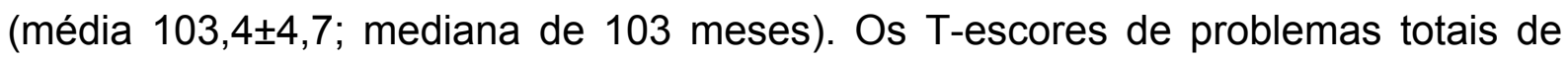
comportamento variaram de 37 a 91, com valor médio de 53,74 \pm 11,16 e mediana de 53. Em três casos os dados não puderam ser analisados. As frequências de distribuição dos T-escores são mostradas na figura 3.

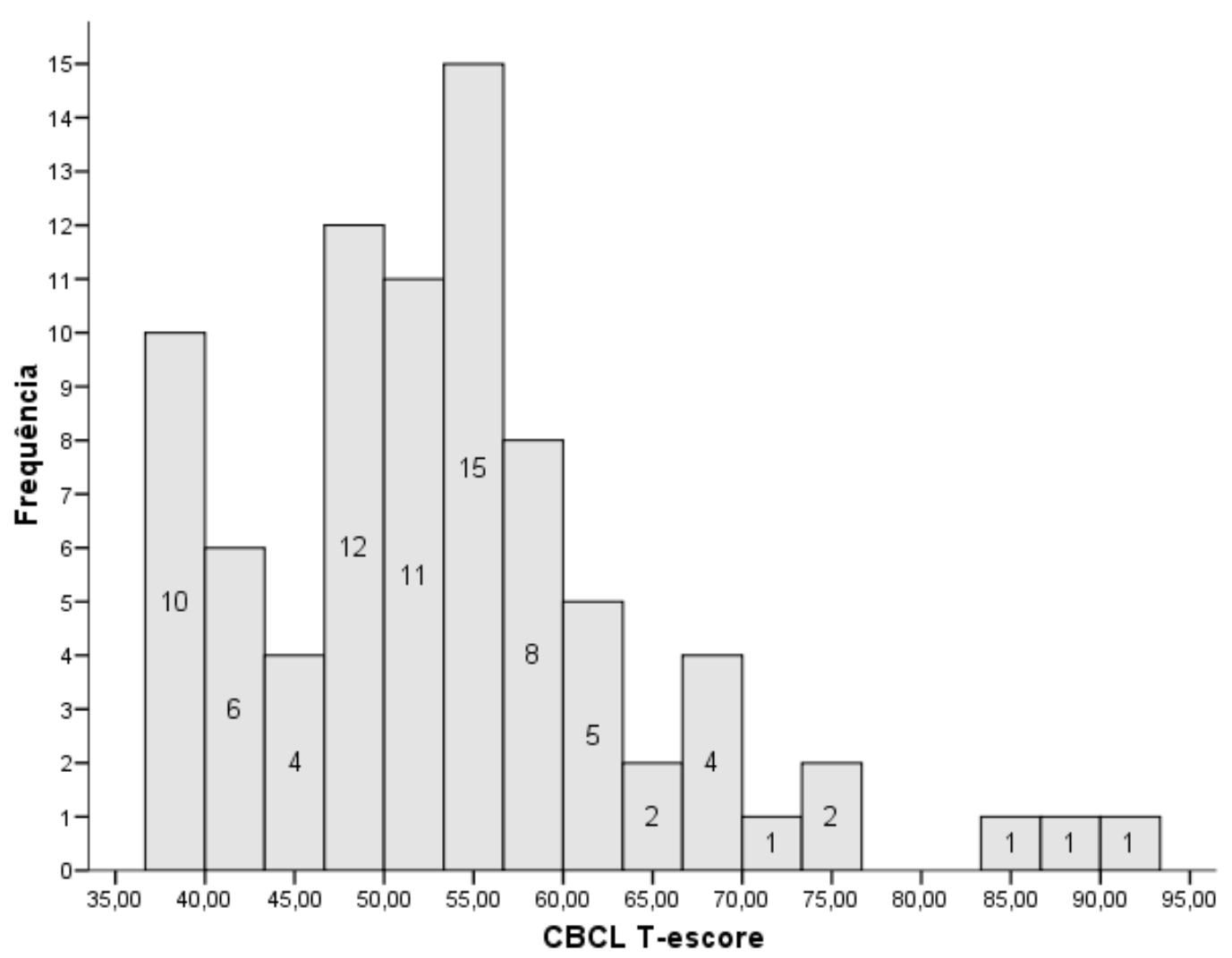

Figura 3 - Frequências dos T-escores de problemas totais de comportamento do CBCL obtidos nas 83 crianças avaliadas. 


\section{CBCL versus variáveis analisadas}

\section{Teste t-Student}

Foram analisados pelo teste t-Student a associação entre os T-escores de problemas totais de comportamento obtidos no questionário $\mathrm{CBCL}$ como variável contínua e as variáveis dicotômicas T-ACE (positivo versus negativo), uso de qualquer quantidade de álcool consumida no $1^{\circ}, 2^{\circ}$ e $3^{\circ}$ trimestres ou durante os três trimestres, problema ou evento relacionado ao uso de álcool antes e durante a gestação em qualquer frequência, uso de tabaco durante a gestação (dado GESTAÁLCOOL), uso de qualquer quantidade de álcool consumida no $1^{\circ}, 2^{\circ}$ e $3^{\circ}$ trimestres ou durante qualquer fase da gestação, média de dias de uso de qualquer quantidade de álcool na gestação, média de uso de três ou mais doses de álcool por ocasião durante a gestação e uso de tabaco atual (dado retrospectivo - INFANTO-ÁLCOOL). Foram analisados também os dados sociodemográficos e gestacionais: estado civil (casada/amasiada versus solteira ou separada ou viúva), escolaridade (ensino fundamental versus médio ou superior), situação de emprego (ativo versus inativo), renda familiar (menor versus maior ou igual a cinco salários mínimos), número de filhos (menor versus maior ou igual a três filhos), tipo de parto (normal versus fórceps/cesárea), religião (praticante versus não praticante), índice de Apgar no $1^{\circ} \mathrm{e}$ $5^{\circ}$ minutos (menor versus maior ou igual a sete), cor referida da pele (branca versus mulata/negra) e idade materna (entre 18 e 36 anos versus menor que 18 ou maior que 36 anos) (dado GESTA-ÁLCOOL). Também foram analisados os T-escores do CBCL em relação aos escores médios e de um desvio-padrão da média de RPI obtidos na Escala de Maturidade Mental Columbia. Diferenças significativas foram observadas em relação ao uso de álcool durante a gestação no $2^{\circ}, 3^{\circ}$ trimestres e 
uso nos três trimestres com dados do GESTA-ÁLCOOL $(p=0,05, p=0,01$ e $p=$ 0,02 respectivamente) e no $1^{\circ}$ trimestre da gestação $(p=0,05)$, uso de qualquer quantidade de álcool em dias acima da média $(p=0,01)$, uso de três ou mais doses por ocasião acima da média $(p=0,05)$ com dados do INFANTO-ÁLCOOL. Foram observadas também diferenças significativas em relação ao uso atual de tabaco ( $p=$ $0,006)$, religião $(p=0,03)$ e escores médios de RPI da Escala de Maturidade Mental Columbia $(p=0,002)$ e escores de RPI um desvio-padrão abaixo da média ( $p=$ 0,03). Não foram observadas diferenças de média para nenhuma das outras variáveis analisadas. Estes dados são mostrados na tabela 6 . 
Tabela 6 - T-escores de problemas totais de comportamento obtidos pelo CBCL versus variáveis dicotômicas analisadas (teste t- Student).

\begin{tabular}{|c|c|c|c|c|c|}
\hline Variável dicotômica & & $\mathbf{N}$ & $\begin{array}{c}\text { Escore bruto } \\
\text { (média) }\end{array}$ & Desvio padrão & $\mathbf{p}$ \\
\hline \multirow[t]{3}{*}{ T-ACE } & Negativo & 66 & 53,22 & 10,24 & 0,41 \\
\hline & Positivo & 17 & 55,76 & 14,41 & \\
\hline & Total & 83 & 53,74 & 11,16 & \\
\hline \multirow{3}{*}{$\begin{array}{l}\text { Uso álcool } 3^{\circ} \text { trim* } \\
\text { (gesta-álcool) }\end{array}$} & Negativo & 57 & 51,45 & 8,81 & 0,01 \\
\hline & Positivo & 25 & 59,40 & 13,92 & \\
\hline & Total & 82 & 53,78 & 11,22 & \\
\hline \multirow{3}{*}{$\begin{array}{l}\text { Uso álcool } 2^{\circ} \text { trim* } \\
\text { (gesta-álcool) }\end{array}$} & Negativo & 51 & 51,68 & 8,65 & 0,05 \\
\hline & Positivo & 30 & 57,43 & 14,12 & \\
\hline & Total & 81 & 53,81 & 11,26 & \\
\hline \multirow{3}{*}{$\begin{array}{l}\text { Uso álcool } 1^{\circ} \text { trim* } \\
\text { (gesta-álcool) }\end{array}$} & Negativo & 44 & 52,20 & 8,18 & 0,22 \\
\hline & Positivo & 34 & 55,44 & 13,74 & \\
\hline & Total & 78 & 53,61 & 10,99 & \\
\hline \multirow{3}{*}{$\begin{array}{l}\text { Uso álcool } 3 \text { trimestres* } \\
\text { (gesta-álcool) }\end{array}$} & Negativo & 66 & 51,83 & 8,94 & 0,02 \\
\hline & Positivo & 17 & 61,17 & 15,49 & \\
\hline & Total & 83 & 53,74 & 11,16 & \\
\hline \multirow{3}{*}{$\begin{array}{l}\text { Uso álcool antes da gestação* } \\
\text { (gesta-álcool) }\end{array}$} & Negativo & 48 & 52,22 & 8,44 & 0,29 \\
\hline & Positivo & 31 & 55,22 & 14,21 & \\
\hline & Total & 79 & 53,40 & 11,08 & \\
\hline \multirow{3}{*}{$\begin{array}{l}\text { Problema/evento relacionado álcool } \\
\text { antes da gestação (gesta-álcool) }\end{array}$} & Negativo & 51 & 53,43 & 10,61 & 0,74 \\
\hline & Positivo & 32 & 54,25 & 12,14 & \\
\hline & Total & 83 & 53,74 & 11,16 & \\
\hline \multirow{3}{*}{$\begin{array}{l}\text { Problema/evento relacionado álcool } \\
\text { durante da gestação (gesta-álcool) }\end{array}$} & Negativo & 74 & 53,50 & 11,13 & 0,56 \\
\hline & Positivo & 9 & 55,77 & 11,88 & \\
\hline & Total & 83 & 53,74 & 11,16 & \\
\hline \multirow{3}{*}{$\begin{array}{l}\text { Uso álcool } 3^{\circ} \text { trim* } \\
\text { (infanto-álcool) }\end{array}$} & Negativo & 68 & 53,00 & 10,37 & 0,16 \\
\hline & Positivo & 14 & 57,57 & 14,57 & \\
\hline & Total & 82 & 53,78 & 11,22 & \\
\hline \multirow{3}{*}{$\begin{array}{l}\text { Uso álcool } 2^{\circ} \text { trim* } \\
\text { (infanto-álcool) }\end{array}$} & Negativo & 67 & 52,95 & 10,43 & 0,16 \\
\hline & Positivo & 15 & 57,46 & 14,10 & \\
\hline & Total & 82 & 53,78 & 11,22 & \\
\hline \multirow{3}{*}{$\begin{array}{l}\text { Uso álcool } 1^{\circ} \text { trim* } \\
\text { (infanto-álcool) }\end{array}$} & Negativo & 60 & 52,33 & 10,28 & 0,05 \\
\hline & Positivo & 22 & 57,78 & 12,91 & \\
\hline & Total & 82 & 53,78 & 11,22 & \\
\hline \multirow{3}{*}{$\begin{array}{l}\text { Uso álcool gestação* } \\
\text { (infanto-álcool) }\end{array}$} & Negativo & 55 & 52,98 & 10,45 & 0,36 \\
\hline & Positivo & 27 & 55,40 & 12,71 & \\
\hline & Total & 82 & 53,78 & 11,22 & \\
\hline \multirow{3}{*}{$\begin{array}{l}\text { Uso álcool gestação (dias) } \\
\text { (infanto-álcool) }\end{array}$} & >média $(12,3)$ & 70 & 52,57 & 10,24 & 0,01 \\
\hline & <média $(12,3)$ & 12 & 60,83 & 14,37 & \\
\hline & Total & 82 & 53,78 & 11,22 & \\
\hline \multirow{3}{*}{$\begin{array}{l}\text { Uso de } \geq 3 \text { doses/ocasião álcool } \\
\text { gestação (infanto-álcool) }\end{array}$} & >média $(9,16)$ & 74 & 53,00 & 10,91 & 0,05 \\
\hline & $<$ média $(9,19)$ & 8 & 96,88 & 12,47 & \\
\hline & Total & 82 & 53,78 & 11,22 & \\
\hline
\end{tabular}

* - qualquer quantidade e freqüência de uso. 
Tabela 6 - T-escores de problemas totais de comportamento obtidos pelo CBCL versus variáveis dicotômicas analisadas (teste t- Student) (continuação).

\begin{tabular}{|c|c|c|c|c|c|}
\hline Variável dicotômica & & $\mathbf{N}$ & $\begin{array}{l}\text { Escore bruto } \\
\text { (média) }\end{array}$ & $\begin{array}{l}\text { Desvio } \\
\text { padrão }\end{array}$ & $\mathbf{p}$ \\
\hline \multirow[t]{3}{*}{ Uso tabaco* } & Negativo & 71 & 52,53 & 9,79 & 0,006 \\
\hline & Positivo & 11 & 62,36 & 15,85 & \\
\hline & Total & 82 & 53,78 & 11,22 & \\
\hline \multirow[t]{3}{*}{ Uso tabaco na gestação* } & Negativo & 71 & 52,90 & 10,77 & 0,09 \\
\hline & Positivo & 12 & 58,75 & 12,59 & \\
\hline & Total & 83 & 53,74 & 11,16 & \\
\hline \multirow[t]{3}{*}{ Estado civil } & Casada/amasiada & 71 & 53,42 & 11,31 & 0,52 \\
\hline & Solteiro/separada/viúva & 12 & 55,66 & 10,46 & \\
\hline & Total & 83 & 53,74 & 11,16 & \\
\hline \multirow[t]{3}{*}{ Escolaridade } & Fundamental & 29 & 54,10 & 7,92 & 0,83 \\
\hline & Médio/superior & 54 & 53,55 & 12,63 & \\
\hline & Total & 83 & 53,74 & 11,16 & \\
\hline \multirow[t]{3}{*}{ Situação emprego } & Ativo & 20 & 53,65 & 9,46 & 0,96 \\
\hline & Inativo & 63 & 53,77 & 11,72 & \\
\hline & Total & 83 & 53,74 & 11,16 & \\
\hline \multirow[t]{3}{*}{ Renda familiar } & < 5 salários mínimos & 55 & 54,20 & 12,59 & 0,55 \\
\hline & $\geq 5$ salários mínimos & 28 & 52,85 & 7,74 & \\
\hline & Total & 83 & 53,74 & 11,16 & \\
\hline Número de filhos & $<3$ & 73 & 54,17 & 10,61 & 0,34 \\
\hline \multirow[t]{2}{*}{ (gesta-álcool) } & $\geq 3$ & 10 & 50,60 & 14,90 & \\
\hline & Total & 83 & 53,74 & 11,16 & \\
\hline \multirow[t]{3}{*}{ Tipo de parto } & Normal & 42 & 54,00 & 10,20 & 0,71 \\
\hline & Cesárea/fórceps & 28 & 53,00 & 12,01 & \\
\hline & Total & 70 & 53,60 & 10,89 & \\
\hline \multirow[t]{3}{*}{ Religião } & Praticante & 43 & 56,18 & 11,88 & 0,03 \\
\hline & Não Praticante & 40 & 51,12 & 9,81 & \\
\hline & Total & 83 & 53,74 & 11,16 & \\
\hline \multirow[t]{3}{*}{ Apgar $1^{\circ}$ minuto } & $\geq 7$ & 56 & 52,82 & 9,16 & 0,57 \\
\hline & $<7$ & 15 & 55,40 & 16,38 & \\
\hline & Total & 71 & 53,36 & 10,99 & \\
\hline \multirow[t]{3}{*}{ Apgar $5^{\circ}$ minuto } & $\geq 7$ & 70 & 53,24 & 11,02 & NA \\
\hline & $<7$ & 1 & 62,00 & & \\
\hline & Total & 71 & 53,36 & 10,99 & \\
\hline Cor da pele & Branca & 46 & 52,69 & 9,57 & 0,34 \\
\hline \multirow[t]{2}{*}{ (referida) } & Mulata/negra & 37 & 55,05 & 12,89 & \\
\hline & Total & 83 & 53,74 & 11,16 & \\
\hline \multirow[t]{3}{*}{ Idade materna } & Entre 18 e 36 anos & 72 & 53,06 & 10,85 & 0,16 \\
\hline & $<18$ ou $>36$ anos & 11 & 58,18 & 12,68 & \\
\hline & Total & 83 & 53,74 & 11,16 & \\
\hline \multirow[t]{3}{*}{ Columbia } & $>$ média & 50 & 50,78 & 10,31 & 0,002 \\
\hline & $<$ média & 33 & 58,24 & 11,03 & \\
\hline & Total & 83 & 53,74 & 11,16 & \\
\hline \multirow[t]{3}{*}{ Columbia } & $>1 \mathrm{DP}$ & 66 & 52,40 & 10,81 & 0,03 \\
\hline & $<1 \mathrm{DP}$ & 17 & 58,94 & 11,31 & \\
\hline & Total & 83 & 53,74 & 11,16 & \\
\hline
\end{tabular}


Separando a amostra por gênero, observamos T-escores maiores de CBCL em meninos filhos de mães que declararam uso $(65,40 \pm 13,44)$ versus não uso de tabaco durante a gestação $(51,97 \pm 10,80)(p=0,01)$, uso de tabaco atual $(66,20 \pm$ $12,37)$ versus não uso $(52,05 \pm 10,89)(p=0,01)$. T-escores maiores de CBCL também foram observados em filhos de mães que referiram uso $(58,62 \pm 14,66)$ versus não uso de álcool durante a gestação no $2^{\circ}$ trimestre $(50,40 \pm 8,45)(p=$ 0,05), uso $(61,53 \pm 14,66)$ versus não uso no $3^{\circ}$ trimestre $(50,18 \pm 8,26)(p=0,02)$ e uso $(61,90 \pm 15,76)$ versus não uso nos três trimestres $(50,56 \pm 8,46)(p=0,04)$ com dados do GESTA-ÁLCOOL. Foi observado também T-escores maiores de CBCL em filhos de mães que referiram uso em dias de qualquer quantidade de álcool na gestação maior $(71,80 \pm 13,82)$ versus menor que a média $(51,00 \pm 9,18)$ ( $p<$ 0,0001) e também naqueles em que as mães usaram de três ou mais doses de álcool por ocasião durante a gestação acima $(67,75 \pm 12,06)$ ou abaixo da média $(52,08 \pm 10,90)(p=0,01)$ com dados obtidos do INFANTO-ÁLCOOL (figura 4). Não foram observadas diferenças significativas para as outras variáveis analisadas. 

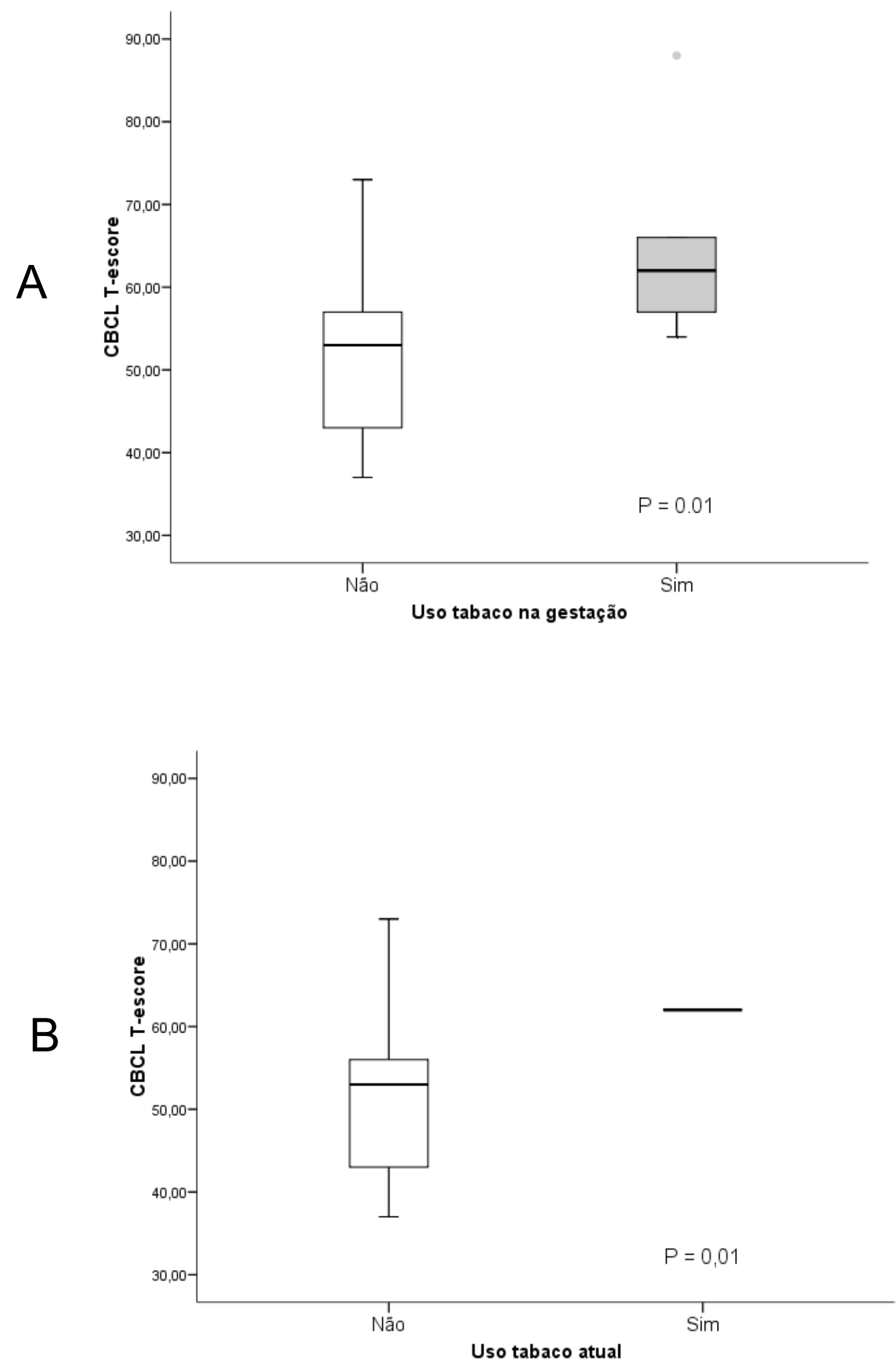

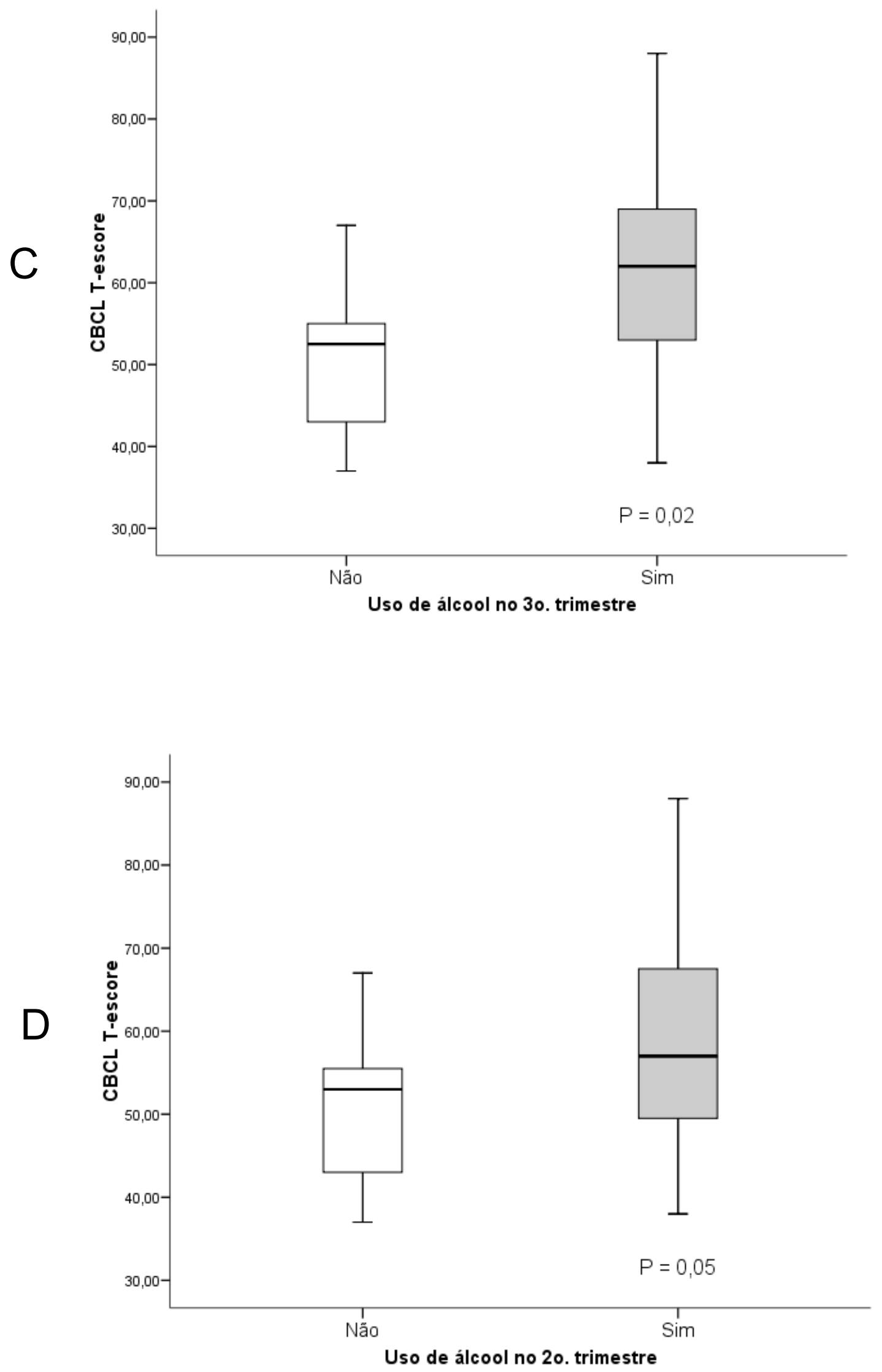

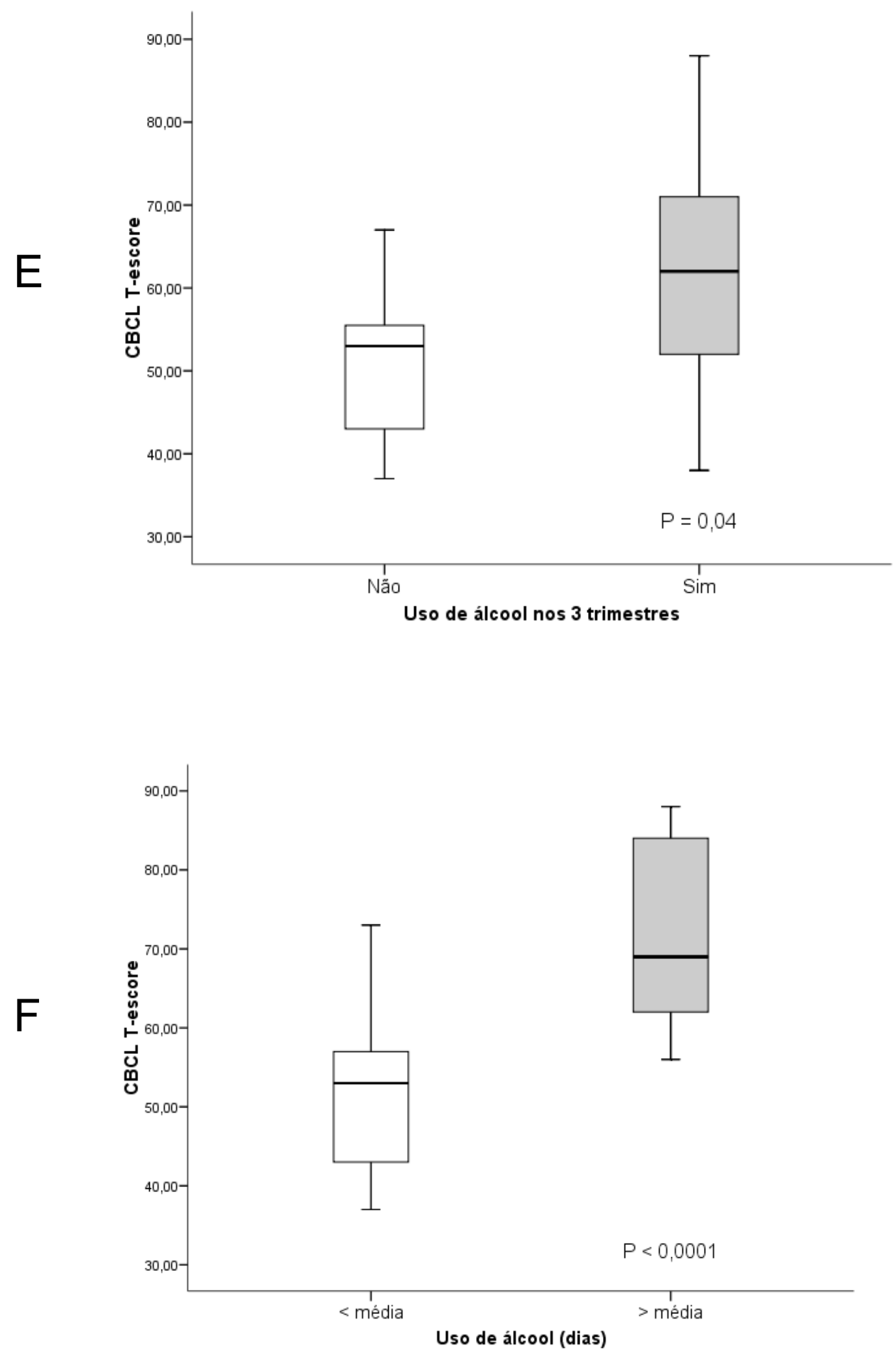


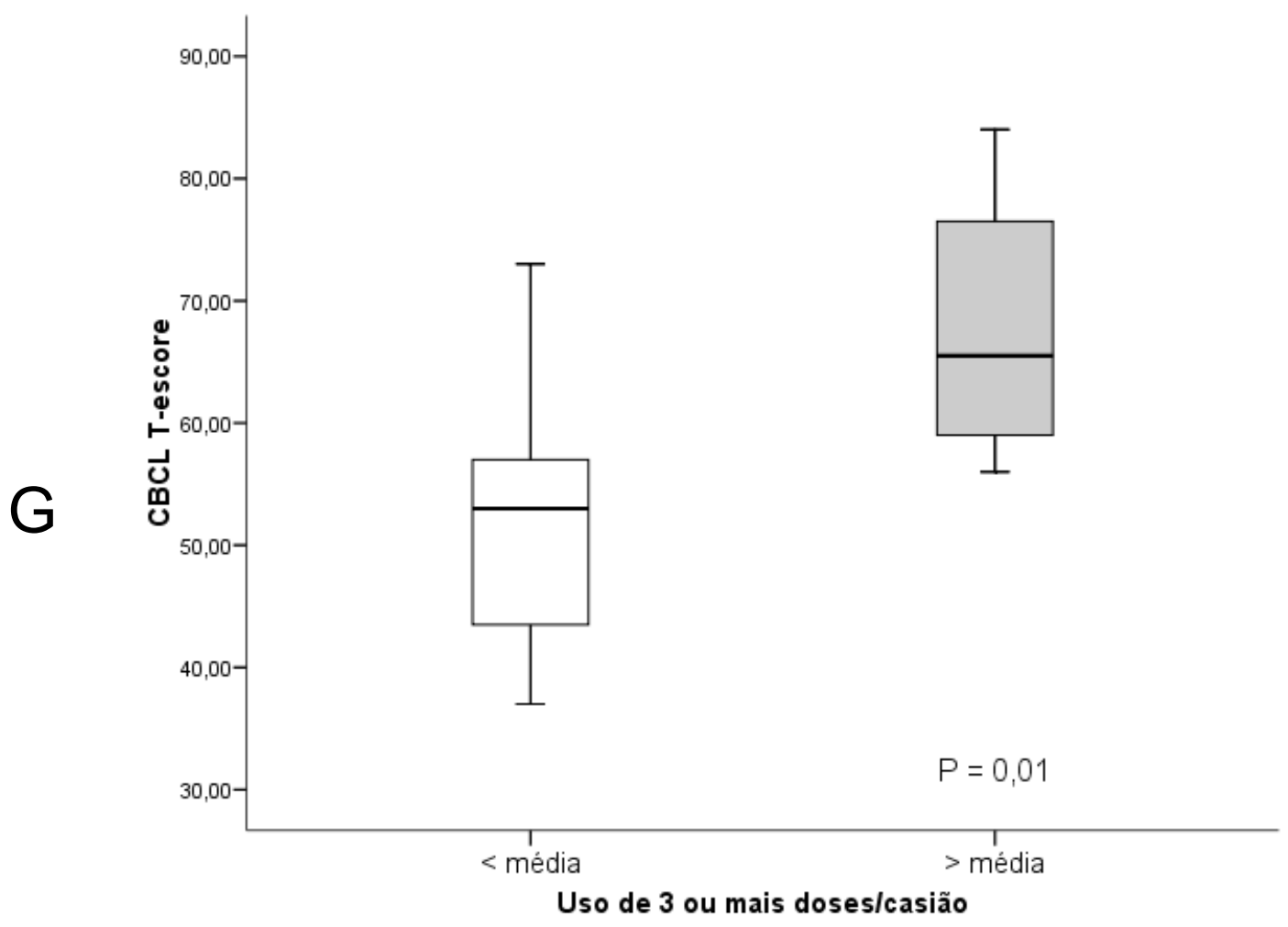

Figura 4 - Valores de T-escores de problemas totais em relação ao uso de tabaco na gestação (A), uso de tabaco atual (B), uso de álcool pela mãe no $3^{\circ}$ trimestre (C), uso de álcool pela mãe no $2^{\circ}$ trimestre (D), uso de álcool pela mãe nos três trimestres de gestação $(E)$, uso pela mãe em dias de qualquer quantidade de álcool na gestação $(F)$ e uso de três ou mais doses de álcool por ocasião durante a gestação $(G)$ em crianças do sexo masculino. As linhas correspondem ao valor médio do escore bruto do CBCL.

Em relação às meninas, T-escores médios maiores de CBCL foram observados naquelas em que as mães se declararam praticantes $(55,18 \pm 11,75)$ versus não praticantes de qualquer religião $(49,73 \pm 6,67)(p=0,05)$ e em relação a valores de RPI da Escala Columbia menores $(61,00 \pm 11,80)$ versus maiores que a média $(50,32 \pm 8,03)$ ( $p=0,001)$. Nenhuma outra associação significativa foi encontrada entre valores de T-escores de CBCL e as variáveis analisadas. 

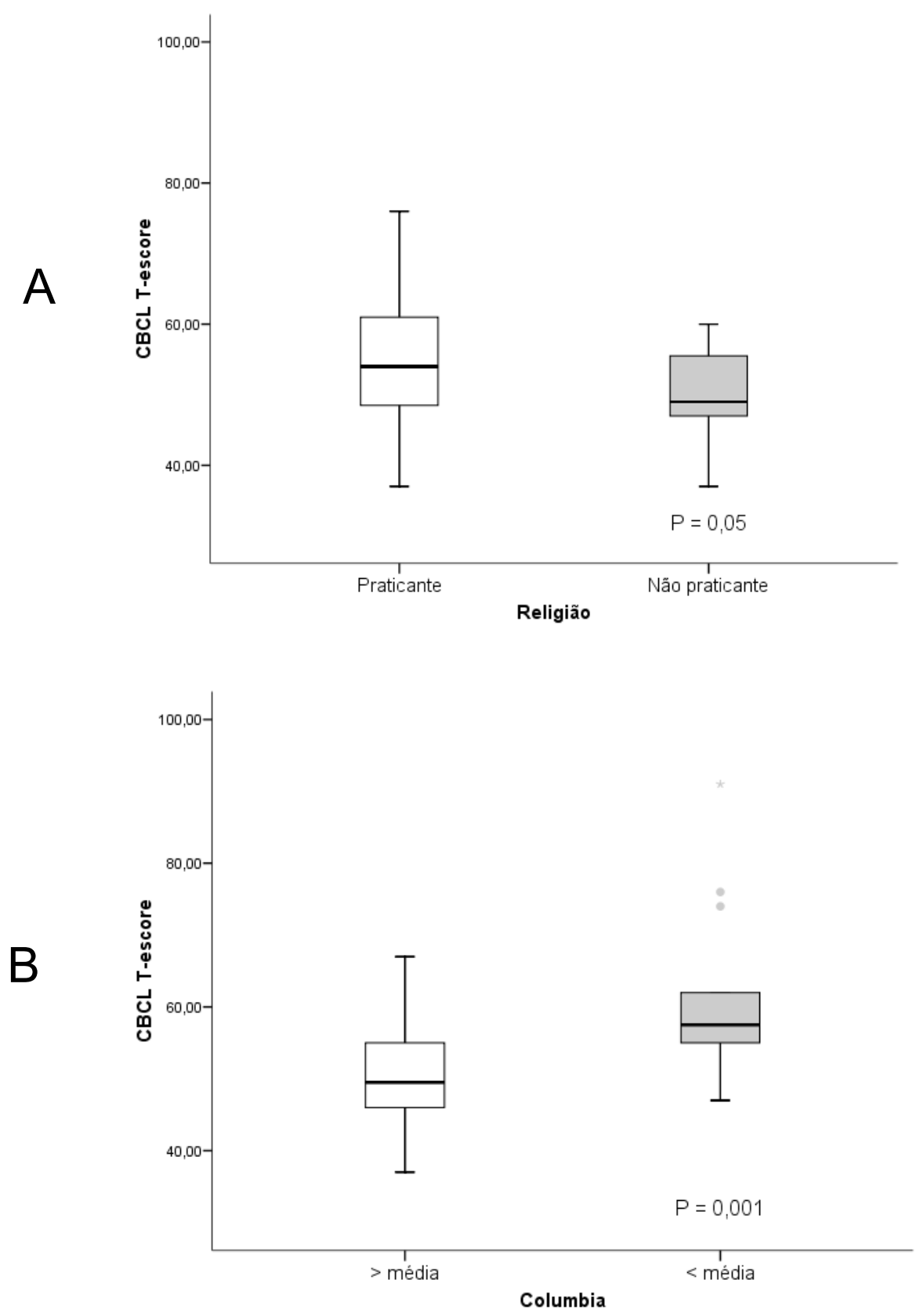

Figura 5 - Valores de T-escores de problemas totais em relação à religião $(A)$, e escores da Escala de Maturidade Mental Columbia (B) em crianças do sexo feminino. As linhas correspondem ao valor médio do T-escore do CBCL.

\section{Regressão linear múltipla}

O modelo de regressão linear múltipla foi utilizado para predizer o resultado da variável dependente, a partir de um conjunto de variáveis independentes. Foi calculado o coeficiente de determinação $\left(R^{2}\right)$ e os coeficientes de regressão (CR) e $95 \%$ de intervalo de confiança (95\% IC). Foram incluídas as variáveis coletadas na gestação 
(GESTA-ÁLCOOL) que obtiveram maior significância no teste t-Student, excluindo-se as variáveis de colinearidade. Devido ao pequeno número de casos analisados $(n=83)$, foram utilizadas apenas quatro variáveis independentes no modelo. Como variável dependente foi utilizado o T-escore de problema total do CBCL e como variáveis independentes o uso de álcool no $3^{\circ}$ trimestre (GESTA-ÁLCOOL) além do uso de tabaco na gestação, religião e idade materna, usadas como variáveis confundidoras. $\mathrm{O}$ uso de qualquer quantidade de álcool no $3^{\circ}$ trimestre (GESTA-ÁLCOOL) foi a variável com maior grau de associação com valores de T-escore do CBCL $(p=0,007)$ (tabela 7).

Tabela 7 - Modelo final de regressão linear múltipla para T-escores do CBCL com as variáveis uso de álcool no $3^{\circ}$ trimestre (GESTA-ÁLCOOL), uso de tabaco na gestação, religião e idade materna

\begin{tabular}{lccc}
\hline Variável dicotômica & \multicolumn{2}{c}{ T-escore (problemas totais) } \\
& $\mathrm{p}$ & $\mathrm{t}$ & $\mathrm{CR}(95 \% \mathrm{IC})$ \\
\hline Uso álcool 30 trimestre $^{1}$ & $\mathbf{0 , 0 0 7}$ & 2,79 & $7,02(2.01-12,04)$ \\
\hline Uso tabaco na gestação & 0.14 & 1,46 & $4,77(-1,73-11,27)$ \\
\hline Religião & 0,09 & $-1,66$ & $-3,09(-8,55-0,75)$ \\
\hline Idade materna & 0,32 & 0,99 & $2,20(-3,45-10,18)$ \\
\hline $\mathrm{R}^{2}=0,18, \mathrm{CR}$ - coeficiente de regressão, ${ }^{-}-$GESTA-ÁLCOOL &
\end{tabular}

\section{Teste exato de Fisher}

Foram analisados ainda os T-escores de problemas totais de comportamento do CBCL como variáveis dicotômicas, utilizando os escores de 60 como pontos de corte como proposto por Achenbach (SOOD et al., 2001) em associação às variáveis dicotômicas T-ACE (positivo versus negativo), uso de qualquer quantidade de álcool consumida no $1^{\circ}, 2^{\circ}$ e $3^{\circ}$ trimestres ou durante os três trimestres de gestação (dado GESTA-ÁLCOOL), problema ou evento relacionado ao uso de álcool antes e durante a gestação em qualquer frequência (dado GESTA-ÁLCOOL), uso de tabaco na gestação, uso de tabaco atual, uso de qualquer quantidade de álcool consumida no $1^{\circ}, 2^{\circ}$ e $3^{\circ}$ trimestres, uso de qualquer quantidade de álcool em dias acima da média 
ou uso de três ou mais doses por ocasião acima da média (dado retrospectivo INFANTO-ÁLCOOL). Dezenove pacientes (22,9\%) apresentaram T-escores de problemas totais de comportamento do $\mathrm{CBCL} \geq 60$. Foi observada associação estatisticamente significativa para uso de álcool no $2^{\circ}$ e $3^{\circ}$ trimestres, uso de álcool nos três trimestres (dados GESTA-ÁLCOOL) e uso de tabaco durante a gestação e uso atual. Estes dados são mostrados na tabela 8.

Tabela 8 - Significância (valor de p), odds ratio e 95\% de intervalo de confiança (OR - 95\% IC) para T-escores de problemas totais de comportamento do CBCL em associação com variáveis dicotômicas estudadas (teste exato de Fisher).

\begin{tabular}{|c|c|c|}
\hline \multirow[t]{2}{*}{ Variável dicotômica } & \multicolumn{2}{|c|}{ T-escore (problemas totais) } \\
\hline & OR (95\% IC) & $\mathbf{p}$ \\
\hline T-ACE & $2,24(0,69-7,13)$ & 0,20 \\
\hline Uso álcool $3^{\circ}$ trimestre ${ }^{1}$ & $3,55(1,21-10,37)$ & 0.02 \\
\hline${\text { Uso álcool } 2^{\circ} \text { trimestre }}^{1}$ & $3,11(1,07-8,97)$ & 0,05 \\
\hline Uso álcool $1^{\circ}$ trimestre $^{1}$ & $2,20(0,73-6,67)$ & 0,17 \\
\hline Uso nos 3 trimestres gestação ${ }^{1}$ & $4,44(1,40-14,05)$ & 0,01 \\
\hline $\begin{array}{l}\text { Problema/evento relacionado ao uso de álcool } \\
\text { antes da gestação }\end{array}$ & $1,21(0,42-3,43)$ & 0,79 \\
\hline $\begin{array}{l}\text { Problema/evento relacionado ao uso de álcool } \\
\text { durante a gestação }^{1}\end{array}$ & $0,95(0,18-5,04)$ & 1,00 \\
\hline Uso de tabaco na gestação ${ }^{1}$ & $4,46(1,23-16,07)$ & 0,02 \\
\hline Uso de tabaco atual $^{2}$ & $8,60(2,17-34,17)$ & 0,002 \\
\hline Uso álcool $3^{\circ}$ trimestre ${ }^{2}$ & $2,14(0,61-7,41)$ & 0,29 \\
\hline Uso álcool $2^{\circ}$ trimestre ${ }^{2}$ & $1,89(0,55-6,44)$ & 0,32 \\
\hline Uso álcool $1^{\circ}$ trimestre ${ }^{2}$ & $2,54(0,85-7,55)$ & 0,13 \\
\hline Uso álcool gestação (dias) ${ }^{2}$ & $2,85(0,78-10,36)$ & 0,13 \\
\hline Uso de $\geq 3$ doses/ocasião álcool ${ }^{2}$ & $3,93(0,88-17,51)$ & 0,07 \\
\hline
\end{tabular}

Estes dados sugerem que o uso leve/moderado de álcool na gestação está associado à menor desempenho cognitivo e problemas comportamentais totais, especialmente em meninos. 
A exposição pré-natal ao álcool tem sido associada a prejuízos no desenvolvimento cognitivo infantil. A maioria dos estudos tem investigado predominantemente os efeitos do uso excessivo de álcool durante a gestação, em relação à Síndrome Fetal do Álcool (SFA) e às manifestações menos graves geralmente identificadas na literatura como Efeitos Fetais do Álcool (EFA). Existem achados conflitantes sobre a associação entre uso baixo e moderado de álcool na gestação e prejuízos no desenvolvimento cognitivo e comportamental dos filhos (SOOD et al., 2001; LARROQUE et al., 1995; HUIZINK; MULDER, 2006; KELLY et al.; 2009; ROBINSON et al.; 2010). Neste estudo foi investigada a relação entre consumo de álcool na gestação e desenvolvimento cognitivo dos filhos na idade escolar.

Em relação aos dados sociodemográficos, os resultados obtidos entre o grupo das 86 mães analisadas foi similar ao grupo total de 450 gestantes avaliadas no GESTA-ÁLCOOL. A idade média no momento do parto foi de 24,9 anos na amostra analisada versus 23,9 anos no grupo total de gestantes. No grupo analisado $54,6 \%$ das mães se declararam brancas contra $58,9 \%$ no grupo do GESTA-ÁLCOOL (PINHEIRO et al., 2005).

Em relação à amostra total nossos resultados mostraram associação entre escores de RPI maiores que a média e maior idade materna, maior peso médio da criança ao nascimento e em relação ao número de filhos.

Crianças cujas famílias tinham três ou mais filhos apresentaram RPI médio maior quando comparadas àquelas com famílias com menos de três filhos. Um trabalho conduzido em Salvador, Bahia, mostrou uma frequência maior de transtornos mentais, psicossomáticos e neuróticos em crianças de família com prole menos numerosa. No entanto, outros estudos têm sugerido que crianças e 
adolescentes de famílias numerosas apresentam uma maior incidência de desajustes (ALMEIDA-FILHO; BURNETT, 1983).

Estudos têm sugerido associação entre déficits no desenvolvimento cognitivo infantil e baixo peso ao nascimento. TONG et al. (2006) encontraram associação estatisticamente significante entre baixo peso e menor desempenho cognitivo aos dois anos de idade mas com decréscimo gradual da associação em idades posteriores (sete, 11 e 13 anos). RICHARDS et al. (2001) em um estudo longitudinal de uma coorte seguida desde o nascimento, encontraram associação estatisticamente significativa e positiva entre peso ao nascimento e função cognitiva aos oito, 11, 26 e 43 anos.

Nossos resultados mostraram diferenças de gênero em relação à cognição, consumo aumentado de álcool na gestação e cor referida da pele. Observamos decréscimo no desempenho cognitivo dos meninos cujas mães declararam cor negra ou mulata, que fizeram uso em dias de qualquer quantidade de álcool na gestação maior que a média e também naqueles em que as mães usaram três ou mais doses de álcool por ocasião durante a gestação acima da média. Não foram observadas diferenças significativas para as outras variáveis analisadas.

Em relação às meninas nenhuma associação significativa foi encontrada entre valores de RPI e as variáveis analisadas. É importante considerar que diferenças étnicas relacionadas ao desenvolvimento cognitivo são mediadas por fatores socioeconômicos, características maternas, ambiente domiciliar e consumo excessivo de álcool. Willford et. al. (2006) encontraram associação significativa entre uso moderado de álcool durante primeiro e segundo trimestres de gestação e decréscimos de escores de QI entre crianças afro-americanas de 10 anos de idade, porém a mesma associação não foi encontrada entre as crianças que eram 
caucasianas. BAILEY et al. (2004) mostraram associação significativa entre exposição pré-natal ao álcool e Ql em crianças afro-americanas de sete anos de idade cujas mães fizeram consumo "binge" de álcool.

KELLY et al. (2009) encontraram diferenças de gênero em relação à exposição pré-natal ao álcool e comportamento e cognição em crianças de três anos de idade. Meninos apresentaram escores médios maiores nos problemas comportamentais e escores médios menores no teste cognitivo quando comparados às meninas.

Nossos resultados mostraram associação entre problemas comportamentais das crianças avaliadas pelo $\mathrm{CBCL}$ e exposição pré-natal ao álcool com dados prospectivos (colhidos na entrevista com a gestante no terceiro trimestre, durante o projeto GESTA-ÁLCOOL) e retrospectivos (fornecidos pela mãe durante avaliação da criança na idade escolar - INFANTO-ALCOOL)

É importante ressaltar que uma das variáveis do GESTA-ÁLCOOL referia-se ao consumo durante toda a gestação e das três variáveis do INFANTO-ÁLCOOL duas referiam-se a um consumo aumentado de álcool durante a gestação. Utilizando modelo linear de regressão, nossos resultados encontraram a variável uso de álcool nos três trimestres de gestação (GESTA-ÁLCOOL) com maior força de predição para problemas comportamentais totais das crianças avaliadas, embora deva ser considerado o número pequeno de variáveis confundidoras analisadas. Dezenove pacientes $(22,9 \%)$ apresentaram T-escores de problemas totais de comportamento do $\mathrm{CBCL}$ com ponto de corte maior que $\geq 60$. Foi observada associação estatisticamente significativa para uso de álcool no $2^{\circ}$ e $3^{\circ}$ trimestres, uso de álcool nos três trimestres (dados GESTA-ÁLCOOL) e uso de tabaco durante a gestação e uso atual. 
Os desfechos neurocomprtamentais da exposição pré-natal ao álcool têm sido reportados por vários estudos, no entanto, existem dados controversos relacionados a níveis baixos e moderados de exposição. BROWN et. al. (1990) reportaram associação entre consumo de álcool ao longo de toda a gestação e problemas comportamentais internalizáveis e externalizáveis nas crianças expostas. SOOD et. al.(2001) reportaram associação entre exposição a baixos níveis de consumo de álcool durante a gestação e comportamentos agressivos e externalizáveis em uma amostra de crianças negras de seis a sete anos de idade. Efeitos no comportamento delinquente e nos escores totais de comportamento foram observados com níveis moderado/pesado de exposição ao álcool. KELLY et. al. (2009) em um estudo longitudinal prospectivo não encontraram associação entre consumo leve de álcool durante a gestação e risco aumentado de problemas comportamentais e cognitivos em crianças de três anos de idade. ROBINSON et. al. (2010) em um estudo prospectivo de uma coorte de crianças seguidas até os 14 anos sugerem que o consumo leve/moderado de álcool durante o $1^{\circ}$ trimestre de gestação não é um fator de risco para o desenvolvimento de problemas comportamentais.

Foram observadas também diferenças significativas em relação ao uso atual de tabaco, prática de qualquer religião e menores escores médios de RPI da Escala de Maturidade Mental Columbia e escores de RPI um desvio-padrão abaixo da média. Não foram observadas diferenças de média para nenhuma das outras variáveis analisadas. De forma diferente do observado neste estudo, alguns autores têm sugerido uma relação entre maior religiosidade e melhor auto-regulação (BRODY; FLOR, 1998) e menor incidência de comportamento anti-social e delinquência em crianças e adolescentes (MABE; JOSEPHSON, 2004). Este achado necessita melhor investigação. 
Estudos anteriores também encontraram associação entre o consumo de tabaco durante a gestação e após o nascimento da criança e efeitos adversos no desenvolvimento neurocomportamental e cognitivo, sendo a associação dose dependente. Os principais desfechos neurocomportamentais investigados na infância têm sido o déficit de atenção e hiperatividade e comportamentos externalizáveis (MAUGHAN et. al.; 2001; ERNST et. al.; 2001; LINNET et. al.; 2003).

Nossos resultados também mostraram diferenças de gênero em relação ao comportamento das crianças. Observamos escores médios maiores de problemas totais de comportamento no CBCL em meninos filhos de mães que declararam uso de tabaco durante a gestação e uso de tabaco atual. Escores médios maiores de problemas totais de comportamento no CBCL também foram observados em filhos de mães que referiram uso de álcool durante a gestação no $2^{\circ}$ trimestre, uso no $3^{\circ}$ trimestre e uso nos três trimestres com dados prospectivos (GESTA-ÁLCOOL). Foram observados também escores médios significantemente maiores de problemas totais de comportamento no CBCL em filhos de mães que referiram uso em dias de qualquer quantidade de álcool na gestação maior que a média e também naqueles em que as mães usaram três ou mais doses de álcool por ocasião durante a gestação acima da média com dados retrospectivos (INFANTO-ÁLCOOL). Não foram observadas diferenças significativas para as outras variáveis analisadas.

Em relação às meninas, escores médios maiores de problemas totais de comportamento no $\mathrm{CBCL}$ foram observados naquelas em que as mães se declararam praticantes de qualquer religião e em relação a valores de RPI da Escala Columbia menores que a média. Nenhuma outra associação significativa foi encontrada entre valores de CBCL e as variáveis analisadas. Estudos anteriores também reportaram diferenças de gênero em relação aos problemas 
comportamentais. KELLY et al. (2009) em um estudo longitudinal prospectivo sobre exposição pré-natal ao álcool reportaram que meninos apresentaram escores médios maiores nos problemas comportamentais e escores médios menores no teste cognitivo quando comparados às meninas. RASMUSSEN et. al.; (2010) reportaram que meninas expostas ao álcool na gestação apresentaram maior dificuldade em habilidades sociais, problemas internalizáveis e problemas comportamentais quando comparadas aos meninos.

Em relação ao relato materno sobre consumo de álcool durante a gestação, nossos resultados mostraram níveis de consumo maiores obtidos através dos dados prospectivos quando comparados com os retrospectivos. Em geral os estudos têm considerado os dados prospectivos sobre exposição pré-natal ao álcool mais acurados e válidos quando comparados aos dados retrospectivos devido viés da recordação. Outros estudos sugerem que as mulheres podem subestimar níveis de consumo de álcool durante a gestação devido estigma associado ao uso neste período e por isso os dados retrospectivos seriam mais válidos (HANNIGAN et. al.; 2010; JACOBSON et. al.; 2002).

Embora pareça clara a associação entre o consumo crônico e pesado de álcool durante a gestação e o desenvolvimento da SFA, há controvérsias com relação à quantidade de álcool necessária para produzir efeitos menos severos. Dados de estudos na literatura parecem refletir esta controvérsia como mostrado na tabela 9 . 
Tabela 9 - Descrição dos artigos selecionados que avaliam escore de QI médio de acordo com exposição de crianças ao álcool na gestação.

\begin{tabular}{|c|c|c|c|c|}
\hline Autores & $\mathbf{N}$ & Idade & QI Médio & Testes \\
\hline Nulman et al., 2004 & $\begin{array}{c}22 \text { ( } \geq 5 \text { drinks/episódio) } \\
22 \text { controle }\end{array}$ & 3 a 7 anos & $\begin{array}{l}104,26(\mathrm{DP}=27,53) \\
110,18(\mathrm{DP}=12,58)\end{array}$ & $\begin{array}{l}\text { McCarthy } \\
(\mathrm{GCl})\end{array}$ \\
\hline Larroque and Kaminski, 1998 & $\begin{array}{c}32 \geq 1,5 \text { oz AA/dia } \\
123<1,5 \text { oz AA/dia }\end{array}$ & $\begin{array}{c}4,5 \text { anos } \\
\text { Média }(55,7 \mathrm{~m} \mathrm{DP}=2,7)\end{array}$ & $\begin{array}{c}89,5 \\
103,2 \\
\end{array}$ & $\begin{array}{l}\text { McCarthy } \\
(\mathrm{GCl})\end{array}$ \\
\hline Janzen et al., 1995 & $\begin{array}{c}10 \text { SFA } \\
10 \text { controle }\end{array}$ & $\begin{array}{l}52,7 \text { meses }(\mathrm{SD}=8,82) \\
52,5 \text { meses }(\mathrm{DP}=9,5)\end{array}$ & $\begin{array}{c}67,6 \\
100,6\end{array}$ & $\begin{array}{l}\text { McCarthy } \\
\text { (GCI) }\end{array}$ \\
\hline Freid et al., 1992 & $\begin{array}{l}64<0,14 \text { oz AA/dia } \\
71 \geq 0,14 \text { oz AA/dia } \\
70<0,14 \text { oz AA/dia } \\
67 \geq 0,14 \text { oz AA/dia }\end{array}$ & $\begin{array}{l}5 \text { anos } \\
6 \text { anos }\end{array}$ & $\begin{array}{l}122,2 \\
120,9 \\
124,2 \\
126,8\end{array}$ & $\begin{array}{l}\text { McCarthy } \\
\text { (GCI) }\end{array}$ \\
\hline Coles et al., 1991 & $\begin{array}{l}25 \text { (toda a gestação) } \\
22 \text { (3 meses) } \\
21 \text { (não uso) }\end{array}$ & $\begin{array}{l}5 \text { a } 8 \text { anos } \\
\text { Média (5 a } 10 \text { meses) }\end{array}$ & $\begin{array}{l}83,91(\mathrm{DP}=12,61) \\
89,29(\mathrm{DP}=11,21) \\
91,91(\mathrm{DP}=13,81)\end{array}$ & $\mathrm{K}-\mathrm{ABC}(\mathrm{MC})$ \\
\hline Russell et al., 1991 & $\begin{array}{c}151 \mathrm{IPD} \leq 1 \\
13 \mathrm{IPD}>1\end{array}$ & $\begin{array}{c}6 \text { anos } \\
\text { Média }(74,6 \mathrm{~m} \text { SD }=2,3)\end{array}$ & $\begin{array}{l}108,3(\mathrm{DP}=0,94) \\
101,8(\mathrm{DP}=3,30)\end{array}$ & WPPSI (VIQ) \\
\hline Greene et al., 1991 & 260 & $4^{\mathrm{a}} 10 \mathrm{~m}$ & $87,7(\mathrm{DP}=16,6)$ & WPPSI (FSIQ) \\
\hline Freid et al., 1990 & $\begin{array}{l}64<0,14 \text { oz AA/dia } \\
69 \geq 0,14 \text { oz AA/dia } \\
59<0,14 \text { oz AA/dia } \\
71 \geq 0,14 \text { oz AA/dia }\end{array}$ & $\begin{array}{l}3 \text { anos } \\
4 \text { anos }\end{array}$ & $\begin{array}{l}114,8 \\
115,8 \\
124,4 \\
123,4\end{array}$ & $\begin{array}{l}\text { McCarthy } \\
\text { (GCI) }\end{array}$ \\
\hline Streissguth et al., 1989 & 421 & 4 anos e 3 meses & $110,5(\mathrm{DP}=14,4)^{*}$ & WPPSI (FSIQ) \\
\hline Korkman et al., 1998 & $\begin{array}{c}16 \text { pararam ou reduziram } 1^{\circ} \text { trimestre } \\
16 \text { expostas no } 1^{\circ} \text { e } 2^{\circ} \text { trimestre } \\
14 \text { expostas em toda gestação } \\
26 \text { não expostas }\end{array}$ & 5 a 9 anos & $\begin{array}{c}95(\mathrm{DP}=17,0) \\
92(\mathrm{DP}=14,2) \\
84,2(\mathrm{DP}=14,3) \\
102(\mathrm{DP}=11,8)\end{array}$ & WISC-R (VIQ) \\
\hline Jacobson et al., 2004 & 337 (>1 drink/dia) & $7 a$ e 6 meses & $84,2(\mathrm{DP}=12,3)$ & $\begin{array}{l}\text { WISC } \\
(F S I Q)\end{array}$ \\
\hline Bailey et al., 2004 & $\begin{array}{c}\text { 56( } \geq 5 \text { drinks/episódio) } \\
481 \text { Controle }\end{array}$ & $5,9-7,9$ anos (negras) & $\begin{array}{l}75 \\
81\end{array}$ & WPPSI (VIQ) \\
\hline Willford et al., 2006 & $\begin{array}{l}324 \text { negros (<1 drink/dia) } \\
287 \text { brancos ( }<1 \text { drink/dia) }\end{array}$ & 10 anos & $\begin{array}{l}87,7 \\
95,9\end{array}$ & Stanford Binet \\
\hline O'Callaghan et al., 2007 & 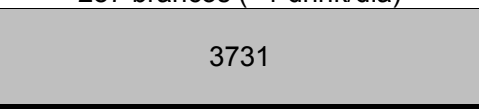 & 14 anos & $\begin{array}{c}\text { Sem associação com uso <1 drink/dia para atenção, } \\
\text { aprendizagem e cognição } \\
\text { Associação maior com uso > 1drink/dia. } \\
\end{array}$ & $\begin{array}{l}\text { WRAT-R } \\
\text { RAVEN }\end{array}$ \\
\hline
\end{tabular}

*Diferença de QI de crianças cujas mães referiram consumo > 1,5 oz AA/dia durante a gestação foi de $-4,8$ pontos (Dp=1,81), oz - onça flúda (medida de volume equivalente a 29,57 ml)

AA - álcool absoluto; SFA - Síndrome Fetal do Álcool; K-ABC - Kaufman Assessment Battery for Children; IPD- indications of problem drinking; WPPSI- Wechsler Preschool and Primary Scales of Intelligence; McCarthy Scales of Children's Abilities; WRAT-R- Wide Range Achievement Test - Revised; Raven's Standard Progressive Matrices Test; GCI- General Cognitive Index;MC- Mental composite; VIQ - Verbal Intelligence Quotient; FSIQ- Full Scale Intelligence Quotient. 
Dos quatorze estudos selecionados, 10 mostraram associação entre uso de álcool durante a gestação e déficits no desenvolvimento cognitivo infantil e em cinco esta associação não conseguiu ser demonstrada. Diversos fatores podem ter contribuído para estes resultados controversos, como a utilização de diferentes pontos de corte da quantidade de álcool consumida para comparação dos grupos. Naqueles estudos em que os pontos de corte de consumo de álcool utilizados foram maiores (STREISSGUTH et. al., 1989; LARROQUE; KAMINSKI, 1998; KORKMAN et. al., 1998; JACOBSON et. al., 2004; BAILEY et. al., 2004) foi encontrada associação com diminuição dos escores médios de QI das crianças avaliadas. As amostras dos cinco estudos que não encontraram esta associação relataram consumo relativamente baixo de álcool durante a gestação (FRIED; WATKINSON, 1990; GREENE et. al., 1991; FRIED et. al., 1992; NULMAN et. al., 2004; O'CALLAGHAN et. al., 2007). Em um estudo foi encontrada diferença de valores médios de Ql apenas no grupo de crianças afro-americanas, mesmo com consumo relativamente baixo de álcool (WILLFORD et. al., 2006). Outra explicação poderia ser o tamanho pequeno da maioria das amostras e dos sub-grupos comparados que podem ter influenciado a força estatística das análises e contribuído para um viés relacionado aos resultados. Os instrumentos de avaliação cognitiva utilizados parecem não ter influenciado estas diferenças nos resultados, já que estudos que utilizaram o mesmo teste de avaliação cognitiva encontraram resultados controversos (STREISSGUTH et. al., 1989; FRIED; WATKINSON, 1990; GREENE et. al., 1991; RUSSELL et. al., 1991; FRIED et. al., 1992; LARROQUE; KAMINSKI, 1998; KORKMAN et. al., 1998; JACOBSON et. al., 2004; BAILEY et. al., 2004; NULMAN et. al., 2004). A associação encontrada entre exposição pré-natal ao álcool e escores médios menores em algumas sub-escalas dos testes de avaliação 
cognitiva utilizados por alguns estudos, sugere que pode haver funções cognitivas específicas que sejam mais vulneráveis aos danos, sendo necessária uma avaliação neuropsicológica mais específica que possibilite uma melhor compreensão dos déficits. Quanto ao delineamento, a maioria dos estudos foi longitudinal e prospectivo (COLES et. al., 1991; STREISSGUTH et. al., 1989; FRIED; WATKINSON, 1990; GREENE et. al., 1991; RUSSELL et. al., 1991; FRIED et. al., 1992; LARROQUE; KAMINSKI, 1998; KORKMAN et. al., 1998; JACOBSON et. al., 2004; BAILEY et. al., 2004; NULMAN et. al., 2004), possibilitando a investigação das consequências da exposição pré-natal ao álcool ao longo do desenvolvimento do indivíduo e uma análise mais acurada das co-variáveis.

No entanto é importante observar que as medidas de uso de álcool obtidas pelos estudos selecionados não correspondem diretamente a real quantidade de álcool a que o feto foi exposto, já que em nenhum dos estudos foi feita a verificação bioquímica da exposição ao álcool relatada pelas gestantes, podendo ocorrer subestimação do consumo e consequente viés relacionado à informação pouco acurada. Além disso, a utilização de pontos de corte pode dificultar a detecção de efeito dose-resposta, pois alguns sub-grupos de gestantes podem consumir uma quantidade maior de álcool em determinados períodos da gestação (HUIZINK; MULDER, 2006). Dessa forma, é importante considerar que os níveis de exposição ao álcool utilizados pelos estudos para comparação dos grupos, não indicam que haja limites "seguros" de consumo de álcool durante a gestação (STREISSGUTH et. al., 1989; SOOD et. al., 2001).

Os dados analisados em nosso estudo sugerem um padrão de consumo baixo de álcool, como referido pelas mães, o que poderia estar associado aos resultados negativos relacionados à cognição, exceção aos dados por gênero, que 
mostraram associação entre exposição ao álcool durante a gestação e menor desempenho cognitivo em meninos. Além disto, o percentual de perdas e exclusão no seguimento do nosso estudo foi alto, sendo que o tamanho pequeno dos subgrupos comparados pode ter influenciado a força estatística das análises e também contribuído para um viés relacionado aos resultados. Embora haja dificuldade de controlar os múltiplos fatores preditores do funcionamento intelectual, outra limitação deste estudo é que alguns fatores como QI parental, psicopatologia materna e qualidade da estimulação ambiental não foram avaliados.

Maiores níveis de exposição ao álcool na gestação parecem estar mais associados aos problemas comportamentais totais na amostra estudada, especialmente em meninos.

Em resumo, o uso leve/moderado de álcool na gestação esteve associado à menor desempenho cognitivo e problemas comportamentais totais, especialmente em meninos. Apesar dos efeitos da exposição pré-natal ao álcool no desenvolvimento cognitivo e comportamental infantil serem amplamente documentados, os dados obtidos até o momento têm se mostrado controversos, especialmente com exposição leve/moderada ao álcool na gestação, possivelmente devido aos diferentes delineamentos utilizados e a complexidade da análise dos diversos fatores pré e pós-natais relacionados aos desfechos. Estudos controlados com um número maior de casos e a introdução de marcadores biológicos de exposição ao álcool na gestação são necessários, a fim de possibilitar uma detecção precoce dos efeitos adversos, uma melhor compreensão da gravidade e da extensão dos danos no desenvolvimento cognitivo e identificação de funções cognitivas específicas que possam ser mais afetadas pela exposição pré-natal ao álcool, propiciando uma intervenção precoce nos possíveis déficits encontrados. 
6 - CONCLUSÕES 
- A exposição pré-natal ao álcool esteve associada ao menor desempenho cognitivo em meninos em idade escolar.

- Em relação às condições sociodemográficas, menor desempenho cognitivo foi observado, em crianças com menor peso ao nascimento, filhos de mães mais jovens e com menor número de filhos. Em meninos houve associação entre menor desempenho cognitivo e cor mulata ou negra.

- Uso de álcool e tabaco na gestação, uso de tabaco após a gestação e a prática de qualquer religião e menores escores médios de RPI da Escala Columbia estiveram associados a maiores escores médios de problemas comportamentais totais. 


\section{7 - REFERÊNCIAS BIBLIOGRÁFICAS}


ACHENBACH, T. M. Manual for the Child Behavior Checklist/4-18 and 1991 profile. Burlington, VT, USA: Department of Psychiatry, University of Vermont, 1991.

ALMEIDA-FILHO, N.; BURNETT; C. K. Family size and child mental disorders in Bahia, Brazil. Population and Environment, v. 6, n. 1, p. 3-16, 1983.

ALVES, I.C.B.; DUARTE, J.L. Escala de Maturidade Mental Columbia: Manual para aplicação e interpretação, $1^{a}$ edição brasileira, São Paulo, Casa do Psicólogo, 1993. Tradução e padronização brasileira de BURGEMEISTER, B.B.; BLUM, L.H.; LORGE, I. Columbia Mental Maturity Scale, $3^{a}$ edição, The Psychological Corporation, USA, 1972.

BAILEY, B.N., et al. Prenatal exposure to binge drinking and cognitive and behavioral outcomes at age 7 years. American Journal of Obstetrics and Gynecology, v.191, n.3, p.1037-1043, 2004.

BMA. Board of Science: Fetal Alcohol Spectrum Disorders: A Guide for Healthcare Professionals. 58 p. British Medical Association, BMA House, Tavistock Square, London, UK, 2007, 58p.

BORDIN, I.A.S.; PAULA, C.S.; DUARTE, C.S. Inventário de Comportamentos para Crianças e Adolescentes de 6 a 18 anos - versão brasileira do "Child Behavior Checklist for ages 6-18" (CBCL/6-18). Departamento de Psiquiatria, Universidade Federal de São Paulo - Escola Paulista de Medicina, São Paulo, SP, Brasil, 1995.

BRODY, G.H.; FLOR, D.L. Maternal resources, parenting practices, and child competence in rural, single-parent African American families. Child Development, v.69, n.3, p.803-816, 1998.

BROWN, R.T., et al. Effects of prenatal alcohol exposure at school age. II. Attention and behavior. Neurotoxicology and Teratology, v.13, n.4, p.369-376, 1991.

CEBRID 2005 - II Levantamento Nacional Domiciliar sobre o uso de drogas no Brasil - SENAD/ CEBRID 2005. Disponível em http://200.144.91.102/sitenovo/ default.aspx

COLES, C.D., et al. Effects of prenatal alcohol exposure at school age. I. Physical and cognitive development. Neurotoxicology and Teratology, v.13, n.4, p.357-367.

COSTA, M.T.Z., et al. Drogas de abuso na gestação: as orientações no pré-natal são suficientes? Pediatria (São Paulo), v.20, n.4, p.316-322, 1998. 
DUARTE, C.S.; BORDIN, I.A.S. Instrumentos de avaliação. Revista Brasileira Psiquiatria, v.22, n.S2, p.55-58, 2000.

ERNST, M.; MOOLCHAN, E.T.; ROBINSON, M.L. Behavioral and neural consequences of prenatal exposure to nicotine. Journal of the American Academy of Child and Adolescent Psychiatry, v.40, n.6, p.630-641, 2001

ERVALAHTI N., et al. Relationship between dysmorphic features and general cognitive function in children with fetal alcohol spectrum disorders. American Journal of Medical Genetics Part A, v.143A, n.24, p.2916-2923, 2007.

FABBRI, C.E.; FURTADO, E.F.; LAPREGA, M.R. Alcohol consumption in pregnancy: performance of the Brazilian version of the questionnaire T-ACE. Revista de Saúde Publica, v.41, n.6, p.979-984, 2007.

FAGERLUND, A., et al. Risk factors for behavioural problems in foetal alcohol spectrum disorders. Acta Paediatrica, v.100, n.11, p.1481-1488, 2011.

FERNANDES, J.; PULLIN, A.C. Estudo da adequação da "Escala de Maturidade Mental Columbia" na avaliação de pré-escolares de baixo nível socioeconômico. Revista de Saúde Pública, v.15, p.126-137, 1981.

FOBE J.L., et al. IQ in hydrocephalus and myelomeningocele. Implications of surgical treatment. Arquivos de Neuropsiquiatria, v.57, n.1, p.44-50, 1999.

FREIRE, T.M., et al. Effects of alcohol consumption during pregnancy. Revista Brasileira de Ginecologia e Obstetrícia, v.27, n.7, p.376-781, 2005.

FRIED, P.A.; WATKINSON, B. 36- and 48-month neurobehavioral follow-up of children prenatally exposed to marijuana, cigarettes, and alcohol. Journal of Developmental and Behavioral Pediatrics, v.11, n.2, p.49-58, 1990.

FRIED, P.A.; O'CONNELL, C.M.; WATKINSON B. 60- and 72-month follow-up of children prenatally exposed to marijuana, cigarettes, and alcohol: cognitive and language assessment. Journal of Developmental and Behavioral Pediatrics, v.13, n.6, p.383-391, 1992.

FURTADO, E.F.; LAUCHT, M.; SCHMIDT, M.H. Gender-related pathways for behavior problems in the offspring of alcoholic fathers. Brazilian Journal of Medical and Biological Research, v.39, p.659-669, 2006. 
FURTADO, E.F.; LAUCHT, M.; SCHMIDT, M.H. Estudo Longitudinal prospectivo sobre risco de adoecimento psiquiátrico na infância e alcoolismo paterno. Revista Psiquiatria Clínica, v.29, n.2, p.71-80, 2002.

GREENE, T., et al. Prenatal alcohol exposure and cognitive development in the preschool years. Neurotoxicology and Teratology, v.13, n.1, p.57-68, 1991.

GUTBROD, T., et al. Effects of gestation and birth weight on the growth and development of very low birthweight small for gestational age infants: a matched group comparison. Archives of Disease in Childhood, Fetal and Neonatal Edition, v.82, n.3, p.F208-F214, 2000.

HANNIGAN, J.H., et al. A 14-year retrospective maternal report of alcohol consumption in pregnancy predicts pregnancy and teen outcomes. Alcohol, v.44, n.7-8, p.583-594, 2010.

HUIZINK, A.C.; MULDER E.J. Maternal smoking, drinking or cannabis use during pregnancy and neurobehavioral and cognitive functioning in human offspring. Neuroscience and Biobehavioral Reviews, v.30, n.1, p.24-41, 2006.

JACOBSON, S.W., et al. Maternal age, alcohol abuse history, and quality of parenting as moderators of the effects of prenatal alcohol exposure on 7.5-year intellectual function. Alcoholism: Clinical and Experimental Research, v.28, n.11, p.1732-1745, 2004.

JACOBSON, S.W., et al. Validity of maternal report of prenatal alcohol, cocaine, and smoking in relation to neurobehavioral outcome. Pediatrics, v.109, n.5, p.815-825, 2002.

JACOBSON, S.W., et al. Biobehavioral markers of adverse effect in fetal alcohol spectrum disorders. Neuropsychology Review, v.21, n.2, p.148-166, 2011.

JANZEN, L.A. ; NANSON, J.L. ; BLOCK, G.W. Neuropsychological evaluation of preschoolers with fetal alcohol syndrome. Neurotoxicology and Teratology, v.17, n.3, p.273-279, 1995.

KELLY, S.J.; DAY, N.; STREISSGUTH, A.P. Effects of prenatal alcohol exposure on social behavior in humans and other species. Neurotoxicology and Teratology, v.22, n.2, p.143-149, 2000.

KELLY, Y., et al. Light drinking in pregnancy, a risk for behavioural problems and cognitive deficits at 3 years of age? International Journal of Epidemiology, v.38, n.1, p.129-40, 2009. 
KORKMAN, M., et al. Neuropsychological effects at early school age of fetal alcohol exposure of varying duration. Child Neuropsychology, v.4, n.3, p.199-212, 1998.

KURSTJENS, S.; WOLKE D. Effects of maternal depression on cognitive development of children over the first 7 years of life. Journal of Child Psychology and Psychiatry, v.42, n.5, p.623-336, 2001.

LARROQUE, B.; KAMINSKI, M. Prenatal alcohol exposure and development at preschool age: main results of a French study. Alcoholism: Clinical and Experimental Research, v.22, n.2, p.295-303, 1998.

LARROQUE, B., et al. Moderate prenatal alcohol exposure and psychomotor development at preschool age. American Journal of Public Health, v.85, n.12, p.1654-1661, 1995.

LINNET, KM., et al. Maternal lifestyle factors in pregnancy risk of attention deficit hyperactivity disorder and associated behaviors: review of the current evidence. American Journal of Psychiatry, v.160, n.6, p.1028-1040, 2003.

MABE, P.A.; JOSEPHSON, A.M. Child and adolescent psychopatholgy: spiritual and religious perspectives. Child and Adolescent Psychiatric Clinics of North America, v.13, p.111-125, 2004.

MANNING, M.A.; EUGENE HOYME, H. Fetal alcohol spectrum disorders: a practical clinical approach to diagnosis. Neuroscience Biobehavioral Reviews, v.31, n.2, p.230-238, 2007.

MARQUES, S.L., et al. Avaliação cognitiva de crianças com dificuldades de aprendizagem: precisão do teste de Goodenough (1926) e da EMMC (1993) / Reliability of Goodenough test (1926) and CMMS (1993) in cognitive assessment of children with learning difficulties. Paidéia, v.12, n.23, p.105-112, 2002.

MATTSON, S.N.; RILEY, E.P. A review of the neurobehavioral deficits in children with fetal alcohol syndrome or prenatal exposure to alcohol. Alcoholism: Clinical and Experimental Research, v.22, n.2, p.279-294, 1998.

MAUGHAN, B., et al. Pregnancy smoking and childhood conduct problems: a causal association? Journal of Child Psychology and Psychiatry, v.42, n.8, p.1021-1028, 2001.

NICCOLS, A. Fetal alcohol syndrome and the developing socio-emotional brain. Brain and Cognition, v.65, n.1, p.135-142, 2007. 
NULMAN, I., et al. Binge alcohol consumption by non-alcohol-dependent women during pregnancy affects child behavior, but not general intellectual functioning; a prospective controlled study. Archives of Women's Mental Health, v.7, n.3, p.173181, 2004.

O'CALLAGHAN, F.V., et al. Prenatal alcohol exposure and attention, learning and intellectual ability at 14 years: a prospective longitudinal study. Early Human Development, v.83, n.2, p.115-123, 2007.

PINHEIRO, S.N.; LAPREGA, M.R.; FURTADO, E.F. Psychiatric morbidity and alcohol use by pregnant women in a public obstetric service. Revista Saúde Pública, v.39, n.4, p.593-598, 2005.

RASMUSSEN, C., et al. An evaluation of social skills in children with and without prenatal alcohol exposure. Child: Care, Health and Development, v.37, n.5, p.711718, 2011.

RICHARDS, M., et al. Birth weight and cognitive function in the British 1946 birth cohort: longitudinal population based study. British Medical Journal, v.322, n.7280, p.199-203, 2001.

RILEY, E.P.; INFANTE, M.A.; WARREN, K.R. Fetal alcohol spectrum disorders: an overview. Neuropsychology Review, v.21, n.2, p.73-80, 2011.

ROBINSON, M., et al. Low-moderate prenatal alcohol exposure and risk to child behavioural development: a prospective cohort study. BJOG: An International Journal of Obstetrics and Gynaecology, v.117, n.9, p.1139-1150, 2010.

ROEBUCK, T.M.; MATTSON, S.N.; RILEY, E.P. Behavioral and psychosocial profiles of alcohol-exposed children. Alcoholism: Clinical and Experimental Research, v.23, n.6, p.1070-1076, 1999.

ROOM, R.; BABOR, T.; REHM, J. Alcohol and public health. Lancet, v.365, n.9458, p.519-530, 2005.

RUSSELL, M., et al. Measures of maternal alcohol use as predictors of development in early childhood. Alcoholism: Clinical and Experimental Research, v.15, n.6, p.991-1000, 1991.

SAMPSON, P.D., et al. Incidence of fetal alcohol syndrome and prevalence of alcohol-related neurodevelopmental disorder. Teratology, v.56, n.5, p.317-326, 1997. 
SOOD, B., et al. Prenatal alcohol exposure and childhood behavior at age 6 to 7 years: I. dose-response effect. Pediatrics, v.108, n.2, p.E34, 2001.

SPARROW, S.S.; DAVIS, S.M. Recent advances in the assessment of intelligence and cognition. Journal of Child Psychology and Psychiatry, v.41, n.1, p.117-131, 2000.

SPOHR, H.L.; WILLMS, J.; STEINHAUSEN, H.C. Prenatal alcohol exposure and long-term developmental consequences. Lancet, v.341, n.8850, p.907-910, 1993.

STADE, B., et al. The burden of prenatal exposure to alcohol: revised measurement of cost. Canadian Journal of Clinical Pharmacology, v.16, n.1, p.e91-e102, 2009.

STEINHAUSEN, H.C.; NESTLER, V.; SPOHR, H.L. Development and psychopathology of children with the fetal alcohol syndrome. Journal of Developmental and Behavioral Pediatrics, v.3, n.2, p.49-54, 1982.

STEINHAUSEN, H.C.; WILLMS, J.; SPOHR, H.L. Long-term psychopathological and cognitive outcome of children with fetal alcohol syndrome. Journal of American Academy of Child and Adolescent Psychiatry, v.32, n.5, p.990-994, 1993.

STEINHAUSEN, H.C.; WILLMS, J.; SPOHR, H.L. Correlates of psychopathology and intelligence in children with fetal alcohol syndrome. Journal of Child Psychology and Psychiatry, v.35, n.2, p.323-331, 1994.

STEINHAUSEN, H.C.; SPOHR, H.L. Long-term outcome of children with fetal alcohol syndrome: psychopathology, behavior, and intelligence. Alcoholism: Clinical and Experimental Research, v.22, n.2, p.334-338, 1999.

STEINHAUSEN, H.C., et al. Behavioural phenotype in foetal alcohol syndrome and foetal alcohol effects. Development Medicine and Child Neurology, v.45, n.3, p.179-182, 2003.

STREISSGUTH, A.P., et al. IQ at age 4 in relation to maternal alcohol use and smoking during pregnancy. Developmental Psychology, v.25, n.1, p.3-11, 1989.

STREISSGUTH, A.P., et al. Prenatal alcohol and offspring development: the first fourteen years. Drug and Alcohol Dependence, v.36, n.2, p.89-99, 1994.

STREISSGUTH, A.P., et al.Fetal alcohol syndrome in adolescents and adults. Journal of American Medical Association, v.265, n.15, p.1961-1967, 1991. 
STREISSGUTH, A.P., et al. The long-term neurocognitive consequences of prenatal alcohol exposure: a 14-year study. Psychological Science, v.10, n.3, p.186-190, 1999,

TONG, S.; BAGHURST, P.; MCMICHAEL, A. Birthweight and cognitive development during childhood. Journal of Paediatric Child Health, v.42, n.3, p.98-103, 2006.

WILLFORD, J.; LEECH, S.; DAY, N. Moderate prenatal alcohol exposure and cognitive status of children at age 10. Alcoholism: Clinical and Experimental Research, v.30, n.6, p.1051-1059, 2006. 
APÊNDICE 
Artigo decorrente desta tese a ser submetido na revista Cadernos de Saúde Pública. 


\section{Consumo de álcool na gestação e desenvolvimento cognitivo dos filhos na} idade escolar

\section{Alcohol consumption in pregnancy and children cognitive development at school age}

Luciana Inácia de Alcântara*; Erikson Felipe Furtado

Departamento de Neurociências e Ciências do Comportamento, Faculdade de Medicina de Ribeirão Preto, Universidade de São Paulo

* Autor correspondente:

Luciana Inácia de Alcântara, Departamento de Neurociências e Ciências do Comportamento, Faculdade de Medicina de Ribeirão Preto, Universidade de São Paulo, Avenida Bandeirantes 3900, CEP: 14049-900, Ribeirão Preto, São Paulo, Brasil. E-mail: alcant@usp.br.

Título abreviado: álcool na gestação e desenvolvimento cognitivo

Palavras chave: Álcool, gestação, desenvolvimento cognitivo infantil, Escala de Maturidade Mental Columbia, CBCL

\section{Agradecimentos:}

Os autores agradecem aos Dr Mateus Angelucci, e Dr Ricardo Dmetruk, a Secretaria de Ensino do Estado de São Paulo, a Fundação de Apoio ao Ensino e Pesquisa (FAEPAHCFMR-USP) e ao PAI-PAD.

\section{Colaboradores}

L. I. Alcântara e E. F. Furtado contribuíram com a concepção, planejamento, análise e interpretação dos dados, elaboração e aprovação da versão final do manuscrito 


\section{Resumo}

O consumo de álcool durante a gestação tem sido associado a alterações no desenvolvimento físico, neurológico e comportamental da criança. No presente estudo foi avaliado o desenvolvimento cognitivo em relação ao padrão de consumo de álcool materno em 86 crianças de oito a nove anos de idade cujas mães haviam sido entrevistadas durante o terceiro trimestre de gestação sobre o padrão de consumo de álcool. Para avaliação cognitiva do grupo de crianças na idade escolar foi utilizada a Escala de Maturidade Mental Columbia. Foi observada associação estatisticamente significativa entre os escores de resultado padrão por idade (RPI) acima da média e maior idade materna e maior peso ao nascimento $(p=0,01$ e 0,05 , respectivamente). Diferença significativa também foi observada em relação ao número de filhos $(p=0,04)$. Separando a amostra por gênero, observamos escores médios menores na Escala de Maturidade Mental Columbia em meninos filhos de mães que declararam cor mulata ou negra $(p=0,02)$, que fizeram uso em dias de qualquer quantidade de álcool na gestação maior que a média $(\mathrm{p}=0,01)$ e também naqueles em que as mães usaram três ou mais doses de álcool por ocasião durante a gestação acima da média $(\mathrm{p}<0,0001)$. Não foram observadas diferenças significativas para as outras variáveis analisadas. O uso leve/moderado de álcool na gestação esteve associado ao menor desempenho cognitivo, especialmente em meninos. 


\begin{abstract}
Alcohol use during pregnancy has been associated to problems in physical, neurological and behavioral child development. This study evaluated the cognitive development of 86 children from eight to nine years old in relation to pattern of maternal alcohol consumption during gestation. Cognitive performance of children at school age was accessed using Columbia Mental Maturity Scale. Significant statistically differences were observed among age deviation scores (ADS) above mean and higher maternal age and higher birth weight ( $\mathrm{p}=$ 0.01 e 0.05 , respectively). Significant difference was observed in relation to parity ( $p=0.04)$. Analyzing the sample by gender, we observed lower mean scores in Columbia Mental Maturity Scale in boys whose mothers declared they were mulatto or black $(p=0.02)$, used in days any quantity of alcohol during pregnancy higher than mean $(\mathrm{p}=0.01)$ and also in those boys whose mothers used three or more doses of alcohol per occasion during pregnancy above mean $(p<0.0001)$. No significant differences were observed for other variables analyzed. Low/moderate alcohol use during pregnancy was associated to lower cognitive performance, particularly in boys.
\end{abstract}




\section{Introdução}

O consumo de álcool durante a gestação tem sido associado a alterações no desenvolvimento físico, neurológico e comportamental da criança, sendo que muitas das consequências sobre o desenvolvimento infantil apresentam ampla variação em extensão e gravidade $^{1-7}$. Nos Estados Unidos, mais de 50\% das mulheres em idade fértil consomem álcool, sendo que $20 \%$ continuam a consumir durante a gestação ${ }^{8}$. Aproximadamente $16 \%$ das crianças são expostas ao álcool no período pré-natal ${ }^{2}$. Na Grã-Bretanha aproximadamente 90\% das mulheres consomem bebidas alcoólicas pelo menos ocasionalmente sendo que vem ocorrendo também um aumento significativo do consumo pesado de álcool entre mulheres jovens $^{9}$ (BMA, 2007). No Brasil, estudos mostram que a prevalência de dependência de álcool no sexo feminino é de $5,7 \%$ e aproximadamente $22 \%$ das mulheres consomem álcool em níveis de risco para o feto durante a gestação ${ }^{10,11}$. A confirmação do uso de álcool na gestação nem sempre é fácil por uma série de fatores incluindo: a subestimação do consumo pela mulher devido constrangimento em informá-lo em função do estigma social associado ao uso; despreparo do profissional de saúde para investigar adequadamente ou valorizar as queixas compatíveis com o hábito de beber; dificuldade de especificar os níveis de consumo nos primeiros estágios da gravidez; pouca acurácia dos registros de uso de álcool materno; uso limitado de instrumentos de rastreamento do padrão de consumo de álcool materno e ausência de marcadores biológicos confiáveis para consumo de álcool materno ${ }^{9,12-14}$.

Os efeitos da exposição pré-natal ao álcool podem variar desde uma relativa normalidade até a morte perinatal e Síndrome Fetal do Álcool ${ }^{15}$. O uso de álcool está associado de maneira dose-dependente à restrição do crescimento fetal, deficiências cognitivas, aumento da morbidade e mortalidade, desenvolvimento da Síndrome fetal do álcool (SFA) e outros transtornos do comportamento infantil associados à exposição intraútero ao álcool (formas incompletas da SFA). O termo Distúrbios do Espectro Alcoólico Fetal (DEAF) tem sido utilizado para descrever uma ampla variedade de efeitos adversos observados em indivíduos que foram expostos ao álcool durante a gestação e a Síndrome Fetal do Álcool representa o desfecho mais severo deste espectro ${ }^{7,16}$. Estima-se que nos Estados Unidos, aproximadamente 1/100 nascidos vivos apresentem formas completas ou incompletas de $\mathrm{SFA}^{17}$. Na Itália a incidência de DEAF foi entre 20,3 a 40,5/1000 nascidos vivos $^{9,18}$. As mais altas taxas de SFA completa ou incompleta têm sido reportadas na África do Sul, variando de 68,0 a 89,2/1000 nascidos vivos em uma população miscigenada do ponto de vista racial e com alta prevalência de uso de álcool de risco. Na Austrália entre as 
populações indígenas, a incidência de DEAF foi estimada em 4,7/1000 nascidos vivos. As populações que apresentam maior risco são aquelas que apresentam maior grau de privação social e pobreza ${ }^{9,18}$. No Brasil, há poucos dados estatísticos sobre a incidência de SFA, estima-se que 1/1000 recém-nascidos apresentem $\mathrm{SFA}^{19}$.

O dano causado pelo álcool no desenvolvimento da criança depende do padrão de consumo materno, do estágio da gestação em que a exposição ao álcool ocorreu além de outros fatores de risco como: fatores genéticos, metabolismo materno e fetal, estado nutricional da mãe, uso de outras drogas, condição de saúde da mãe, idade materna e padrão socioeconômico. Estudos têm mostrado evidências consistentes da associação entre o consumo pesado de álcool durante a gestação e desenvolvimento da SFA, no entanto resultados de estudos sobre níveis de consumo de baixo a moderado ainda são controversos $^{7,9,18}$.

Os efeitos adversos da exposição pré-natal ao álcool sobre o desenvolvimento da criança variam num continuum. Os indivíduos afetados podem apresentar rebaixamento cognitivo, dificuldades relacionadas à abstração, atenção, linguagem receptiva, função executiva, concentração, memorização e julgamento crítico. Alterações do comportamento como hiperatividade, impulsividade, problemas de conduta como mentir e roubar, comportamento sexual inadequado e comportamento opositor são comuns e diferem quantitativamente e qualitativamente de outras alterações encontradas em formas diferentes de retardo mental ${ }^{6,9,20-25}$. Em relação ao funcionamento cognitivo, estudos têm mostrado uma associação da exposição pré-natal ao álcool a um decréscimo dos escores de QI (quociente de inteligência). A maioria das crianças com diagnóstico de SFA apresenta escores médios de QI de 60 a 65 variando de 16 a 120. Os achados variam dependendo da amostra do estudo, dos instrumentos de avaliação utilizados, de fatores potencialmente confundidores como nível socioeconômico e cultural, QI materno, uso de outras substâncias psicoativas e outros. Estudos longitudinais indicam que os escores de QI dessas crianças permanecem estáveis até a idade adulta. Um aspecto controverso relacionado ao funcionamento cognitivo dessas crianças diz respeito ao grau em que os déficits encontrados são decorrência da exposição prénatal ao álcool ou de um ambiente pouco estimulante e/ou negligente propiciado por mães usuárias de álcool ${ }^{7,15,26}$. A maioria dos estudos tem investigado predominantemente os efeitos do uso excessivo de álcool durante a gestação, em relação à Síndrome Fetal do Álcool. Apenas recentemente estudos têm sugerido a associação entre uso baixo e moderado de álcool na gestação e prejuízos no desenvolvimento cognitivo e comportamental dos filhos ${ }^{2,6,12}$. 
Considerando que em geral os testes neuropsicológicos padronizados são complexos e multifacetados, podendo propiciar pouca informação sobre aspectos específicos do funcionamento do sistema nervoso central que podem estar afetados nos distúrbios do espectro alcoólico fetal, alguns estudos tem proporcionado avanços no diagnóstico diferencial utilizando técnicas de neuroimagem para identificação de anormalidades estruturais em determinadas regiões cerebrais e biomarcadores de exposição a álcool ${ }^{18,27}$.

O presente estudo tem como objetivo estudar o desenvolvimento cognitivo, comparativamente, em crianças em idade escolar, filhos de mães que consumiram e mães que não consumiram álcool durante a gestação.

\section{Métodos}

O presente estudo é longitudinal e retrospectivo. Trata-se de uma amostra de conveniência para o estudo do consumo de álcool na gestação e sua relação com desenvolvimento na idade escolar.

A amostra do estudo foi constituída de crianças de oito a nove anos de idade cujas mães ( $\mathrm{N}=449)$ foram entrevistadas em 2001 (projeto Gesta-Álcool), em um serviço obstétrico da rede municipal da cidade de Ribeirão Preto, conveniada ao Sistema Único de Saúde (SUS) durante o $3^{\mathrm{o}}$ trimestre de gestação ( $31^{\mathrm{a}}$ e $32^{\mathrm{a}}$ semanas). Foram coletados dados sociodemográficos, história gestacional, saúde materna e padrão de consumo de álcool. $\mathrm{O}$ critério de inclusão foi a concordância mediante assinatura do Termo de Consentimento Livre e Esclarecido pela mãe ou cuidador. O critério de exclusão foi a não concordância de participação no estudo. A coleta de dados foi feita no período de 18 de agosto de 2009 a 7 de outubro de 2010.

Das 449 mães participantes do estudo Gesta-Álcool, um grupo de 183 mães foi localizado das quais 86 foram entrevistadas, 64 recusaram e 33 não compareceram à entrevista. Setenta e nove mães localizadas não puderam ser contatadas.

No projeto Gesta-Álcool em 2001, quando foram colhidas informações diretamente com as mães durante o seu terceiro trimestre de gestação, foi utilizado o questionário T$\mathrm{ACE}^{11}$ como critério para consumo de álcool de risco. Também foi utilizado um questionário estruturado para coleta de dados sociodemográficos, história gestacional e saúde materna e questionário estruturado para avaliação de uso nocivo ou dependência ao álcool de acordo com a Classificação Internacional de Doenças (CID-10) ${ }^{28}$. 
No projeto atual (Infanto-Álcool) foram aplicados instrumentos de avaliação em dois grupos de sujeitos. O primeiro grupo foi constituído pelas mães ou cuidadores que responderam a um questionário sobre as condições sociodemográficas, saúde geral, uso materno de álcool durante a gestação e recente.

O segundo grupo foi constituído pelas crianças. Para avaliação cognitiva do grupo de crianças na idade escolar foi utilizada a Escala de Maturidade Mental Columbia. Os examinadores responsáveis pela aplicação da escala nas crianças, não tiveram conhecimento dos dados referentes ao uso de álcool durante a gestação assim como, dos demais dados obtidos dos instrumentos de avaliação do projeto.

A Escala de Maturidade Mental Columbia é um teste individual, não-verbal, que fornece uma estimativa da capacidade de raciocínio geral de crianças com idade entre três anos e seis meses e nove anos e 11 meses. Ela é composta de 92 itens de classificação pictóricos e figurativos, que estão organizados em uma série de oito níveis sobrepostos. A criança realiza um segmento do teste correspondente ao nível mais adequado para a sua idade cronológica. A descrição de desempenhos na Escala é feita através do Resultado Padrão de Idade (RPI), que é um escore padrão com variação de 50 a 150, com média de 100 e desvio padrão de 16 unidades para cada grupo de idade cronológica que produziu os dados normativos ${ }^{29}$.

Os informantes (mães ou cuidadores) foram informados e consultados sobre sua concordância em participar do estudo. Foram selecionados aqueles que concordaram em participar, expresso através do Termo de Consentimento Livre e Esclarecido, redigido conforme os princípios da Resolução n 196/96 sobre pesquisa envolvendo seres humanos Conselho Nacional de Saúde/ Ministério da Saúde.

Foram analisados a associação entre os valores de RPI e dados obtidos durante a gestação (Projeto Gesta-Álcool), idade gestacional, idade da mãe no momento do parto, religião (praticante versus na praticante), escolaridade (básico/fundamental versus médio/superior), número de filhos (menor que 3 versus maior ou igual a 3 filhos), situação de emprego (ativo versus inativo), cor referida da pele (branco versus mulata/negra), estado civil (união estável versus não estável), renda familiar (menor que 5 salários mínimos versus maior ou igual a 5 salários mínimos), tipo de parto (normal versus cesária/fórceps), peso ao nascimento, índice de Apgar do recém-nascido no primeiro e no quinto minuto, pontuação no teste T-ACE (consumo de risco versus ausência de consumo de risco), consumo de qualquer quantidade de álcool no $1^{\circ}, 2^{\circ}$ e $3^{\circ}$ trimestres da gestação, uso nos 3 trimestres de gestação, uso de álcool anterior a gestação, ocasião ou problema relacionado ao uso de álcool antes e 
durante a gestação. Foram analisados também os dados obtidos durante entrevista atual com as mães (Infanto-Álcool): consumo de álcool durante a gestação (dado retrospectivo), e atual (analisado pelo teste AUDIT).

Para exame comparativo entre grupos utilizando medidas de distribuição central foi utilizado o teste t-Student bi-caudal. As análises foram realizadas utilizando-se o software SPSS versão 15.0, sendo considerados como significantes valores de $\mathrm{p} \leq 0,05$.

\section{Resultados}

A idade das mães variou de 15 a 40 anos, com média de 24,9 e mediana de 24 anos. A idade gestacional $(n=68)$ variou de 36 a 42 semanas, com média de 39,92 e mediana de 40 semanas. Em relação ao gênero, 44 (51,2\%) eram meninos e 42 (48,8\%) meninas. O peso das crianças $(\mathrm{n}=73)$ ao nascimento variou de 2.390 a $4.275 \mathrm{~g}$ com média de $3.246 \mathrm{~g}$ e mediana de 3.357 g. Em relação ao tipo de parto $(n=72) 42$ foram naturais $(58,3 \%), 3$ fórceps $(4,2 \%)$ e $27(37,5 \%)$ cesáreas. O escore de Apgar médio no $1^{\circ}$ minuto foi de 8,1 e no $5^{\circ}$ minuto de 9,6. Em relação à escolaridade $(n=86), 15$ mães $(17,4 \%)$ tinham ensino básico, $41(47,7 \%)$ ensino fundamental, 29 (33,7\%) ensino médio/técnico e 1 (1,2\%) ensino superior. Em relação à cor referida da pele $47(54,6 \%)$ se declararam brancas, $20(23,2 \%)$ negras e $18(20,9 \%)$ mulatas/pardas e 1 outros $(1,2 \%)$.

Em relação ao estado civil, 12 (13,9\%) se declararam solteiras ou separadas, 34 (40\%) casadas, 39 (45,9\%) amasiadas, $1(1,2 \%)$ viúva. Quanto à renda familiar 29 (33,7\%) tinham renda maior que 5 salários mínimos e 57 (66,3\%) de menos de 5 salários mínimos. Vinte mães $(23,3 \%)$ declararam situação de emprego ativo, 50 (58,1\%) inativo e $16(18,6 \%)$ estavam licenciadas para tratamento. Quarenta e cinco $(52,3 \%)$ mães eram praticantes de algum tipo de religião e $41(47,7 \%)$ não praticantes.

Em relação à escolaridade das crianças no momento da aplicação do Columbia, cinco (6\%) crianças cursavam o $2^{\circ}$ ano do ensino fundamental, $61(72,6 \%)$ o $3^{\circ}$ ano, $17(20,2 \%)$ o $4^{\circ}$ ano e uma $(1,2 \%)$ o $5^{\circ}$ ano. Em duas crianças este dado não estava disponível.

Dos dados coletados durante a gestação foram avaliados o consumo de álcool através pontuação no teste T-ACE, uso de qualquer quantidade de álcool durante toda a gestação, no $1^{\circ}, 2^{\circ}$ e $3^{\circ}$ trimestres, uso de álcool anterior a gestação e ocasião ou problema relacionado ao uso de álcool antes e durante a gestação. 
Uso de qualquer quantidade de álcool durante qualquer período da gestação foi referido por 44 de 86 gestantes $(51,2 \%)$, destas $26(30,2 \%)$ utilizaram no $3^{\circ}$ trimestre, 33 $(38,3 \%)$ no $2^{\circ}$ trimestre e $37(43 \%)$ no $1^{\circ}$ trimestre. Dezessete gestantes $(20 \%)$ referiram uso de álcool durante toda a gestação. Dez gestantes referiram algum tipo de problema decorrente do uso de álcool (sintomas físicos de intoxicação). O teste T-ACE positivo, indicando consumo de risco durante a gestação, foi observado em 19/86 (22,1\%) das gestantes entrevistadas.

Os dados sobre o consumo de álcool obtidos retrospectivamente, mostraram diferença em relação aos obtidos durante a gestação. Nesta entrevista 15 de 86 mães $(17,4 \%)$ referiram ter utilizado qualquer quantidade de álcool durante o $3^{\circ}$ trimestre da gestação, 14 (16,3\%) durante o $2^{\circ}$ trimestre e $25(29 \%)$ durante o $1^{\circ}$ trimestre. Trinta mães $(34,9 \%)$ referiram uso de álcool em qualquer quantidade durante a gestação. O uso de 3 ou mais doses por ocasião foi referida por 13 mães $(15,1 \%)$ durante toda a gestação, com variação de 1 a 270 ocasiões. Apenas 2 pacientes apresentaram mais de 75 ocasiões/gestação. A quantidade de mães que referiram uso de álcool em qualquer quantidade e uso de 3 ou doses por ocasião são mostrados na tabela 1. Considerando todas as mães analisadas a média de dias de uso de álcool durante a gestação foi de 12,3 dias e uso de 3 ou mais doses por ocasião de 9,19.

[inserir tabela 1]

A Escala de Maturidade Mental COLUMBIA foi aplicada em 86 crianças, sendo 44 $(51,8 \%)$ do sexo masculino e $42(48,2 \%)$ do sexo feminino. Idade das crianças variou de 95 120 meses (média de 103,4, DP \pm 4,67; mediana de 103 meses). O RPI (resultado padrão por idade) variou de 64 a 134, com valor médio de 99,95, DP $\pm 16,01$ e mediana de 103. As freqüências de distribuição dos escores de RPI são mostradas na figura 1.

[inserir figura 1]

Foram analisadas a associação entre os escores de RPI abaixo ou acima da média $(99,95)$ ou abaixo ou acima de um DP $(83,9)$, e as variáveis obtidas durante a gestação (projeto gesta-álcool) e entrevista atual (Infanto-Álcool), utilizando-se o teste t-Student.

Associação estatisticamente significativa foi observada apenas entre os escores de RPI acima de 99,95 e maior idade materna $(\mathrm{p}=0,01)$ e peso da criança ao nascimento $(\mathrm{p}=0,05)$. 
A idade média das mães do grupo com RPI $\geq 99,95$ no momento do parto foi de $25,98 \pm 5,4$ anos versus $23,3 \pm 4,5$ para o grupo de mães de crianças com RPI $<99,95$. O peso médio das crianças do grupo com RPI $\geq 99,95$ foi de $3.420 \pm 444$ gramas versus $3220 \pm 410$ gramas para o grupo de crianças com RPI $<99,95$.

Foram analisados também pelo teste t-Student a associação entre os escores de RPI obtidos na escala COLUMBIA como variável contínua e as variáveis dicotômicas obtidas durante a gestação (projeto Gesta-Álcool) e entrevista atual (Infanto-Álcool). Diferença significativa foi observada apenas em relação ao número de filhos. Crianças com famílias com 3 ou mais filhos apresentaram RPI médio de 106,4 versus RPI de 99,10 para aquelas com famílias com menos de 3 filhos $(p=0,04)$. Não foram observadas diferenças de média para nenhuma das outras variáveis analisadas.

Separando a amostra por gênero, observamos escores médios menores na Escala de Maturidade Mental Columbia em meninos filhos de mães que declaram cor mulata/negra $(92,47 \pm 17,22 \times 103,43 \pm 13,37, p=0,02)$, que fizeram uso em dias de qualquer quantidade de álcool na gestação maior que a média $(89,33 \pm 6,34 \times 99,60 \pm 16,79, p=0,01)$ e também naqueles em que as mães usaram 3 ou mais doses de álcool por ocasião durante a gestação acima da média $(87,00 \pm 3,08 \times 99,64 \pm 16,57, \mathrm{p}<0.0001)$ (figura 2$)$. Não foram observadas diferenças significativas para as outras variáveis analisadas.

\section{[inserir figura 2]}

Em relação às meninas nenhuma associação significativa foi encontrada entre valores de RPI e as variáveis analisadas.

\section{Discussão}

Existem achados conflitantes sobre a associação entre uso baixo e moderado de álcool na gestação e prejuízos no desenvolvimento cognitivo e comportamental dos filhos ${ }^{2,6,12,30,31}$. Neste estudo foi investigada a relação entre consumo de álcool na gestação e desenvolvimento cognitivo dos filhos na idade escolar.

Em relação aos dados sociodemográficos, os resultados obtidos entre o grupo das 86 mães analisadas foi similar ao grupo total de 450 gestantes avaliadas no projeto GestaÁlcool ${ }^{28}$. 
Em relação à amostra total nossos resultados mostraram associação entre escores de RPI maiores que a média e maior idade materna, maior peso médio da criança ao nascimento e em relação ao número de filhos.

Crianças cujas famílias tinham 3 ou mais filhos apresentaram RPI médio maior quando comparadas àquelas com famílias com menos de 3 filhos. Um trabalho conduzido em Salvador, Bahia, mostrou uma frequência maior de transtornos mentais, psicossomáticos e neuróticos em crianças de família com prole menos numerosa. No entanto, outros estudos têm sugerido que crianças e adolescentes de famílias numerosas apresentam uma maior incidência de desajustes ${ }^{32}$.

Estudos têm sugerido associação entre déficits no desenvolvimento cognitivo infantil e baixo peso ao nascimento. Tong et al. ${ }^{33}$ encontraram associação estatisticamente significante entre baixo peso e menor desempenho cognitivo aos 2 anos de idade mas com decréscimo gradual da associação em idades posteriores (7, 11 e 13 anos). Richards et al. ${ }^{34} \mathrm{em}$ um estudo longitudinal de uma coorte seguida desde o nascimento, encontraram associação estatisticamente significativa e positiva entre peso ao nascimento e função cognitiva aos 8,11 , 26 e 43 anos.

Nossos resultados mostraram diferenças de gênero em relação à cognição, consumo aumentado de álcool na gestação e cor referida da pele. Observamos decréscimo no desempenho cognitivo dos meninos cujas mães declararam cor negra ou mulata, que fizeram uso em dias de qualquer quantidade de álcool na gestação maior que a média e também naqueles em que as mães usaram 3 ou mais doses de álcool por ocasião durante a gestação acima da média. Não foram observadas diferenças significativas para as outras variáveis analisadas.

Em relação às meninas nenhuma associação significativa foi encontrada entre valores de RPI e as variáveis analisadas. É importante considerar que diferenças étnicas relacionadas ao desenvolvimento cognitivo são mediadas por fatores socioeconômicos, características maternas, ambiente domiciliar e consumo excessivo de álcool. Willford et. al. ${ }^{35}$ encontraram associação significativa entre uso moderado de álcool durante primeiro e segundo trimestres de gestação e decréscimos de escores de QI entre crianças afro-americanas de 10 anos de idade, porém a mesma associação não foi encontrada entre as crianças que eram caucasianas. Bailey et al. ${ }^{8}$ mostraram associação significativa entre exposição pré-natal ao álcool e QI em crianças afro-americanas de 7 anos de idade cujas mães fizeram consumo "binge" de álcool.

Kelly et al. ${ }^{30}$ encontraram diferenças de gênero em relação à exposição pré-natal ao álcool e comportamento e cognição em crianças de 3 anos de idade. Meninos apresentaram 
escores médios maiores nos problemas comportamentais e escores médios menores no teste cognitivo quando comparados às meninas.

Em relação ao relato materno sobre consumo de álcool durante a gestação, nossos resultados mostraram níveis de consumo maiores obtidos através dos dados prospectivos quando comparados com os retrospectivos. Em geral os estudos têm considerado os dados prospectivos sobre exposição pré-natal ao álcool mais acurados e válidos quando comparados aos dados retrospectivos devido viés da recordação. Outros estudos sugerem que as mulheres podem subestimar níveis de consumo de álcool durante a gestação devido estigma associado ao uso neste período e por isso os dados retrospectivos seriam mais válidos ${ }^{14,36}$.

Embora pareça clara a associação entre o consumo crônico e pesado de álcool durante a gestação e o desenvolvimento da SFA, há controvérsias com relação à quantidade de álcool necessária para produzir efeitos menos severos e diversos fatores parecem contribuir para estes resultados controversos.

A utilização de diferentes pontos de corte da quantidade de álcool consumida para comparação dos grupos parece ser o principal deles. Nos estudos em que os pontos de corte de consumo de álcool utilizados foram maiores ${ }^{8,26,37-39}$, foi encontrada associação com diminuição dos escores médios de QI das crianças avaliadas. As amostras dos estudos que não encontraram esta associação relataram consumo relativamente baixo de álcool durante a gestação $^{40-44}$. Em um estudo foi encontrada diferença de valores médios de QI apenas no grupo de crianças afro-americanas, mesmo com consumo relativamente baixo de álcool ${ }^{35}$. Outra explicação poderia ser o tamanho pequeno da maioria das amostras e dos sub-grupos comparados que podem ter influenciado a força estatística das análises e contribuído para um viés relacionado aos resultados. Os instrumentos de avaliação cognitiva utilizados parecem não ter influenciado estas diferenças nos resultados, já que estudos que utilizaram o mesmo teste de avaliação cognitiva encontraram resultados controversos ${ }^{8,26,37-43,45}$. A associação encontrada entre exposição pré-natal ao álcool e escores médios menores em algumas subescalas dos testes de avaliação cognitiva utilizados por alguns estudos, sugere que pode haver funções cognitivas específicas que sejam mais vulneráveis aos danos, sendo necessária uma avaliação neuropsicológica mais específica que possibilite uma melhor compreensão dos déficits. Quanto ao delineamento, a maioria dos estudos foi longitudinal e prospectivo ${ }^{1,8,26,37-}$ 43,45, possibilitando a investigação das conseqüências da exposição pré-natal ao álcool ao longo do desenvolvimento do indivíduo e uma análise mais acurada das co-variáveis.

No entanto é importante observar que as medidas de uso de álcool obtidas pelos estudos selecionados não correspondem diretamente a real quantidade de álcool a que o feto 
foi exposto, já que em nenhum dos estudos foi feita a verificação bioquímica da exposição ao álcool relatada pelas gestantes, podendo ocorrer subestimação do consumo e conseqüente viés relacionado à informação pouco acurada. Além disso, a utilização de pontos de corte pode dificultar a detecção de efeito dose-resposta, pois alguns sub-grupos de gestantes podem consumir uma quantidade maior de álcool em determinados períodos da gestação ${ }^{6}$. Dessa forma, é importante considerar que os níveis de exposição ao álcool utilizados pelos estudos para comparação dos grupos, não indicam que haja limites "seguros" de consumo de álcool durante a gestação ${ }^{2,37}$.

Os dados analisados em nosso estudo sugerem um padrão de consumo baixo de álcool, como referido pelas mães, o que poderia estar associado aos resultados negativos relacionados à cognição, exceção aos dados por gênero, que mostraram associação entre exposição ao álcool durante a gestação e menor desempenho cognitivo em meninos. Além disto, o percentual de perdas e exclusão no seguimento do nosso estudo foi alto, sendo que o tamanho pequeno dos sub-grupos comparados pode ter influenciado a força estatística das análises e também contribuído para um viés relacionado aos resultados. Embora haja dificuldade de controlar os múltiplos fatores preditores do funcionamento intelectual, outra limitação deste estudo é que alguns fatores como QI parental, psicopatologia materna e qualidade da estimulação ambiental não foram avaliados.

Em resumo, o uso leve/moderado de álcool na gestação esteve associado à menor desempenho cognitivo em meninos. Apesar dos efeitos da exposição pré-natal ao álcool no desenvolvimento cognitivo infantil serem amplamente documentados, os dados obtidos até o momento têm se mostrado controversos, especialmente com exposição leve/moderada ao álcool na gestação, possivelmente devido aos diferentes delineamentos utilizados e a complexidade da análise dos diversos fatores pré e pós-natais relacionados aos desfechos. Estudos controlados com um número maior de casos e a introdução de marcadores biológicos de exposição ao álcool na gestação são necessários, a fim de possibilitar uma detecção precoce dos efeitos adversos, uma melhor compreensão da gravidade e da extensão dos danos no desenvolvimento cognitivo e identificação de funções cognitivas específicas que possam ser mais afetadas pela exposição pré-natal ao álcool, propiciando uma intervenção precoce nos possíveis déficits encontrados. 


\section{Referências Bibliográficas}

1- Coles CD, Brown RT, Smith IE, Platzman KA, Erickson S, Falek A. Effects of prenatal alcohol exposure at school age. I. Physical and cognitive development. Neurotoxicol Teratol. 1991;13(4):357-67.

2- Sood B, Delaney-Black V, Covington C, Nordstrom-Klee B, Ager J, Templin T, Janisse J, Martier S, Sokol RJ. Prenatal alcohol exposure and childhood behavior at age 6 to 7 years: I. dose-response effect. Pediatrics. 2001;108(2):E34.

3- Steinhausen HC, Willms J, Metzke CW, Spohr HL. Behavioural phenotype in foetal alcohol syndrome and foetal alcohol effects. Dev Med Child Neurol. 2003;45(3):179-82

4- Furtado EF, Laucht M, Schmidt MH. Estudo Longitudinal prospectivo sobre risco de adoecimento psiquiátrico na infância e alcoolismo paterno. Rev Psiq Clin 2002; 29(2): 71-80.

5- Furtado EF, Laucht M, Schmidt MH. Gender-related pathways for behavior problems in the offspring of alcoholic fathers. Braz J Med Biol Res, 2006; 39:659-669.

6- Huizink AC, Mulder EJ. Maternal smoking, drinking or cannabis use during pregnancy and neurobehavioral and cognitive functioning in human offspring. Neurosci Biobehav Rev. 2006;30(1):24-41.

7- Niccols A. Fetal alcohol syndrome and the developing socio-emotional brain. Brain Cogn. 2007;65(1):135-42.

8- Bailey BN, Delaney-Black V, Covington CY, Ager J, Janisse J, Hannigan JH, Sokol RJ. Prenatal exposure to binge drinking and cognitive and behavioral outcomes at age 7 years. Am J Obstet Gynecol. 2004;191(3):1037-43.

9- BMA. Board of Science: Fetal Alcohol Spectrum Disorders: A Guide for Healthcare Professionals. 58 pag. British Medical Association, BMA House, Tavistock Square, London, UK, 2007

10- CEBRID 2005 - II Levantamento Nacional Domiciliar sobre o uso de drogas no Brasil SENAD/ CEBRID 2005. Disponível em http://200.144.91.102/sitenovo/default.aspx

11- Fabbri CE, Furtado EF, Laprega MR. Alcohol consumption in pregnancy: performance of the Brazilian version of the questionnaire T-ACE. Rev Saude Publica. 2007;41(6):979-84.

12- Larroque B, Kaminski M, Dehaene P, Subtil D, Delfosse MJ, Querleu D. Moderate prenatal alcohol exposure and psychomotor development at preschool age. Am J Public Health. 1995;85(12):1654-61.

13- Costa, MTZ; Quintal, VS; Haro, FMB; Picchi, M; Salgado, MVS; Okay, Y; Vaz, FAC; Ramos, JLA. Drogas de abuso na gestação: as orientações no pré-natal são suficientes? 
Pediatria (São Paulo) 1998; 20(4):316-322.

14- Jacobson SW, Chiodo LM, Sokol RJ, Jacobson JL. Validity of maternal report of prenatal alcohol, cocaine, and smoking in relation to neurobehavioral outcome. Pediatrics. 2002;109(5):815-25.

15- Mattson SN, Riley EP. A review of the neurobehavioral deficits in children with fetal alcohol syndrome or prenatal exposure to alcohol. Alcohol Clin Exp Res. 1998;22(2):279-94. 16- Ervalahti N, Korkman M, Fagerlund A, Autti-Rämö I, Loimu L, Hoyme HE. Relationship between dysmorphic features and general cognitive function in children with fetal alcohol spectrum disorders. Am J Med Genet A. 2007;143A(24):2916-23.

17- Sampson PD, Streissguth AP, Bookstein FL, Little RE, Clarren SK, Dehaene P, Hanson JW, Graham JM Jr. Incidence of fetal alcohol syndrome and prevalence of alcohol-related neurodevelopmental disorder. Teratology. 1997;56(5):317-26.

18- Riley EP, Infante MA, Warren KR. Fetal alcohol spectrum disorders: an overview. Neuropsychol Rev. 2011;21(2):73-80.

19- Freire TM, Machado JC, Melo EV, Melo DG. Effects of alcohol consumption during pregnancy. Rev Bras Ginecol Obstet. 2005; 27(7): 376-81

20- Streissguth AP, Aase JM, Clarren SK, Randels SP, LaDue RA, Smith DF. Fetal alcohol syndrome in adolescents and adults. JAMA. 1991;265(15):1961-7.

21- Streissguth AP, Barr HM, Sampson PD, Bookstein FL. Prenatal alcohol and offspring development: the first fourteen years. Drug Alcohol Depend. 1994;36(2):89-99.

22- Roebuck TM, Mattson SN, Riley EP. Behavioral and psychosocial profiles of alcoholexposed children. Alcohol Clin Exp Res. 1999;23(6):1070-6.

23- Brown RT, Coles CD, Smith IE, Platzman KA, Silverstein J, Erickson S, Falek A. Effects of prenatal alcohol exposure at school age. II. Attention and behavior. Neurotoxicol Teratol. 1991;13(4):369-76.

23- Janzen LA, Nanson JL, Block GW. Neuropsychological evaluation of preschoolers with fetal alcohol syndrome. Neurotoxicol Teratol. 1995;17(3):273-9.

25- Fagerlund A, Autti-Rämö I, Hoyme HE, Mattson SN, Korkman M. Risk factors for behavioural problems in foetal alcohol spectrum disorders. Acta Paediatr. 2011;100(11):14818.

26- Jacobson SW, Jacobson JL, Sokol RJ, Chiodo LM, Corobana R. Maternal age, alcohol abuse history, and quality of parenting as moderators of the effects of prenatal alcohol exposure on 7.5-year intellectual function. Alcohol Clin Exp Res. 2004 ;28(11):1732-45.

26- Jacobson SW, Jacobson JL, Stanton ME, Meintjes EM, Molteno CD. Biobehavioral 
markers of adverse effect in fetal alcohol spectrum disorders. Neuropsychol Rev. 2011;21(2):148-66.

28- Pinheiro SN, Laprega MR, Furtado EF. Psychiatric morbidity and alcohol use by pregnant women in a public obstetric service. Rev Saude Publica. 2005;39(4):593-8

29- Alves ICB, Duarte JL. Escala de Maturidade Mental Columbia: Manual para aplicação e interpretação, $1^{\mathrm{a}}$ edição brasileira, São Paulo, Casa do Psicólogo, 1993. Tradução e padronização brasileira de Burgemeister BB, Blum LH, Lorge I. Columbia Mental Maturity Scale, $3^{\mathrm{a}}$ edição, The Psychological Corporation, USA, 1972.

30- Kelly Y, Sacker A, Gray R, Kelly J, Wolke D, Quigley MA. Light drinking in pregnancy, a risk for behavioural problems and cognitive deficits at 3 years of age? Int $\mathrm{J}$ Epidemiol. 2009;38(1):129-40.

31- Robinson M, Oddy WH, McLean NJ, Jacoby P, Pennell CE, de Klerk NH, Zubrick SR, Stanley FJ, Newnham JP. Low-moderate prenatal alcohol exposure and risk to child behavioural development: a prospective cohort study. BJOG. 2010;117(9):1139-50.

32- Almeida-Filho N, Burnett CK. Family size and child mental disorders in Bahia, Brazil. Popul Environ. 1983, 6(1):3-16.

33- Tong S, Baghurst P, McMichael A. Birthweight and cognitive development during childhood. J Paediatr Child Health. 2006;42(3):98-103.

34- Richards M, Hardy R, Kuh D, Wadsworth ME. Birth weight and cognitive function in the British 1946 birth cohort: longitudinal population based study. BMJ. 2001;322(7280):199203.

35- Willford J, Leech S, Day N. Moderate prenatal alcohol exposure and cognitive status of children at age 10. Alcohol Clin Exp Res. 2006;30(6):1051-9

36- Hannigan JH, Chiodo LM, Sokol RJ, Janisse J, Ager JW, Greenwald MK, Delaney-Black V. A 14-year retrospective maternal report of alcohol consumption in pregnancy predicts pregnancy and teen outcomes. Alcohol. 2010;44(7-8):583-94.

37- Streissguth AP, Barr HM, Sampson PD, Darby B, Martin DC. IQ at age 4 in relation to maternal alcohol use and smoking during pregnancy. Develop Psychol. 1989;25(1):3-11.

38- Larroque B, Kaminski M. Prenatal alcohol exposure and development at preschool age: main results of a French study. Alcohol Clin Exp Res, 1998; 22(2):295-303.

39- Korkman M, Autti-Rämö I, Koivulehto H, Granström ML. Neuropsychological effects at early school age of fetal alcohol exposure of varying duration. Child Neuropsycol 1998; 4(3):199-212

40- Fried PA, Watkinson B. 36- and 48-month neurobehavioral follow-up of children 
prenatally exposed to marijuana, cigarettes, and alcohol. J Dev Behav Pediatr. 1990;11(2):4958.

41- Greene T, Ernhart CB, Ager J, Sokol R, Martier S, Boyd T. Prenatal alcohol exposure and cognitive development in the preschool years. Neurotoxicol Teratol. 1991;13(1):57-68.

42- Fried PA, O'Connell CM, Watkinson B. 60- and 72-month follow-up of children prenatally exposed to marijuana, cigarettes, and alcohol: cognitive and language assessment. J Dev Behav Pediatr. 1992;13(6):383-91.

43- Nulman I, Rovet J, Kennedy D, Wasson C, Gladstone J, Fried S, Koren G. Binge alcohol consumption by non-alcohol-dependent women during pregnancy affects child behaviour, but not general intellectual functioning; a prospective controlled study. Arch Womens Ment Health. 2004;7(3):173-81.

44- O'Callaghan FV, O'Callaghan M, Najman JM, Williams GM, Bor W. Prenatal alcohol exposure and attention, learning and intellectual ability at 14 years: a prospective longitudinal study. Early Hum Dev. 2007;83(2):115-23.

45- Russell M, Czamecki DM, Cowan R, McPherson E, Mudar PJ. Measures of maternal alcohol use as predictors of development in early childhood. Alcohol Clin Exp Res. 1991;15(6):991-1000. 
Tabela 1 - Quantidade de mães que referiram uso de qualquer quantidade de álcool na gestação e uso de 3 ou mais doses por ocasião obtidas na entrevista retrospectiva.

\begin{tabular}{lll}
\hline & Quantidade de mães & Quantidade de mães/ $\geq 3$ doses*/ocasião \\
\hline $1^{\circ}$ trimestre & $25 / 86(29 \%)$ & $12 / 86(13,9 \%)$ \\
\hline $2^{\circ}$ trimestre & $14 / 86(16,3 \%)$ & $9 / 86(10,4 \%)$ \\
\hline $3^{\circ}$ trimestre & $15 / 86(17,4 \%)$ & $9 / 86(10,4 \%)$ \\
\hline Gestação & $30 / 86(34,9 \%)$ & $13 / 86(15,1 \%)$ \\
\hline
\end{tabular}

* dose: aproximadamente $10 \mathrm{~g}$ álcool puro $(330 \mathrm{ml}$ de cerveja, $140 \mathrm{ml}$ de vinho ou $40 \mathrm{ml}$ de destilado) 
Figura 1 - Freqüências dos escores de RPI obtidos nas 86 crianças avaliadas.

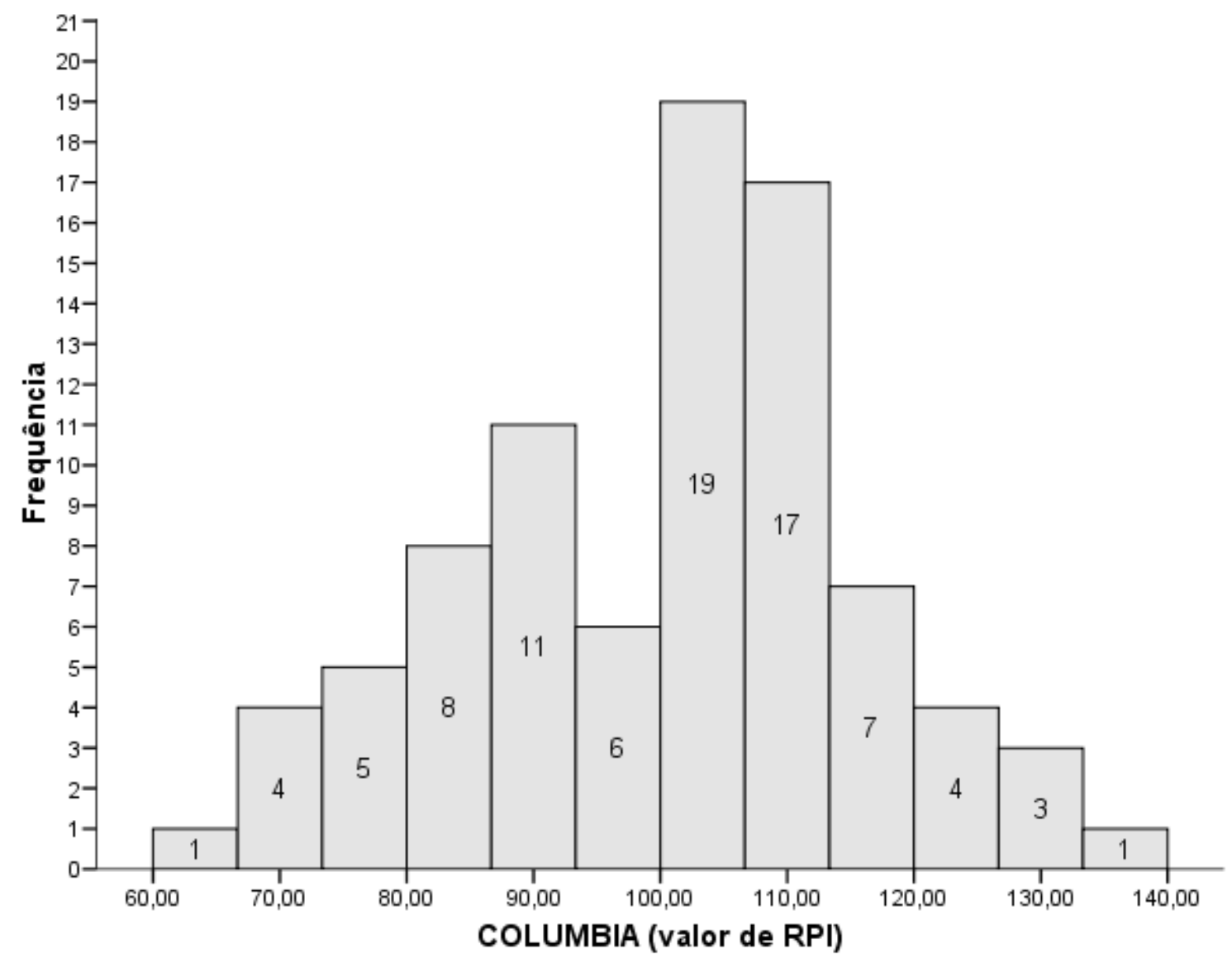


Figura 2 - Escores de RPI da Escala de Maturidade Mental Columbia em meninos em relação à cor referida da pele $(\mathrm{A})$, uso pelas mães em dias de qualquer quantidade de álcool na gestação (B) e uso de 3 ou mais doses de álcool por ocasião durante a gestação (C). As linhas correspondem ao valor médio de RPI.
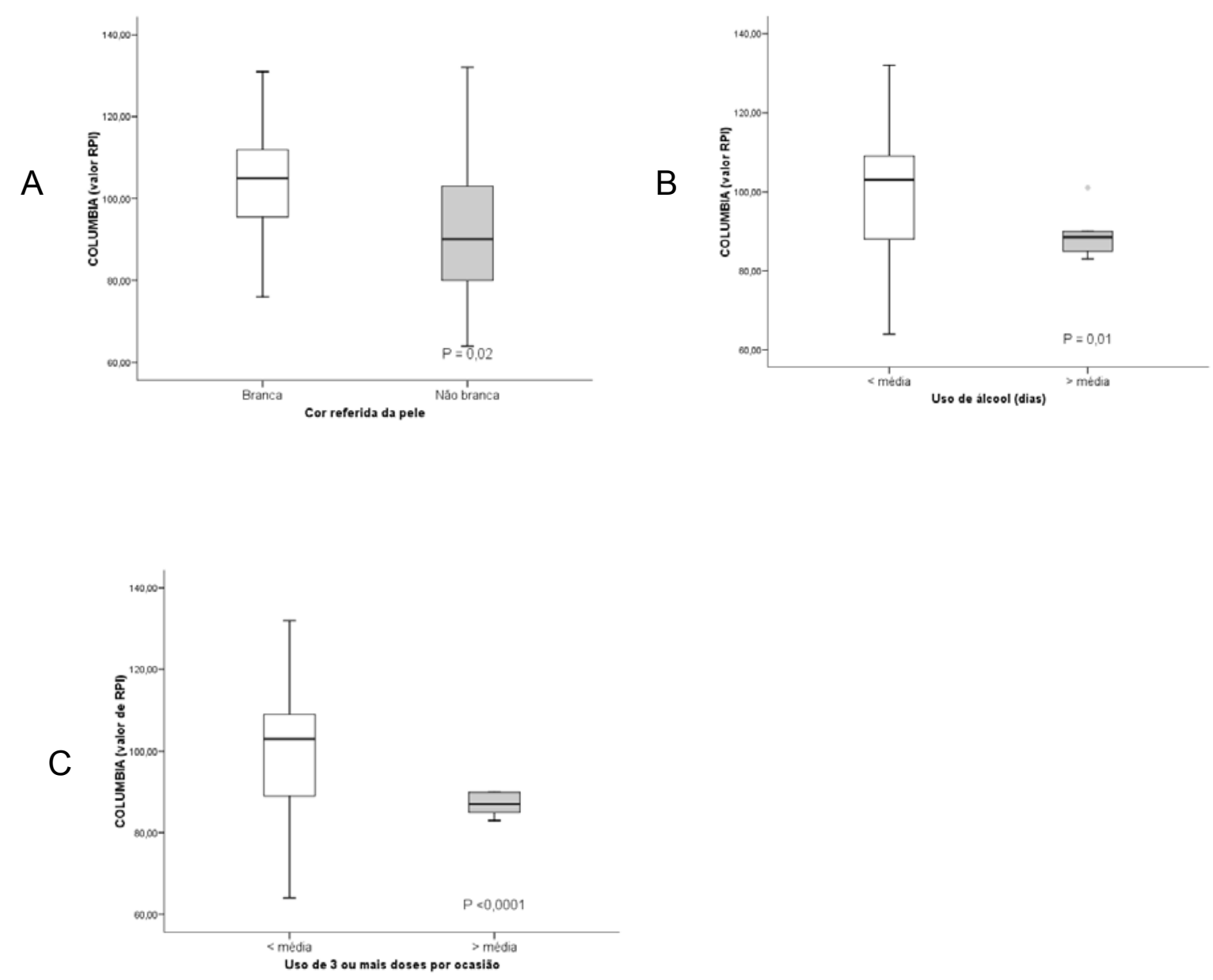
ANEXOS 


\section{INFANTO-ÁLCOOL 2009 - ENTREVISTA MÃE}

$\underline{\underline{\text { Identificação }}}$

1.NÚMERO ID

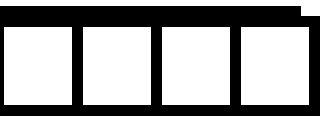

2. NOME DO ENTREVISTADOR:

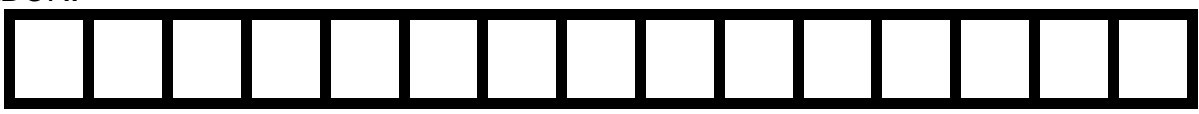

3. DATA DA ENTREVISTA:

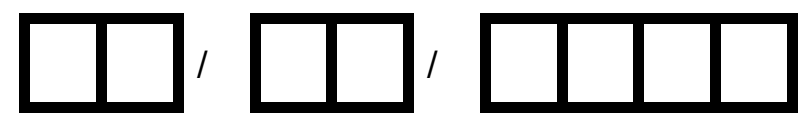

4. NOME DA MÃE:

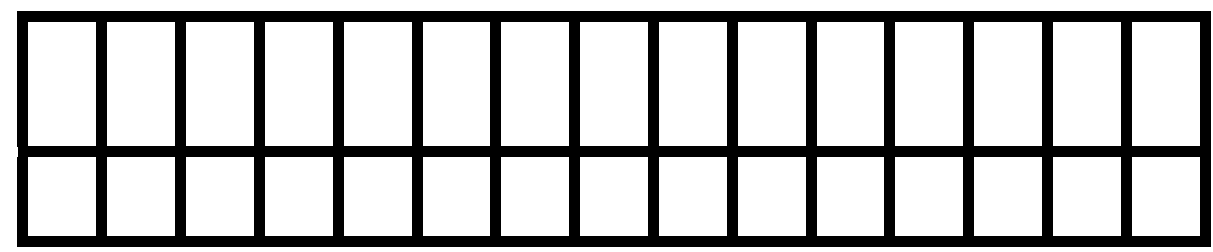

5. DATA DE NASCIMENTO DA MÃE:
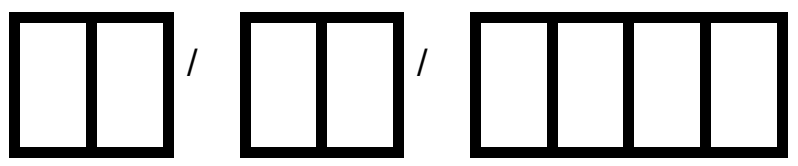

6. QUAL O NOME COMPLETO DA CRIANÇA*?
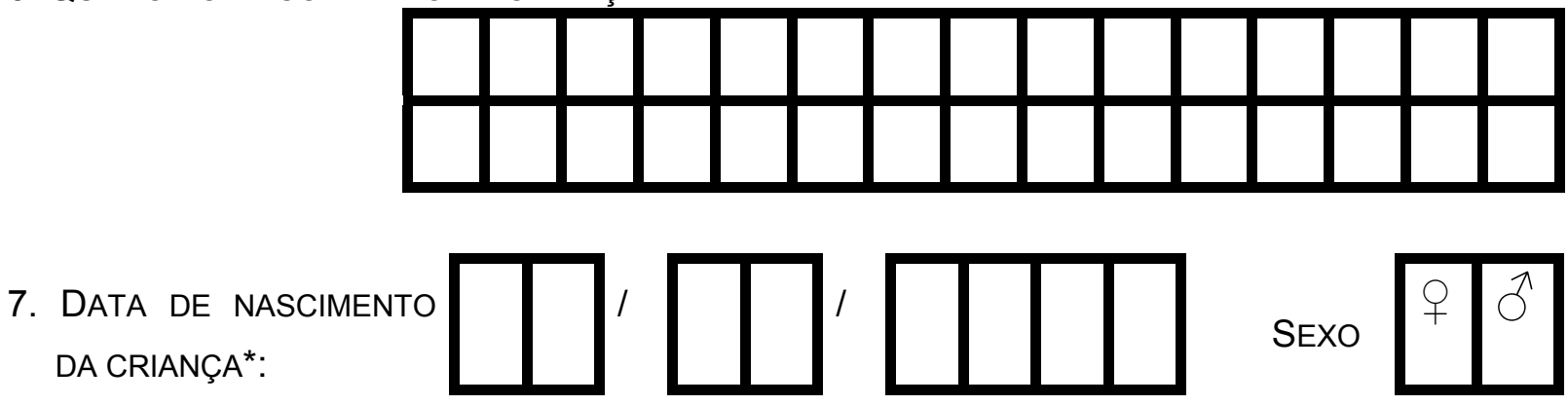

*PARA ESSA PESQUISA A CRIANÇA REFERE-SE AO FILHO NASCIDO DA GESTAÇÃO OCORRIDA NO PERÍODO DA PESQUISA GESTA-ÁLCOOL (2000-2001) 


\section{DADOS SOCIODEMOGRÁFICOS}
8. Nacionalidade
$\square_{1}$ Brasileira
$\square_{2}$ Estrangeira
$\mathrm{U}_{3}$ Estr. Naturalizado
9. Cor da pele
$\square_{1}$ Branca
$\square_{2}$ Parda ou Mulata
$\square_{3}$ Negra

10. A maior parte de sua vida você viveu no Estado de São Paulo?

$\begin{array}{cc}\text { Não } & \operatorname{Sim} \\ \square_{0} & \square_{1} \\ \text { Não } & \operatorname{Sim} \\ \square_{0} & \square_{1}\end{array}$

11. A maior parte de sua vida você viveu em outro Estado Brasileiro?

$$
\text { 11.1.- Qual? (Informe a sigla) }
$$

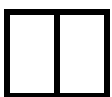

12. A maior parte de sua vida você viveu em Ribeirão Preto?

$\begin{array}{cc}\text { Não } & \text { Sim } \\ \square_{0} & \square_{1} \\ \text { Não } & \text { Sim } \\ \square_{0} & \square_{1} \\ \text { Não } & \text { Sim } \\ \square_{0} & \square_{1}\end{array}$

13. A maior parte de sua vida você viveu em outra cidade acima de 250.000 hab.?

14. A maior parte de sua vida você viveu em meio rural?

15. Seu estado civil:

$$
\begin{aligned}
& u^{1} \begin{array}{l}
\text { Solteira ou } \\
\text { Separada }
\end{array} \text { Casada } \\
& 4 \text { União estável / Amasiada / Amigada }
\end{aligned}
$$

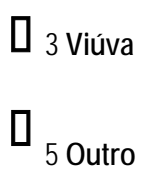

16. Informe, quantos filhos você tem? :

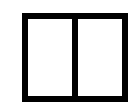

17. Você reside com o pai de X (filho ou filha, em avaliação nesta pesquisa)?

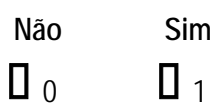

18. Sua renda familiar é:

$$
\begin{aligned}
& 1 \text { até } \mathrm{R} \$ 500,00 \quad \square_{2} \text { até } \mathrm{R} \$ 1500,00 \\
& 4 \text { até } \mathrm{R} \$ 5000,00
\end{aligned}
$$$$
3 \text { até } R \$ 3000,00
$$$$
5 \text { Acima de } R \$ 5000,00
$$

19. Você exerce alguma atividade remunerada (trabalha fora)?

$\begin{array}{cc}\text { Não } & \text { Sim } \\ \square_{0} & \square_{1} \\ \text { Não } & \text { Sim } \\ \square_{0} & \square_{1}\end{array}$

\subsection{Qual?}

21. Nível de Escolaridade:

$\begin{array}{lll}\text { 21.1.Pai/Padrasto } & \square_{1 \text { Sem escolaridade }} & \square_{2 \text { Ensino Fundamental }} \\ & \square_{3 \text { Ensino Médio/Técnico }} & \square_{4 \text { Ensino Superior }} \\ & \square_{1 \text { Sem escolaridade }} & \square_{2 \text { Ensino Fundamental }} \\ & \square_{3 \text { Ensino Médio/Técnico }} & \square_{4 \text { Ensino Superior }}\end{array}$




\section{História Obstétrica:}

22. N GESTAÇÕES (IG > 20 SEM):

23. No ABORTOS (IG < 20 SEM):

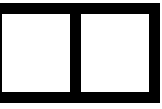

24. № GESTAÇÕES GEMELARES:

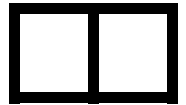

25. No NATIMORTOS:

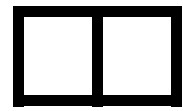

26. No PREMATUROS (IG < 37 SEM):

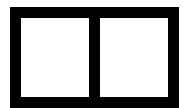

27. No BAIXO PESO (<2500 GR):

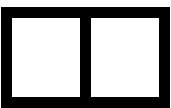

28. TEVE ALGUM FILHO QUE FALECEU DEPOIS DE NASCER?

28A. É A CRIANÇA DESTA PESQUISA?

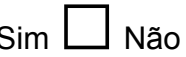

28B. CAUSA?

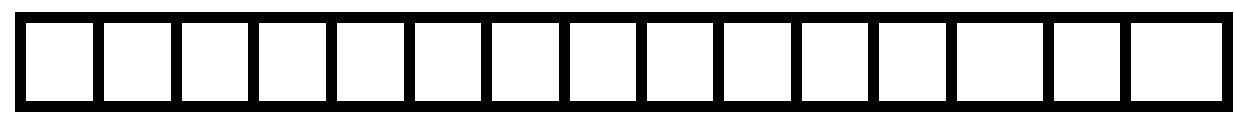

29. TeVe ALgum FILHO COM MÁS-FORMAÇÕES OU DEFEITOS DE NASCENÇA?

29A. É A CRIANÇA DESTA PESQUISA?

29B. CAUSA?

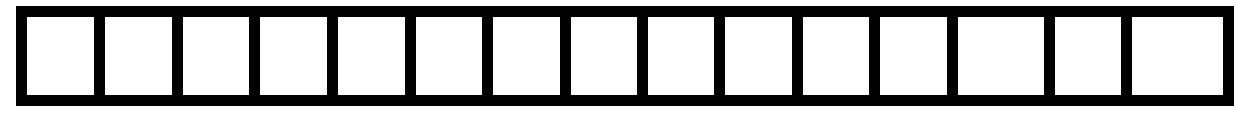

30. TeVe algum filho com doençA genÉtica (P.EX. SíndROME dE DOWN)?

30A. É A CRIANÇA DESTA PESQUISA?

30B. CAUSA?

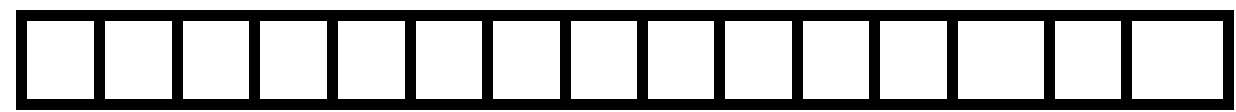

Desenvolvimento da criança:

31. POSIÇÃO DA CRIANÇA:

É PRIMOGÊNITO

SEGUNDO

TERCEIRO

$\square$ OUTRA POSIÇÃO

32. IDADE EM QUE SORRIU: 
33. IDADE EM QUE SENTOU SEM APOIO:

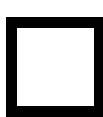

ANOS

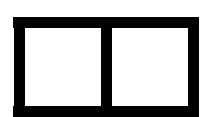

MESES

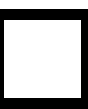

ANOS

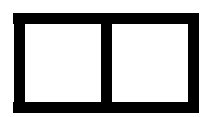

MESES

34. IDADE EM QUE APONTOU OBJETOS:

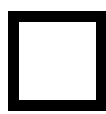

ANOS

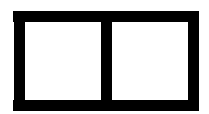

MESES

35. IDADE EM QUE ANDOU SEM APOIO:

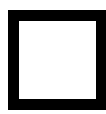

ANOS

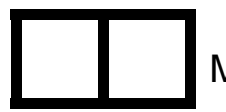

Meses

36. IDADE EM QUE FALOU PALAVRAS:

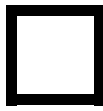

ANOS

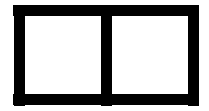

MESES

37. IDADE EM QUE FALOU FRASES:

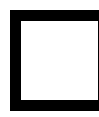

ANOS

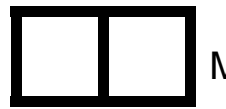

MESES

38. IDADE EM QUE CONTROLOU A URINA:

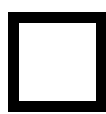
ANOS

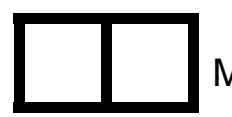
MESES

39. IDADE EM QUE CONTROLOU AS FEZES: ANOS

41. QUAL?

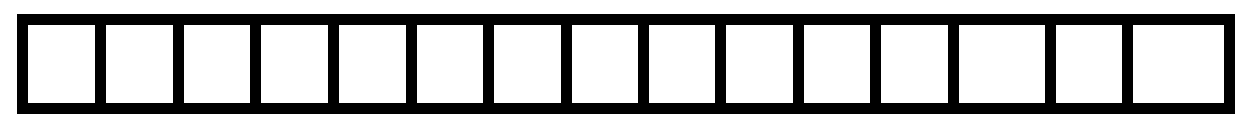

42. A CRIANÇA FAZ TRATAMENTO DE FONOAUDIOLOGIA?

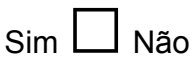

43. A CRIANÇA TEM PROBLEMAS DE SAÚDE, ATUALMENTE?

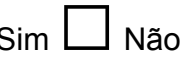

43B. QUAL?

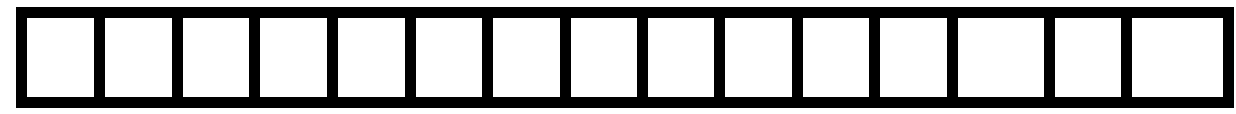

44. A CRIANÇA FAZ TRATAMENTO DE SAÚDE, ATUALMENTE?

$\operatorname{Sim} \square$ Não 
Assinale abaixo, outras doenças da criança:

45. IVAS RECORRENTES?

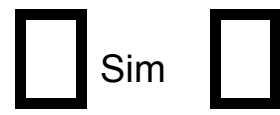

Não

Já foi hospitalizada

46. ASMA?

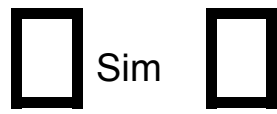

Não

$\square$

Já foi hospitalizada

47. PNEUMONIA?

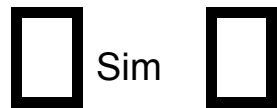

Não

$\square$

Já foi hospitalizada

48. Problema de CoraçÃo?

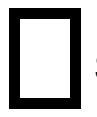

$\operatorname{Sim}$

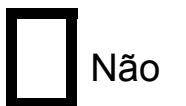

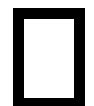

Já foi hospitalizada

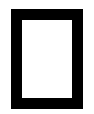

$\operatorname{Sim}$

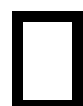

Não

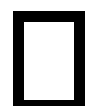

Já foi hospitalizada

50. DIARRÉIA?

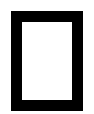

$\operatorname{Sim}$

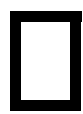

Não

$\square$

Já foi hospitalizada

51. HePATITE/ICTERÍCIA?

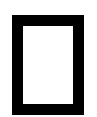

Sim

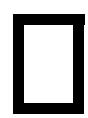

Não

$\square$

Já foi hospitalizada

52. DOENÇA DE PELE?

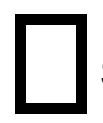

Sim

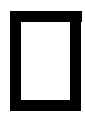

Não

$\square$

Já foi hospitalizada

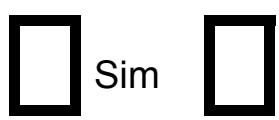

Não

$\square$

Já foi hospitalizada

53. DIABETES?

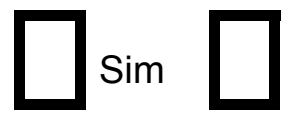

Não<smiles>[CH]1CCC1</smiles>

Já foi hospitalizada

54. DOENÇA RENAL?

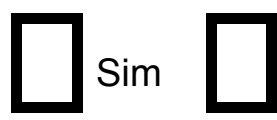

Não<smiles>C1CCC1</smiles>
Já foi hospitalizada

55. ITUS RECORRENTES?

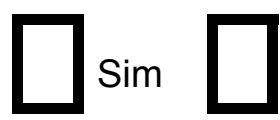

Não<smiles>[CH]1CCC1</smiles>
Já foi hospitalizada

56.PROBLEMA HORMONAL/TIRÓIDE?

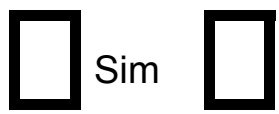

Não<smiles>C1CCC1</smiles>
Já foi hospitalizada

57. ANEMIAS?

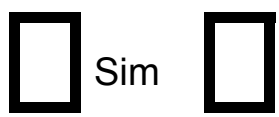

Não Já foi hospitalizada 
59. DORES RECORRENTES?

60. Cefaléia/EnXaQuecA?

61. CONVULSÕES/EPILEPSIA?

62. ACIDENTES/TRAUMATISMOS?

63. TCE?

64. DOENÇAS DOS NERVOS (PSQ)?

65. PARALISIAS?

66. TONTURAS/VERTIGENS?

67. TEM PROBLEMAS DE AUDIÇÃO?

68. TEM PROBLEMAS DE VISÃO?

69. ESTÁ TOMANDO REMÉDIOS?

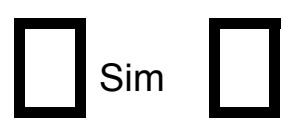
Não<smiles>[CH]1CCC1</smiles>
Já foi hospitalizada

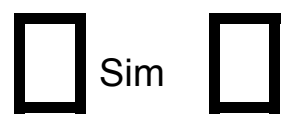
Não<smiles>[CH]1CCC1</smiles>
Já foi hospitalizada

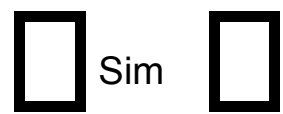
Não<smiles>C1CCC1</smiles>
Já foi hospitalizada
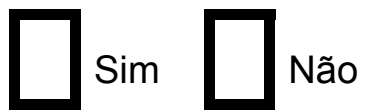<smiles>C1CCC1</smiles>
Já foi hospitalizada

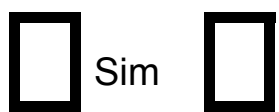
Não<smiles>C1CCC1</smiles>
Já foi hospitalizada

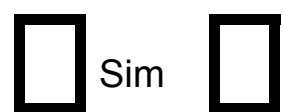
Não<smiles>C1CCC1</smiles>
Já foi hospitalizada

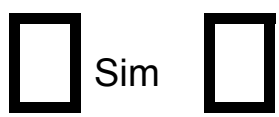

Não<smiles>[CH]1CCC1</smiles>
Já foi hospitalizada

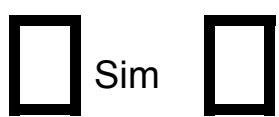

Não<smiles>C1CCC1</smiles>
Já foi hospitalizada

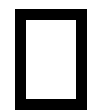
Sim<smiles>C1CC2CC12</smiles>
Não
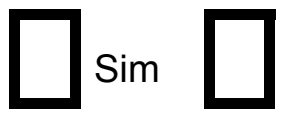
Não

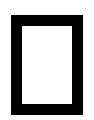
Sim

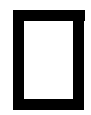
Não

70. QUAIS?

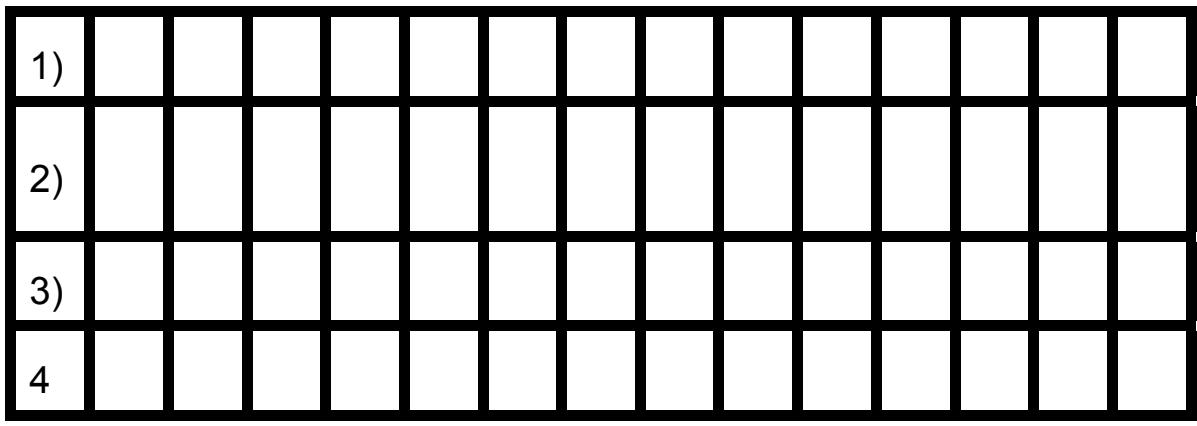


71. QUE DOSAGEM?
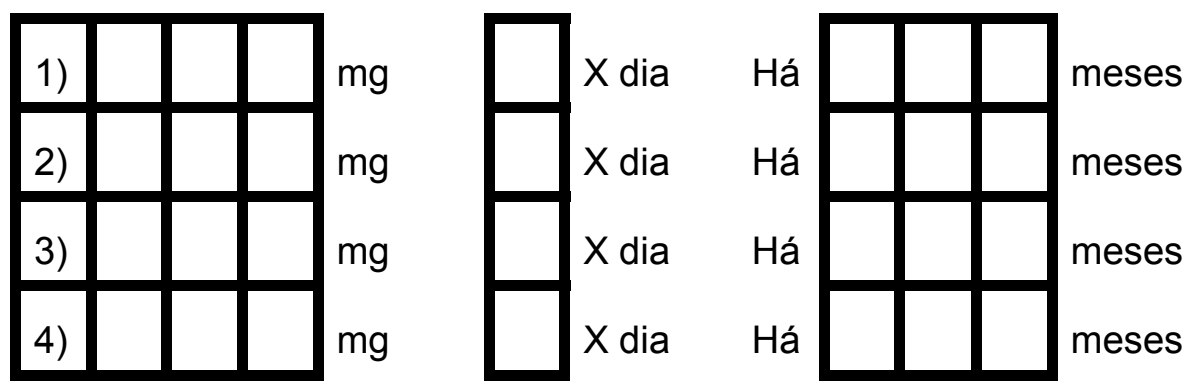

Saúde da Mãe:

72. QUANTOS FILHOS BIOLÓGICOS VOCÊ TEVE?

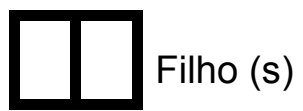

73. TEM PROBLEMAS DE SAÚDE?

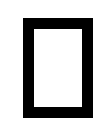
Sim

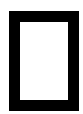

Não

74. SE SIM, QUAIS?

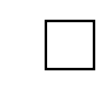

Hipertensão

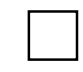

Problemas respiratórios

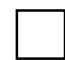

Problemas mentais

74B. OUTRO QUAL?

75. VOCÊ TOMA REMÉDIOS?
Problemas gastrointestinais

Problemas genito- urinários
Diabetes
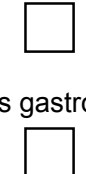

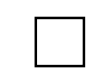

Alergias

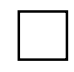

DSTs/ AIDS

Anemia

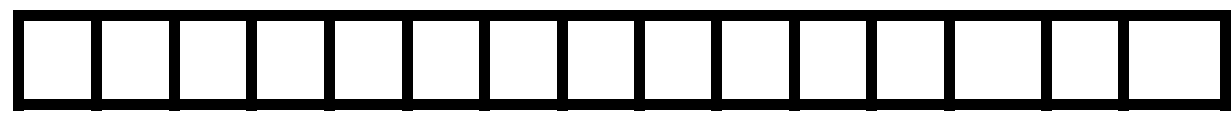

Problemas cardíacos/

circulatório

Problemas renais

Outros 
76. QUAIS?

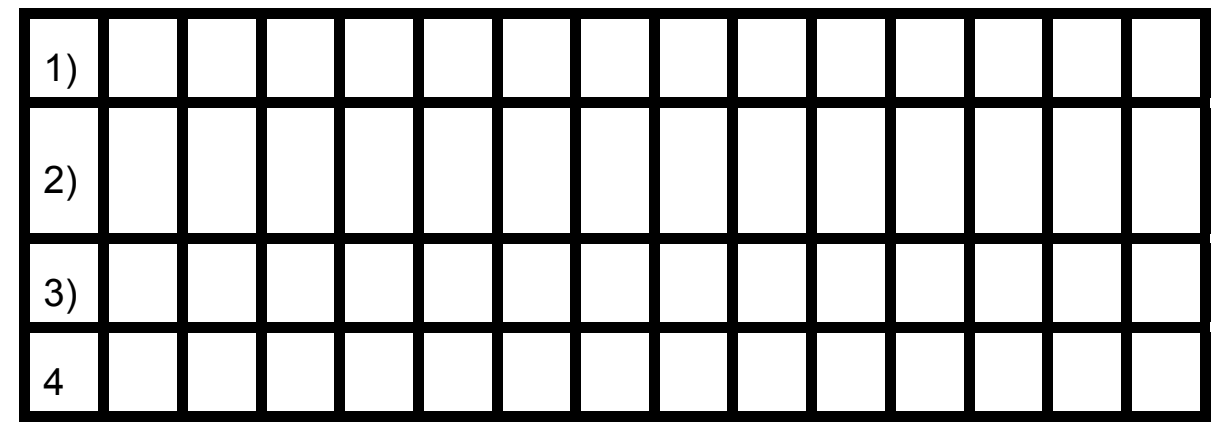

77. QUE DOSAGEM?
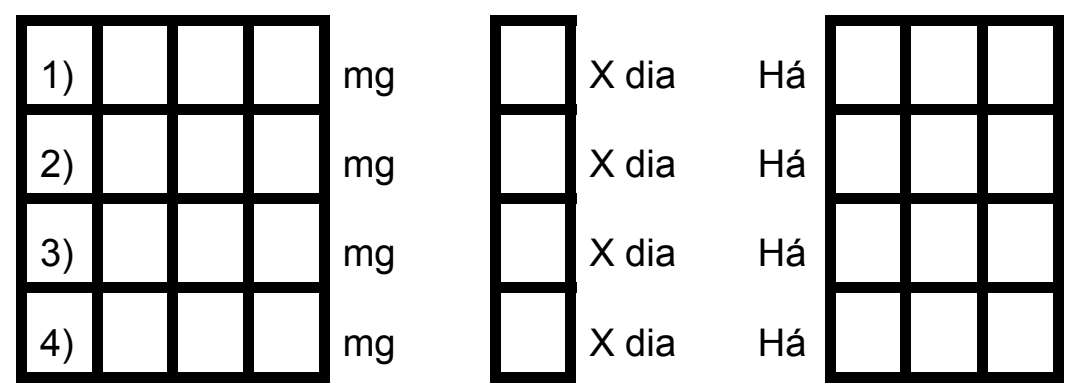

meses

meses

meses

meses

\section{Avaliação atual de sintomas da Mãe:}

78. Tem dores de cabeça freqüentes?

$\square \operatorname{Sim}$

$\square$ Não

79. Tem falta de apetite?

$\square \operatorname{Sim}$

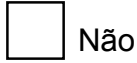

80. Dorme mal?
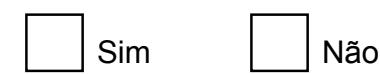

81. Assusta-se com facilidade?
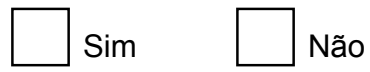

82. Tem tremores na mão?
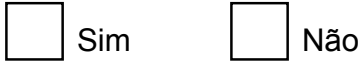

83. Sente-se nervosa, tensa ou preocupada?
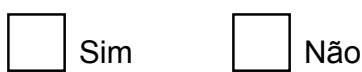

84. Tem má digestão?
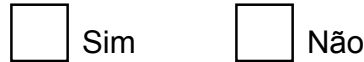

85. Tem dificuldade de pensar com clareza?
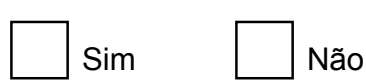

86. Tem se sentido triste ultimamente?

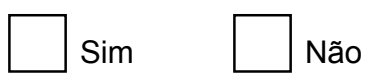

87. Tem chorado mais do que de costume?

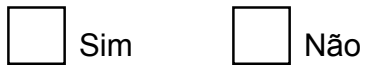

88. Encontra dificuldades para realizar com satisfação suas atividades diárias?

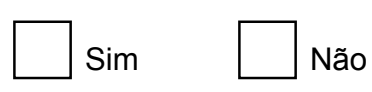


89. Tem dificuldades para tomar decisões?

$\square \operatorname{Sim}$

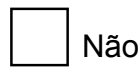

90. Tem dificuldades no serviço (seu trabalho é penoso, causa sofrimento)?

91. Sente-se incapaz de desempenhar um papel útil em sua vida?

92. Tem perdido o interesse pelas coisas?

93. Você se sente uma pessoa inútil, sem préstimo?

94. Tem tido idéias de acabar com a vida

95. Sente-se cansada o tempo todo?

96. Tem sensações desagradáveis no estômago?

97. Você se cansa com facilidade?

98. VOCÊ FAZ TRATAMENTO DE NERVOS (PSQ)?

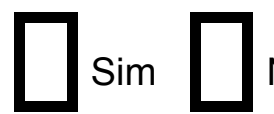

Não

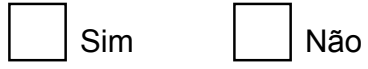

$\square \operatorname{Sim}$

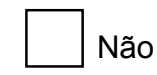

$\square \operatorname{Sim}$

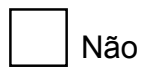

$\square \operatorname{Sim}$

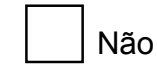

$\square \operatorname{Sim}$

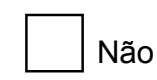

$\square \operatorname{Sim}$

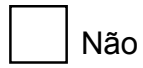

$\square \operatorname{Sim}$

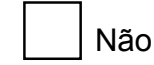

$\square \operatorname{Sim}$

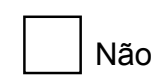
Não

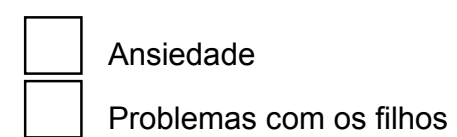

Problemas com os filhos

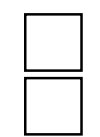
Depressão

Transtornos alimentares

\section{O TRATAMENTO FOI MOTIVADO DEVIDO A ALGUM DOS ITENS A SEGUIR?}

99B. OUTRO QUAL?

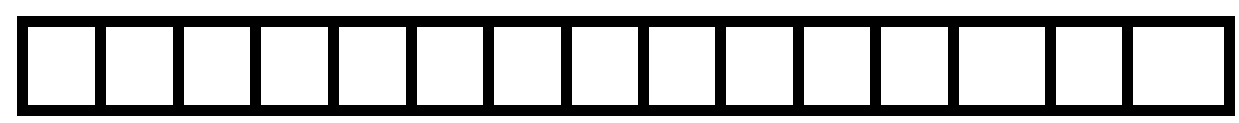


100. ALGUM DOS SEUS FAMILIARES APRESENTA ALGUM PROBLEMA DE SAÚDE?
a. Pai
b. Mãe
c. Irmãos
d. Marido
e. Filhos
f. Outros

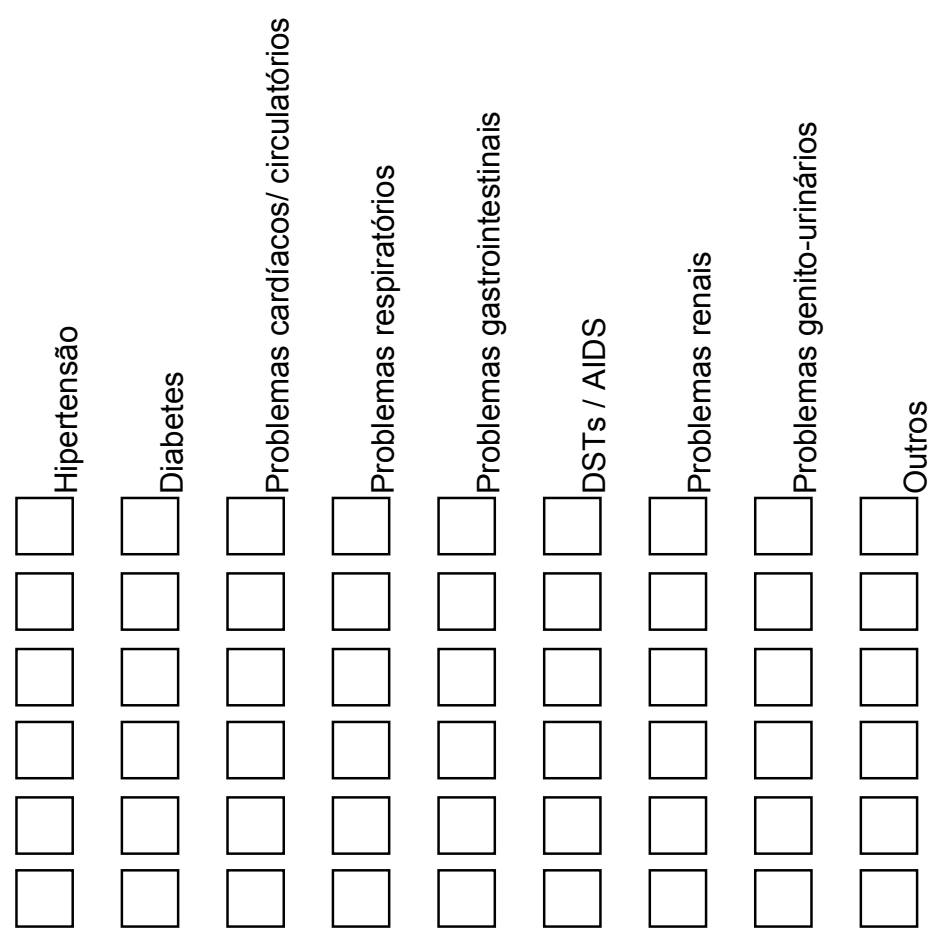

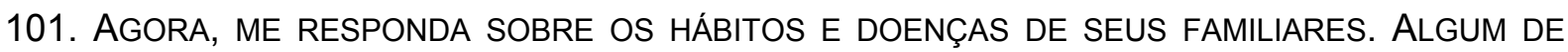
SEUS FAMILIARES (PAI, MÃE, IRMÃOS, MARIDO, FILHOS, OUTROS) TEM O HÁBITO DE FUMAR, BEBER OU USAR DROGAS?
a. Pai
b. Mãe
c. Irmãos
d. Marido
e. Filhos
f. Outros
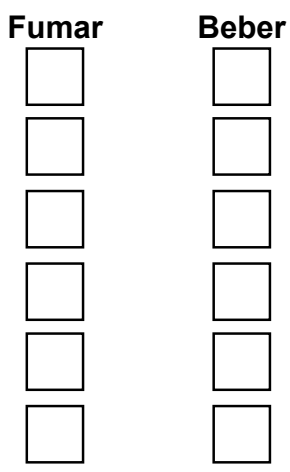

Usar drogas

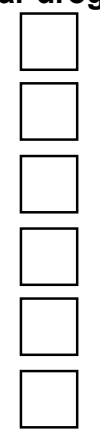




\section{Avaliação do consumo de álcool na gestação de $X$}

AGORA, ME RESPONDA SOBRE O SEU CONSUMO DE BEBIDAS ALCOÓLICAS (POR EX:: CERVEJA, CHOPE, VINHO, PINGA ,BATIDAS, E OUTROS) DURANTE O PRIMEIRO TRIMESTRE":

102. QUANTOS DIAS VOCÊ CONSUMIU BEBIDA ALCOÓLICA?

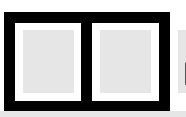
DIAS

103. QUANTAS DOSES, EM MÉDIA, VOCÊ BEBEU NESSAS OCASIÕES?

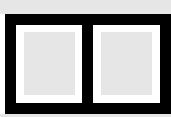

104. QUANTAS VEZES VOCÊ CONSUMIU TRÊS OU MAIS DOSES?

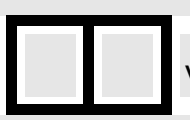

VEZES

"AGORA, ME RESPONDA SOBRE O SEU CONSUMO DURANTE O SEGUNDO TRIMESTRE":

105. QUANTOS DIAS VOCÊ CONSUMIU BEBIDA ALCOÓLICA?

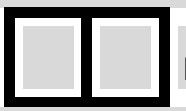

DIAS

106. QUANTAS DOSES, EM MÉDIA, VOCÊ BEBEU NESSAS OCASIÕES?

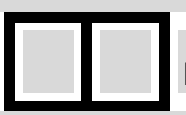

107. QUANTAS VEZES VOCÊ CONSUMIU TRÊS OU MAIS DOSES?

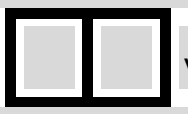

VEZES

"AGORA, ME RESPONDA SOBRE O SEU CONSUMO DURANTE O TERCEIRO TRIMESTRE".

108. QUANTOS DIAS VOCÊ CONSUMIU BEBIDA ALCOÓLICA?

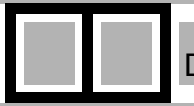

DIAS

109. QUANTAS DOSES, EM MÉDIA, VOCÊ BEBEU NESSAS OCASIÕES?

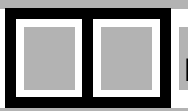

DOSES

110. QUANTAS VEZES VOCÊ CONSUMIU TRÊS OU MAIS DOSES?

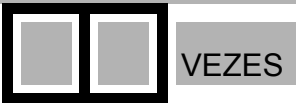

\section{Perguntas}

111. Com que freqüência você consome bebidas alcoólicas?

112. Quantas doses de bebidas alcoólicas você consome num dia normal?

113. Com que freqüência você consome cinco ou
0

1

2

3

Nunca Mensalmente $2 \mathrm{a} 4$ vezes De 2 a 3 vezes 4 ou mais vezes ou menos

o ou 1

2 ou 3

4 ou 5

6 ou 7

8 ou mais

Nunca Menos que 01 Mensalmente Semanalmente Quase todos os vez por mês dias 
mais doses em uma única ocasião?

114. Quantas vezes ao longo dos últimos 12 meses você achou que não conseguiria parar de beber uma vez tendo começado?

115. Quantas vezes ao longo dos últimos 12 meses você não conseguiu fazer o que era esperado de você por causa do álcool?

116. Quantas vezes ao longo dos últimos 12 meses você precisou beber pela manhã para poder se sentir bem ao longo do dia após ter bebido bastante no dia anterior?

117. Quantas vezes ao longo dos últimos 12 meses você se sentiu culpado ou com remorso depois de ter bebido?

118. Quantas vezes ao longo dos últimos 12 meses você foi incapaz de lembrar o que aconteceu devido à bebida?

119. Você já causou ferimentos ou prejuízos a você mesmo ou a outra pessoa após ter bebido?

120. Alguém ou algum parente, amigo ou médico já se preocupou com 0 fato de você beber ou sugeriu que você parasse?
Nunca Menos que 01 Mensalmente Semanalmente Quase todos os vez por mês

dias

Nunca Menos que 01 Mensalmente Semanalmente Quase todos os vez por mês

dias

Nunca Menos que 01 Mensalmente Semanalmente Quase todos os vez por mês

dias

Nunca Menos que 01 Mensalmente Semanalmente Quase todos os vez por mês

dias

Nunca Menos que 01 Mensalmente Semanalmente Quase todos os vez por mês

dias

Nunca

Sim, mas não

Sim, durante 0

no último ano

último ano

Nunca

Sim, mas não

Sim, durante 0

no último ano 
Informações da mãe

Sobre sintomas de $X$
Marque um X sobre o quadro correspondente: 0 = não apresenta; 1 = leve/moderado; 2 = grave/óbvio

AVALIAÇÃO SINAIS FAS, SENSÓRIO-MOTORA E GLOBAL COGNITIVA

121. Dificuldade de coordenação e equilíbrio

122. Dificuldade de articulação da fala

123. Mutismo, não fala

124. Parece não ouvir bem

125. Dificuldades visuais, enxerga mal

126. Estigmas faciais da SFA presentes (OBS.: USE ESCALA EM ANEXO)

127. Erra ao nomear objetos (três: cadeira, mesa, sapato)

128. Erra operações simples de identificar quantidades (um dedo, dois dedos, cinco dedos)

129. Erra ao falar o próprio nome completo

130. Não segura um lápis

131. Não consegue escrever três palavras simples (vovó, bala, picolé)

132. Erra ao desenhar a figura humana (cabeça, tronco, membros)

Data:

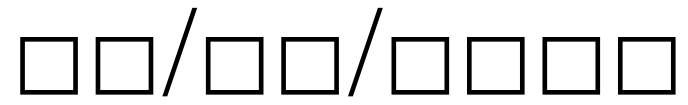

Hora:

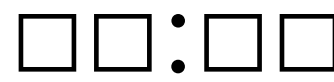




\section{GESTA-ÁLCOOL - FICHA DE REGISTRO DE DADOS}

\section{l- Identificação da paciente:}

Nome (iniciais):

Iniciais do Entrevistador :
$N^{\circ}$ Registro:

Data:

\section{Dados sociodemográficos:}

1.Idade: anos

2.Biotipo e cútis: branca negra mestiça/mulata asiática

3.Estado civil: casado/amasiado solteiro/separado viúvo

4.Escolaridade: nenhuma

até 4 anos - Ensino Básico

até 8 anos - Ensino Fundamental

até 12 anos - Ensino Médio/Técnico

acima de 12 anos - Superior

Anos c/ Repetência: anos

5.Situação de emprego:

Última Profissão exercida

Código da Área de Atuação:

ativo inativo do lar estudante aposentado licenciado para tratamento

6.Nível de renda familiar: até $1 \mathrm{SM}$ até $5 \mathrm{SM}$ até $10 \mathrm{SM}$ acima de 10 SM

7.Religião:

católica

protestante tradicional

protestante pentecostal

espírita kardecista

religiões afrobrasileiras

cultos asiáticos

outros

sem religião 


\section{III- Dados do prontuário do paciente:}

I.Diagnóstico atual do paciente:

$1^{\circ}$

$2^{\circ}$

$3^{\circ}$

2.Período de gestação:

2. Houve registro de uso de alcool? Sim Não

Padrão de uso:

Período de uso:

3.Houve registro de uso de drogas ilícitas? Sim Não

\begin{tabular}{|l|l|l|}
\hline $\begin{array}{l}\text { Drogas } \\
\text { relacionadas }\end{array}$ & $\begin{array}{l}\text { Padrão de } \\
\text { uso }\end{array}$ & $\begin{array}{l}\text { Período de } \\
\text { uso }\end{array}$ \\
\hline & & \\
\hline & & \\
\hline & & \\
\hline
\end{tabular}

4.Houve registro de transtorno relacionado ao álcool? Sim Não

5.Houve registro de antecedentes familiares relacionados a álcool/drogas? Sim Não

6. Houve indicação de algum tratamento específico para transtorno relacionado ao álcool?

Sim Não

7. Houve registro de consumo de tabágicos? Sim Não

8. Não há informação disponível 


\section{IV-Dados colhidos da Gestante:}

1. Quantos filhos a Sra. possui ?

2. Idade na ocasião da primeira gestação: anos

3. Qual o n. ${ }^{\circ}$. de gestações anteriores? G $P$ C__ A

4. Qual a data da última menstruação?

5. Quantos meses ou semanas da gestação atual?

6. Qual o seu peso no início da gravidez? $\mathrm{kg}$

7. Qual o seu peso atual? $\mathrm{kg}$

8. A Sra. faz tratamento para algum problema de saúde ? Sim Não

9. Que problemas de saúde?

10. Liste as doenças ou hábitos dos seus familiares mais próximos:

\begin{tabular}{|c|c|c|}
\hline Parentesco & Doenças & Álcool (A)/drogas (D) Fumo (F) \\
\hline Pai & & \\
\hline Mãe & & \\
\hline Irmãos & & \\
\hline Esposo(a) & & \\
\hline Filhos & & \\
\hline Outros & & \\
\hline
\end{tabular}

11. A Sra. Gosta de Fumar? Sim Não

12. A Sra. Fuma atualmente ? Sim Não

13. Quantos cigarros por dia?

14. Período da Gestação e Consumo de Cigarros:

\begin{tabular}{|c|c|c|}
\hline $1^{\circ}$ Trimestre & $2^{\circ}$ Trimestre & $3^{\circ}$ Trimestre \\
\hline & & \\
\hline
\end{tabular}




\section{V-Rastreamento T-ACE:}

A Sra. tem bom apetite?

O que costuma comer nas refeições principais?

Qual a bebida de sua preferência?

(Explique e pergunte se chope, cerveja, pinga, conhaques, licores, bebidas fortes, batidas, uísque, etc...)

1. T-Qual a quantidade que você precisa beber para se sentir desinibida ou mais "alegre" $? \geq 1 . \quad \geq 2 . \quad \geq 3 \quad \geq 4 \quad$ (Avaliar conforme $n^{\circ}$ de drinquespadrão)

Tem facilidade em fazer amizades?

Relaciona-se bem com seus familiares?

2. A- Alguém tem lhe incomodado por criticar o seu modo de beber? (Ex: cônjuge, filho, pai ou mãe) Sim Não

Tem trabalhado durante a gravidez?

Quais atividades você faz para descansar/relaxar?

3.C - Você tem percebido que deve diminuir seu consumo de bebida? Sim Não

A Sra. dorme bem à noite?

A que horas costuma acordar?

4. E - Você costuma tomar alguma bebida logo pela manhã para manter-se bem ou para se livrar do mal-estar do "dia seguinte" (ressaca) ?

Sim Não

\section{Pontos obtidos no T-ACE:}




\section{VI - Avaliação do padrão de consumo:}

1. Se o paciente teve ou tem problemas com álcool, pergunte:

\begin{tabular}{|c|c|c|c|c|c|c|}
\hline \multirow{2}{*}{ Tipo de bebida } & \multicolumn{4}{|c|}{ Uso no ano (vezes/qtde) } & \multirow{2}{*}{$\begin{array}{l}\text { Uso no mês } \\
\text { (vezes/qtde) }\end{array}$} & \multirow{2}{*}{$\begin{array}{c}\text { Uso na } \\
\text { semana } \\
\text { (vezes/qtde) }\end{array}$} \\
\hline & $A G$ & $1^{\circ} \mathrm{T}$ & $2^{\circ} \mathrm{T}$ & $3^{\circ} \mathrm{T}$ & & \\
\hline \multicolumn{7}{|l|}{$\begin{array}{c}\text { Cerveja/ } \\
\text { Chopp (5\%) }\end{array}$} \\
\hline \multicolumn{7}{|l|}{ Vinho $(13 \%)$} \\
\hline \multicolumn{7}{|l|}{ Destilados $(50 \%)$} \\
\hline Outros: & & & & & & \\
\hline
\end{tabular}

2. Antes da gravidez teve problemas devido ao uso de álcool? (problemas médicos gerais: sintomas físicos relacionados ao uso de álcool, acidentes, faltas ao trabalho, problemas sociais, familiares, escolares ou com envolvimento policial)

Sim

Não

Quais/Quantas ocasiões?

3. Durante a gravidez teve problemas devido ao uso de álcool?

Sim Não

Quais/Quantas ocasiões?

4. Fez ou faz uso de outras substâncias psicoativas ?

$\operatorname{Sim}$ Não

Quais/Quantas ocasiões ? 


\section{CRITÉRIOS DIAGNÓSTICOS - CID X}

VII- USO NOCIVO -

1. Houve dano físico ou psicológico relacionado ao uso de substância psicoativa (lesão/prejuízo nas relações interpessoais) Sim Não

Com qual ou quais substâncias ?

2. Natureza do dano:

3. Padrão de uso contínuo ao longo de um mês ou em episódios repetidos ao longo de 12 meses

Sim Não

4. O paciente não preenche critérios para outros transtornos mentais (exceto intoxicação)

Sim Não

\section{VIII - SÍNDROME DE DEPENDÊNCIA -}

Sim

Não

Três ou mais dos seguintes itens, ocorrendo juntos, por um mês ou repetidamente por doze meses:

1. Forte desejo ou compulsão ? Sim Não

2. Dificuldade de controle no uso ? Sim Não

3. Síndrome de Abstinência ? Sim Não

4. Evidência de tolerância (maiores doses) ? Sim Não

5. Envolvimento com a droga levando a mudança de hábitos ? Sim Não

6. Uso continuado apesar da presença de efeitos nocivos ? Sim Não 


\section{INVENTÁRIO DE COMPORTAMENTOS PARA CRIANÇAS E ADOLESCENTES DE 6 A 18 ANOS VERSÃO BRASILEIRA DO "CHILD BEHAVIOR CHECKLIST FOR AGES 6-18" (CBCL/6-18)}

Número de identificação:

DATA DE HOJE:

$$
\frac{1}{\text { dia }} \frac{\text { mês }}{\text { ano }}
$$

NOME DA CRIANÇA/ADOLESCENTE (completo):

SEXO: $\square$ Masculino $\square$ Feminino

GRUPO ÉTNICO OU RAÇA:

IDADE:

DATA DE NASCIMENTO

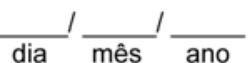

ESCOLARIDADE (série atual):

NÃO FREQUENTA ESCOLA:

ESTÁ FICHA ESTÁ SENDO PREENCHIDA POR (informante):

Nome completo:

Sexo: Masculino Feminino

Grau de parentesco ou tipo de relacionamento com a criança ou adolescente:
$\square$ Pai/Mãe Biológico(a)
Padrasto/Madrasta
Avô/Avó
Pai/Mãe Adotivo(a)
Outro (especificar) exército.

Tipo de trabalho do pai: mesmo que não estejam trabalhando no momento. Favor especificar o tipo de ocupação - por exemplo: mecânico de automóveis, professor do segundo grau, dona de casa, pedreiro, torneiro mecânico, vendedor de sapatos, sargento do

Tipo de trabalho da mãe: 


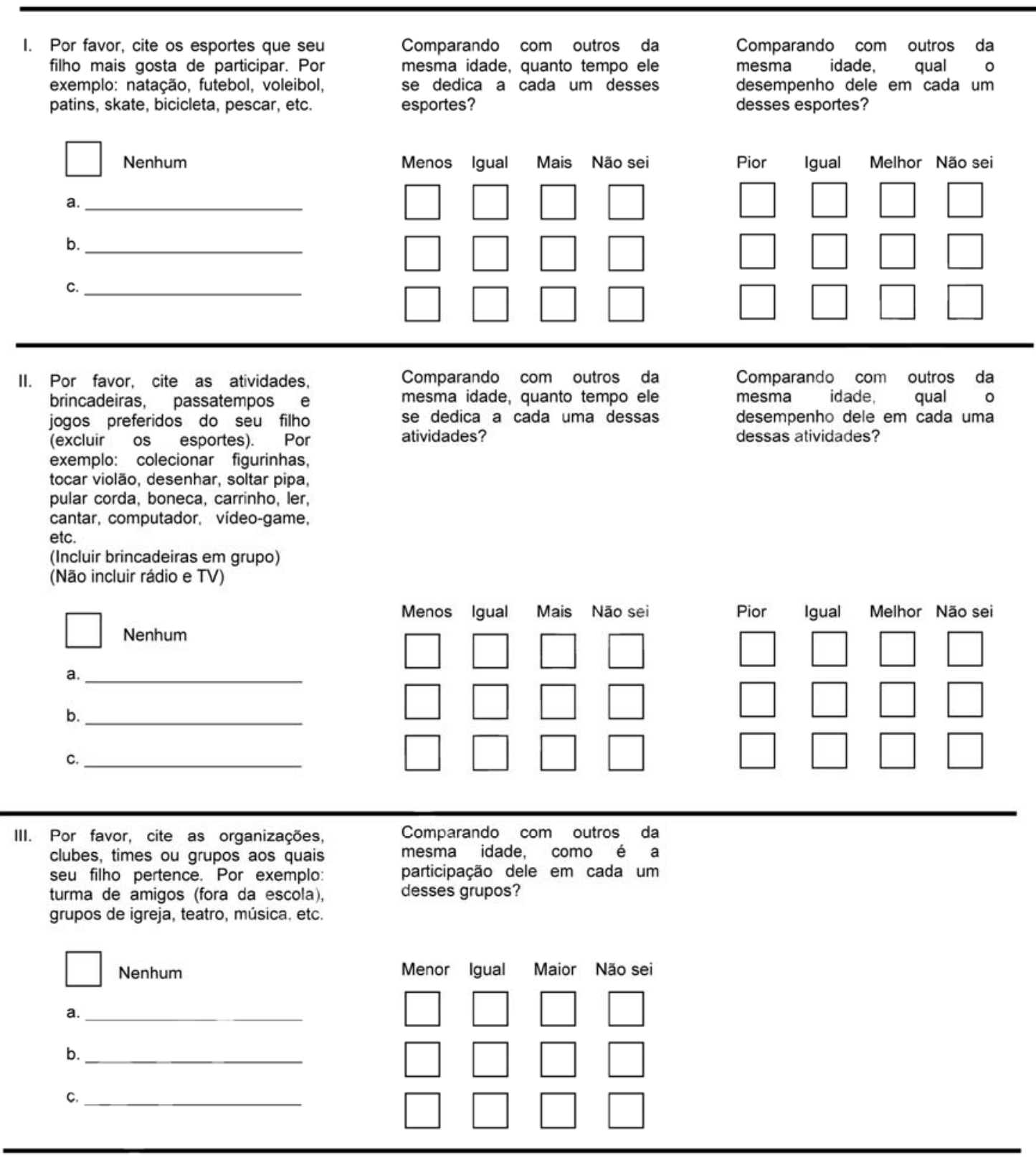


IV. Por favor, cite os trabalhos ou tarefas de seu filho. Por exemplo: office boy, ajudante em feira, trabalho em loja, tomar conta de crianças, varrer a casa, arrumar a cama,

Comparando com outros da mesma idade, qual o lavar louça, etc.

(Incluir trabalhos e tarefas pagos e sem pagamento)

\section{Nenhum}

a.

b.

c.
Pior Igual Melhor Não sei

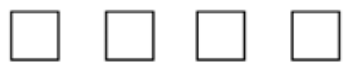

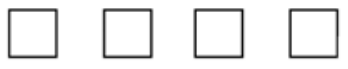

$\square \square \square \square$

\begin{tabular}{|c|c|c|c|c|c|c|c|}
\hline \multirow{2}{*}{\multicolumn{2}{|c|}{$\begin{array}{l}\text { V. 1. Quantos amigos intimos seu filho tem? } \\
\text { (Não incluir irmăos e irmăs) } \\
\text { 2. Quantas vezes por semana seu filho encontra } \\
\text { amigos ou colegas fora do horário da escola? } \\
\text { (Não incluir irmãos e irmãs) }\end{array}$}} & & \multicolumn{2}{|l|}{ Nenhum } & \multirow[t]{2}{*}{1} & 2 ou 3 & \multirow{2}{*}{$\begin{array}{l}4 \text { ou mais } \\
3 \text { ou mais }\end{array}$} \\
\hline & & & \multicolumn{2}{|c|}{ Menos que 1} & & 1 ou 2 & \\
\hline VI. & $\begin{array}{l}\text { Comparando com outros da mesma idade, de que forma } \\
\text { seu filho: }\end{array}$ & Pior & Igual & Melhor & & & \\
\hline & a. Se dá com seus irmãos e irmãs? & & & & & \multicolumn{2}{|c|}{ Não tem irmãos ou irmãs } \\
\hline & $\begin{array}{l}\text { b. Se dá com outras crianças } \\
\text { ou adolescentes? }\end{array}$ & & & & & \multicolumn{2}{|c|}{$\begin{array}{l}\text { Não tem contato com os } \\
\text { irmãos ou irmãs }\end{array}$} \\
\hline & c. Se comporta em relação aos pais? & & & & & & \\
\hline & d. Brinca ou trabalha sozinho? & & & & & & \\
\hline
\end{tabular}


VII. 1. Desempenho nas matérias escolares (esse item năo se aplica á crianças que năo iniciaram o ensino fundamental) Se a criança ou adolescente não estiver freqüentando a escola, favor especificar o motivo:

Comparando com outros da mesma idade, como é o desempenho de seu filho nas matérias escolares? (Só deixe em branco as matérias que seu filho não estiver cursando)

$\begin{gathered}\text { Insuficiente } \\ \text { (abaixo da média } \\ \text { exigida pela escola) }\end{gathered}$
$\square$ Pior

Outras matérias escolares (por exemplo: geografia, inglês, computação, etc.) Não incluir educação física, trabalhos manuais ou artísticos.
a. Português ou Literatura
b. História ou Estudos Sociais
c. Matemática ou Aritmética
d. Ciências
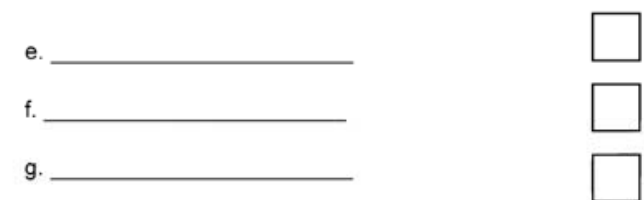

g.

2. Seu filho está em classe especial ou em escola especializada?

3. Seu filho já repetiu de ano? 
4. Seu filho já teve problemas no desempenho escolar ou outros tipos de problemas na escola?

Sim - Descreva-os

Quando começaram esses problemas?

Esses problemas já se resolveram?

$\square$ Não $\square$ Sim - Quando?

Seu filho tem alguma doença ou deficiência (fisica ou mental)?

Não $\square$ Sim-Descreva:

Quais suas maiores preocupaçōes em relação a seu filho?

Descreva as qualidades, os pontos positivos de seu filho.

Confira suas respostas para certificar-se de ter respondido todos os itens. 
A lista abaixo contém itens que descrevem comportamentos de crianças e adolescentes. Considere seu filho ATUALMENTE e NOS ÚLTIMOS 6 MESES e classifique os itens da lista abaixo conforme três possibilidades:

Marque 0 se item FALSO ou comportamento ausente.

Marque 1 se item MAIS OU MENOS VERDADEIRO ou comportamento às vezes presente.

Marque 2 se item BASTANTE VERDADEIRO ou comportamento freqüentemente presente.

Para cada item, faça um círculo ao redor do número 0,1 ou 2 .

Favor responder todos os itens, mesmo aqueles que parecem não ter nenhuma relação com o comportamento de seu filho.

012 1. Comporta-se de modo infantil, como se tivesse menos idade

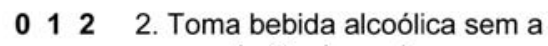
permissão dos pais

Descreva:

0123 . Argumenta muito (apresenta argumentos para não fazer o que se espera que ele faça)

012 4. Não consegue terminar as coisas que começa

012 5. Há poucas coisas que lhe dão prazer

012 6. Faz cocô na calça ou fora do vaso sanitário/ penico

012 7. É convencido, conta vantagem

012 8. Não se concentra, não consegue prestar atenção por muito tempo

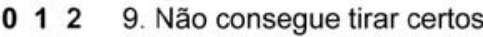
pensamentos da cabeça (obsessões)

Descreva:
012 10. É agitado, não para quieto

012 11. Fica grudado nos adultos, é muito dependente

$\begin{array}{llll}0 & 1 & 2 & 12 . \\ \text { Queixa-se de solidão }\end{array}$

012 13. Parece estar confuso, atordoado

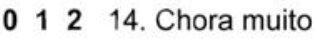

012 15. É cruel com os animais

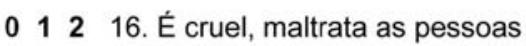

012 17. Fica no "mundo da lua", perdido nos próprios pensamentos (devaneios)

012 18. Machuca-se de propósito ou já tentou suicidar-se

012 19. Exige que prestem atenção nele

012 20. Destrói as próprias coisas

012 21. Destrói as coisas de sua familia ou de outras pessoas

012 22. É desobediente em casa

012 23. É desobediente na escola

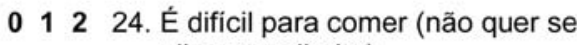
alimentar direito)

012 25. Não se dá bem com outras crianças ou adolescentes 
$\begin{array}{llll}0 & 1 & 2 & 26 .\end{array}$ Falta de arrependimento, não se sente culpado após ter se comportado mal

Descreva

$\begin{array}{llll}0 & 1 & 2 & 27 . \\ \end{array}$

012 28. Desrespeita regras em casa, na escola ou em outros lugares

$\begin{array}{llll}0 & 1 & 2 & 29 . \\ \end{array}$ situações ou lugares (não incluir a escola)

Descreva

01230 . Tem medo da escola

Descreva

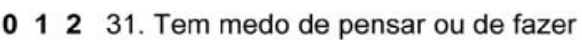
algo destrutivo (contra si ou contra outros

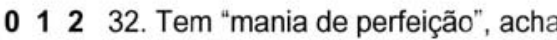
que tem que fazer tudo certinho

01233 . Acha que ninguém gosta dele

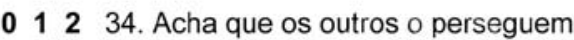

01235 . Sente-se desvalorizado, inferior

012 36. Machuca-se com freqüência, tem tendência a sofrer acidentes

$\begin{array}{llll}0 & 1 & 2 & 37 . \text { Entra em muitas brigas }\end{array}$

$\begin{array}{llll}0 & 1 & 2 & 38 \text {. É alvo de gozações }\end{array}$ freqüentemente

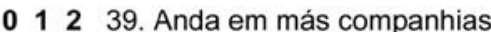

012 40. Escuta sons ou vozes que não existem

Descreva:
012 41. É impulsivo, age sem pensar

$\begin{array}{llll}0 & 1 & 2 & 42 . \\ & \text { Prefere ficar sozinho que na }\end{array}$ companhia de outros

012 43. Mente ou engana os outros

012 44. Rói unhas

012 45. É nervoso ou tenso

012 46. Tem "tique nervoso", cacoete

Descreva:

012 47. Tem pesadelos

012 48. As outras crianças ou adolescentes năo gostam dele

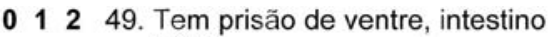
preso

01250 . É apreensivo, aflito ou ansioso demais

01251. Tem tonturas

012 52. Sente-se excessivamente culpado

012 53. Come exageradamente

01254 . Sente-se cansado demais sem motivo

01255 . Está gordo demais

56. Na sua opinião, apresenta problemas físicos por "nervoso" (sem causa médica):

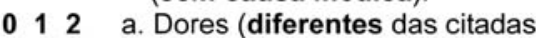
abaixo)

012 b. Dores de cabeça

012 c. Náuseas, enjôos

$\begin{array}{llll}0 & 1 & 2 & \text { d. Problemas com os olhos (que não }\end{array}$ Descreva: desaparecem com o uso de óculos)

012 e. Problemas de pele

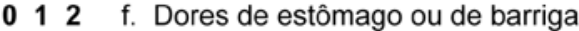

$\begin{array}{llll}0 & 1 & 2 & \text { g. Vômitos }\end{array}$

012 h. Outras queixas

Descreva: 
012 57. Ataca fisicamente as pessoas

012 58. Fica cutucando o nariz, a pele ou outras partes do corpo

Descreva:

012 59. Mexe nas partes intimas em público

012 60. Mexe demais nas partes intimas

012 61. Não vai bem na escola

012 62. É desastrado, desajeitado (tem má coordenação motora)

012 63. Prefere conviver com crianças ou adolescentes mais velhos

012 64. Prefere conviver com crianças ou adolescentes mais novos

012 65. Recusa-se a falar

012 66. Repete certos atos várias vezes seguidas (compulsões)

Descreva:

012 67. Foge de casa

012 68. Grita muito

012 69. É reservado, fechado, não conta suas coisas para ninguém

012 70. Vê coisas que não existem Descreva:

01271 . Fica sem jeito na frente dos outros com facilidade, preocupado com 0 que as pessoas possam achar dele

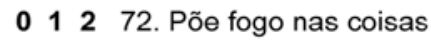

$\begin{array}{llll}0 & 1 & 73 . & \text { Tem problemas sexuais }\end{array}$

Descreva:

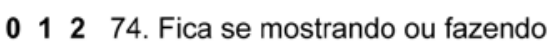
palhaçadas

012 75. É muito tímido

012 76. Dorme menos que a maioria das crianças ou adolescentes

$\begin{array}{llll}0 & 1 & 2 & 77 . \text { Dorme mais que a maioria das }\end{array}$ crianças ou adolescentes durante o dia e/ou a noite

Descreva:

012 78. É desatento, distrai-se com facilidade

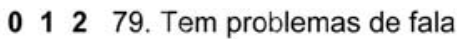

Descreva:

012 80. Fica com o olhar parado, "olhando o vazio"

012 81. Rouba em casa

012 82. Rouba fora de casa

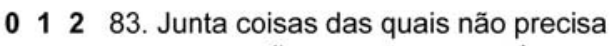
e que não servem para nada.

Descreva:

012 84. Tem comportamento estranho Descreva:

012 85. Tem idéias estranhas

Descreva:

012 86. É mal humorado, irrita-se com facilidade

0112 87. Tem mudanças repentinas de humor ou de sentimentos 
012 88. Fica emburrado facilmente

01289 . É desconfiado

01290 . Xinga ou fala palavrões

01291 . Fala que vai se matar

$\begin{array}{llll}0 & 1 & 2 & 92 . \\ \text { Fala ou anda dormindo }\end{array}$

Descreva:

$\begin{array}{llll}0 & 1 & 2 & 93 . \text { Fala demais }\end{array}$

01294 . Gosta de "gozar da cara" dos outros

01295 . É esquentado, tem acessos de raiva

01296 . Pensa demais em sexo

$\begin{array}{llll}0 & 1 & 2 & 97 . \text { Ameaça as pessoas }\end{array}$

01298 . Chupa o dedo

012 99. Fuma cigarro, masca fumo ou cheira tabaco

012 100. Tem problemas com o sono Descreva:
012 101. Mata aula (cabula aula, gazeia)

012 102. É pouco ativo, movimenta-se vagarosamente ou falta-lhe energia

012 103. É infeliz, triste ou deprimido

012 104. É barulhento demais

$\begin{array}{lll}0 & 2 & 105 . \text { Usa drogas (excluir álcool e } \\ \text { tabaco) }\end{array}$

Descreva:

012 106. Estraga ou destrói coisas públicas (vandalismo)

o 122 107. Faz xixi na roupa durante o dia

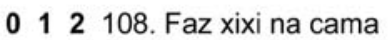

012 109. Fica choramingando, fazendo manha

012110 . Gostaria de ser do sexo oposto

012 111. É retraído, não se relaciona com os outros

012 112. É muito preocupado

113. Favor anotar abaixo outros problemas de seu filho que não foram abordados nos itens acima:

$0 \begin{array}{lll}0 & 1 & 2\end{array}$

012

$0 \begin{array}{lll}0 & 1 & 2\end{array}$ 


\section{Escala de maturidade mental}

Columbia

Padronização Brasileira da Terceira Edição - 1993

Folha de Respostas

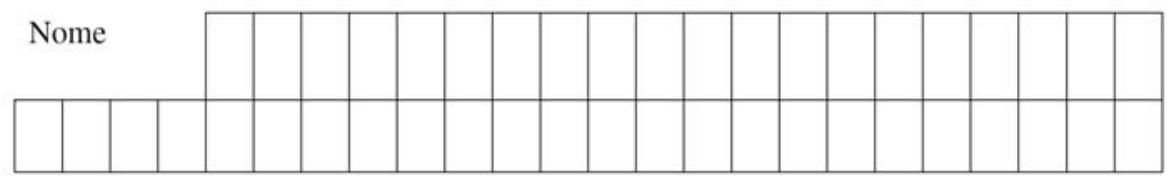

Sexo

Escolaridade

Escola

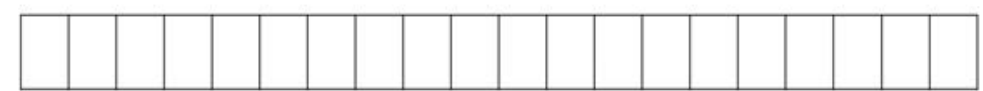

Data do exame

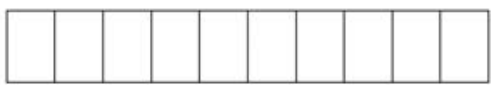

Data de nascimento

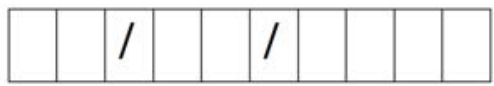

Idade cronológica

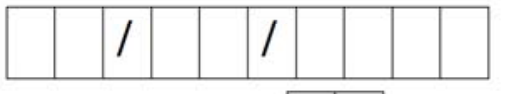

Duração do teste

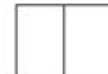

Minutos

Psicólogo

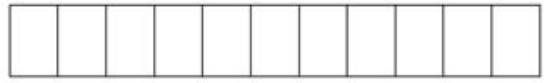

\begin{tabular}{|c|c|c|}
\hline \multicolumn{3}{|c|}{ Observações } \\
\hline NÍVEL & IDADE & ITENS \\
\hline A & 3 a $6 m-3$ a $11 m$ & $1-55$ \\
\hline B & 4 a $0 m-5$ a $5 m$ & $1-62$ \\
\hline $\mathrm{C}$ & 5 a $6 m-5$ a $11 m$ & $10-74$ \\
\hline D & 6 a $0 m-6$ a $5 m$ & $15-74$ \\
\hline E & 6 a $6 m-7$ a $5 m$ & $20-77$ \\
\hline $\mathrm{F}$ & 7 a $6 m-7$ a $11 m$ & $20-85$ \\
\hline $\mathrm{G}$ & 8 a $0 \mathrm{~m}-8$ a $5 \mathrm{~m}$ & $27-87$ \\
\hline $\mathrm{H}$ & 8 a $6 m-9$ a $11 m$ & $27-92$ \\
\hline
\end{tabular}

Nivel

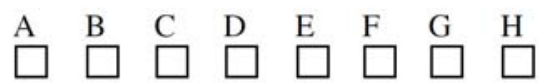

Total de pontos

Resultado padrão de idade

Percentil

Estanino

Índice de maturidade

Observações 
Escala de maturidade mental Columbia

Padronização Brasileira da Terceira Edição - 1993

\begin{tabular}{|c|c|c|c|}
\hline \multicolumn{4}{|c|}{ Exemplos } \\
\hline & EX1 $\square 1 \square 2 \square 3$ & EX2 $\square 1 \otimes 2 \square 3 \square 4$ & EX3 $\square 1 \square 2 \otimes 3 \square 4 \square 5$ \\
\hline \multicolumn{2}{|r|}{ Início A, B } & & Fim B \\
\hline & $\square 1 \square 2 \square 3$ & $31 \square 1 \square 2 \square 3 \square 4 \square 5$ & $63 \square 1 \square 2 \square 3 \square 4 \square 5$ \\
\hline 2 & $\square 1 \square 2 \square 3$ & $32 \square 1 \square 2 \square 3 \square 4 \square 5$ & $64 \square 1 \square 2 \square 3 \square 4$ \\
\hline 3 & $\square 1 \square 2 \square 3$ & $33 \square 1 \square 2 \square 3 \square 4$ & $65 \square 1 \square 2 \square 3 \square 4 \square 5$ \\
\hline 4 & $\square 1 \square 2 \square 3$ & $34 \square 1 \square 2 \square 3 \square 4$ & $66 \square 1 \square 2 \square 3 \square 4 \square 5$ \\
\hline 5 & $\square 1 \square 2 \square 3 \square 4 \square 5$ & $35 \square 1 \square 2 \square 3 \square 4$ & $67 \square 1 \square 2 \square 3 \square 4 \square 5$ \\
\hline 6 & $\square 1 \square 2 \square 3 \square 4$ & $36 \square 1 \square 2 \square 3 \square 4 \square 5$ & $68 \square 1 \square 2 \square 3 \square 4 \square 5$ \\
\hline 7 & $\square 1 \square 2 \square 3$ & $37 \square 1 \square 2 \square 3 \square 4$ & $69 \square 1 \square 2 \square 3 \square 4 \square 5$ \\
\hline 8 & $\square 1 \square 2 \square 3 \square 4$ & $38 \square 1 \square 2 \square 3 \square 4$ & $70 \square 1 \square 2 \square 3 \square 4 \square 5$ \\
\hline & $\square 1 \square 2 \square 3 \square 4$ & $39 \square 1 \square 2 \square 3 \square 4$ & $71 \square 1 \square 2 \square 3 \square 4$ \\
\hline \multicolumn{2}{|r|}{ Início C } & $40 \square 1 \square 2 \square 3 \square 4$ & $72 \square 1 \square 2 \square 3 \square 4 \square 5$ \\
\hline & $\square 1 \square 2 \square 3 \square 4 \square 5$ & $41 \square 1 \square 2 \square 3 \square 4 \square 5$ & $73 \square 1 \square 2 \square 3 \square 4 \square 5$ \\
\hline & $\square 1 \square 2 \square 3 \square 4$ & $42 \square 1 \square 2 \square 3 \square 4 \square 5$ & $74 \square 1 \square 2 \square 3 \square 4 \square 5$ \\
\hline 12 & $\square 1 \square 2 \square 3 \square 4$ & $43 \square 1 \square 2 \square 3 \square 4$ & Fim C, D \\
\hline 13 & $\square 1 \square 2 \square 3 \square 4$ & $44 \square 1 \square 2 \square 3 \square 4 \square 5$ & $75 \square 1 \square 2 \square 3 \square 4 \square 5$ \\
\hline & $\square 1 \square 2 \square 3 \square 4$ & $45 \square 1 \square 2 \square 3 \square 4 \square 5$ & $76 \square 1 \square 2 \square 3 \square 4 \square 5$ \\
\hline \multicolumn{2}{|r|}{ Início D } & $46 \square 1 \square 2 \square 3 \square 4$ & $77 \square 1 \square 2 \square 3 \square 4 \square 5$ \\
\hline & $\square 1 \square 2 \square 3 \square 4 \square 5$ & $47 \square 1 \square 2 \square 3 \square 4 \square 5$ & Fim E \\
\hline 16 & $\square 1 \square 2 \square 3 \square 4$ & $48 \square 1 \square 2 \square 3 \square 4$ & $78 \square 1 \square 2 \square 3 \square 4$ \\
\hline 17 & $\square 1 \square 2 \square 3 \square 4 \square 5$ & $49 \square 1 \square 2 \square 3 \square 4 \square 5$ & $79 \square 1 \square 2 \square 3 \square 4$ \\
\hline 18 & $\square 1 \square 2 \square 3 \square 4$ & $50 \square 1 \square 2 \square 3 \square 4 \square 5$ & $80 \square 1 \square 2 \square 3 \square 4 \square 5$ \\
\hline & $\square 1 \square 2 \square 3 \square 4$ & $51 \square 1 \square 2 \square 3 \square 4$ & $81 \square 1 \square 2 \square 3 \square 4 \square 5$ \\
\hline \multicolumn{2}{|r|}{ Início $\mathrm{E}, \mathrm{F}$} & $52 \square 1 \square 2 \square 3 \square 4 \square 5$ & $82 \square 1 \square 2 \square 3 \square 4 \square 5$ \\
\hline 20 & $\square 1 \square 2 \square 3 \square 4 \square 5$ & $53 \square 1 \square 2 \square 3 \square 4 \square 5$ & $83 \square 1 \square 2 \square 3 \square 4 \square 5$ \\
\hline 21 & $\square 1 \square 2 \square 3 \square 4 \square 5$ & $54 \square 1 \square 2 \square 3 \square 4$ & $84 \square 1 \square 2 \square 3 \square 4 \square 5$ \\
\hline 22 & $\square 1 \square 2 \square 3 \square 4 \square 5$ & $55 \square 1 \square 2 \square 3 \square 4 \square 5$ & $85 \square 1 \square 2 \square 3 \square 4$ \\
\hline 23 & $\square 1 \square 2 \square 3 \square 4$ & Fim A & Fim $\mathrm{F}$ \\
\hline 24 & $\square 1 \square 2 \square 3 \square 4$ & $56 \square 1 \square 2 \square 3 \square 4 \square 5$ & $86 \square 1 \square 2 \square 3 \square 4 \square 5$ \\
\hline & $\square 1 \square 2 \square 3 \square 4$ & \multirow{8}{*}{$\begin{array}{l}57 \square 1 \square 2 \square 3 \square 4 \\
58 \square 1 \square 2 \square 3 \square 4 \\
59 \square 1 \square 2 \square 3 \square 4 \square 5 \\
60 \square 1 \square 2 \square 3 \square 4 \square 5 \\
61 \square 1 \square 2 \square 3 \square 4 \square 5 \\
62 \square 1 \square 2 \square 3 \square 4\end{array}$} & $87 \square 1 \square 2 \square 3 \square 4$ \\
\hline & $\square 1 \square 2 \square 3 \square 4$ & & Fim G \\
\hline \multicolumn{2}{|r|}{ Início G, H } & & \multirow{5}{*}{$\begin{array}{l}88 \square 1 \square 2 \square 3 \square 4 \\
89 \square 1 \square 2 \square 3 \square 4 \square 5 \\
90 \square 1 \square 2 \square 3 \square 4 \square 5 \\
91 \square 1 \square 2 \square 3 \square 4 \square 5 \\
92 \square 1 \square 2 \square 3 \square 4 \square 5\end{array}$} \\
\hline 27 & $\square 1 \square 2 \square 3 \square 4 \square 5$ & & \\
\hline 28 & $\square 1 \square 2 \square 3 \square 4 \square 5$ & & \\
\hline 29 & $\square 1 \square 2 \square 3 \square 4$ & & \\
\hline \multirow{2}{*}{\multicolumn{2}{|c|}{$30 \square 1 \square 2 \square 3 \square 4 \square 5$}} & & \\
\hline & & & Fim H \\
\hline
\end{tabular}

